\title{
ACCEPTANCE AND COMMITMENT THERAPY FOR PUBLIC MENTAL HEALTH PROMOTION
}

\author{
EFFECTIVENESS OF THE \\ "LIVING TO THE FULL" PROGRAMME
}

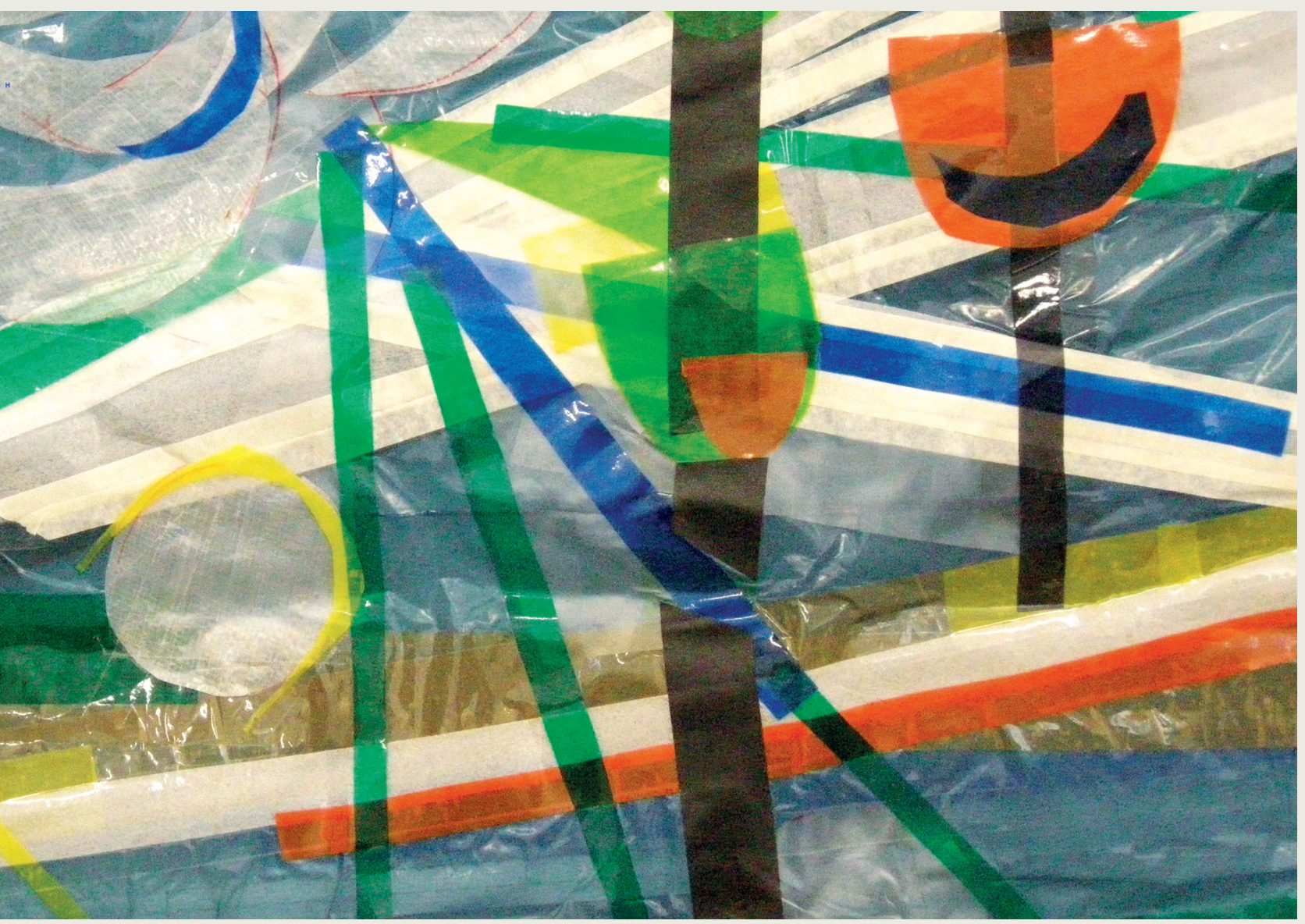

MARTINE FLEDDERUS 


\title{
ACCEPTANCE AND COMMITMENT THERAPY FOR PUBLIC MENTAL HEALTH PROMOTION
}

\author{
EFFECTIVENESS OF THE \\ "LIVING TO THE FULL" PROGRAMME
}

MARTINE FLEDDERUS 
Thesis, University of Twente, 2012

(C) Martine Fledderus

ISBN: 978-90-365-3313-3

Cover art by (C) Studio Gijs

Printed by Gildeprint Drukkerijen, Enschede, the Netherlands 


\title{
ACCEPTANCE AND COMMITMENT THERAPY FOR PUBLIC MENTAL HEALTH PROMOTION
}

\author{
EFFECTIVENESS OF THE \\ "LIVING TO THE FULL" PROGRAMME
}

PROEFSCHRIFT

ter verkrijging van

de graad van doctor aan de Universiteit Twente,

op gezag van de rector magnificus,

prof. dr. H. Brinksma,

volgens besluit van het College voor Promoties

in het openbaar te verdedigen

op vrijdag 10 februari 2012 om 14.45 uur

\author{
door \\ Martine Fledderus \\ geboren op 8 maart 1985 \\ te Deventer
}


Dit proefschrift is goedgekeurd door de promotor prof. dr. E.T. Bohlmeijer en de assistentpromotor dr. M.E. Pieterse. 


\section{Samenstelling promotiecommissie}

Promotor:

prof. dr. E. T. Bohlmeijer, Universiteit Twente

Assistent-promotor:

dr. M. E. Pieterse, Universiteit Twente

Leden:

prof. dr. E. Giebels, Universiteit Twente

dr. G. J. Westerhof, Universiteit Twente

prof. dr. J. van der Palen, Universiteit Twente

prof. dr. A. E. M. Speckens, UMC St. Radboud

prof. dr. G. J. M. Hutschemaekers, Radboud Universiteit Nijmegen 



\section{Contents}

Chapter 1

Chapter 2

Chapter 3

Chapter 4

Chapter 5

Chapter 6

Chapter 7

Chapter 8

Chapter 9

Chapter 10
General introduction: The relevance of Acceptance and Commitment Therapy (ACT) to public mental health promotion

Further evaluation of the psychometric properties of the Acceptance and Action Questionnaire-II

Does experiential avoidance mediate the effects of maladaptive coping styles on psychopathology and mental health?

Efficacy of an early intervention based on Acceptance and Commitment Therapy for adults with depressive symptomatology: Evaluation in a randomized controlled trial

Mental health promotion as a new goal in public mental health care: A randomized controlled trial of an intervention enhancing psychological flexibility

Acceptance and Commitment Therapy as guided self-help for psychological distress and positive mental health: A randomized controlled trial

The impact of changes in psychological flexibility on psychological distress in a randomized controlled trial on Acceptance and Commitment Therapy

General discussion

Summary in Dutch

Dankwoord 

General introduction: The relevance of Acceptance and Commitment Therapy (ACT) to public mental health promotion 


\section{Introduction}

The main aim of this thesis was to evaluate the effectiveness of an intervention based on Acceptance and Commitment Therapy (ACT) for adults with mild to moderate depressive symptomatology. The intervention, called "Living to the full", has been developed as both a group and as a self-help course. With this chapter elaborating on the epidemiology of depression and the need for prevention thereof, the following chapter will introduce a new approach to public mental health promotion and explain what the benefits of ACT are. A short introduction to the theoretical background of ACT and processes that ACT targets will be described, as well the aims and structure of the "Living to the full" programme. The chapter ends with an overview of the studies performed. These studies will be described in subsequent chapters.

\section{Need for prevention of depression}

Depression is a common mental disorder and characterized by a depressed mood or a loss of interest in almost every activity and occurring mostly during the day, almost on a daily basis and lasting at least a fortnight. Symptoms associated with depression are loss of concentration and/or appetite, disturbed sleep, fatigue and loss of energy, feelings of worthlessness, and recurrent thoughts of death (DSM-IV). Depression is highly prevalent in the Netherlands. With data from the Netherlands Mental Health Survey and Incidence Study-II (NEMESIS-II) collected from 2007-2009, the 12-month prevalence of a depression was $5.6 \%$ in the Dutch population between the ages of 18 and 64 years - a total of around 546,500 people. The lifetime prevalence of ever having experienced at least one depressive episode was $13.1 \%$ among men and $24.3 \%$ among women (De Graaf, Ten Have, $\&$ Van Dorsselaer, 2010). From the first NEMESIS data, it was estimated that the incidence rate of depression is more than 285,000 adults a year (Bijl, Ravelli, \& Van Zessen, 1998).

Depression is a disabling disease that contributes greatly to the burden of disease worldwide. It is even the leading cause of the burden of disease in middle- and high-income countries (World Health Organization, 2008). Depression is associated with disability in social, emotional and physical domains of life, low levels of well-being (Bijl \& Ravelli, 2000; Beekman et al., 2002), and even with increased mortality rates (Cuijpers \& Smit, 2002). It is one of the most expensive diseases in the Dutch health care system and is associated with high economic costs (Poos, Smit, Groen, Kommer, \& Slobbe, 2008). Depression leads to increased health care utilization of both mental and general medical care (Bosmans et al, 2010). Furthermore, depressed patients miss more days at work and work less efficiently than non-depressed patients (Stewart, Ricci, Chee, Hahn, \& Morganstein, 2003).

Due to the large impact on quality of life, treatment of depression is highly relevant and necessary. In the last decade many effective treatments for depression have been developed. However, even if the current evidence-based treatment were to be 
optimally implemented, only $40 \%$ of the burden of disease would be avoided (Andrew et al., 2003). Pro-actively offering preventive interventions to people in the community is therefore a necessary complementary strategy for decreasing the burden of disease (Hosman, Jane-Llopis, \& Saxena, 2005) and for public mental health promotion (Smit et al., 2006).

There are three different categories of prevention: universal, selective or indicated (Mzarek \& Haggerty, 1994). Universal prevention is the application of an intervention across a whole population, regardless of an individual's risk of developing a depression, e.g. when each child at a school is given an intervention aimed at reducing depression (Wolfe, Dozois, Fisman, \& DePace, 2008). Selective prevention is the application of an intervention to subgroups of the population with a known risk of developing depression. For example, Pitceathly et al. (2009) examined a brief psychological intervention for preventing depression in patients diagnosed with cancer. Indicated prevention targets people with a high risk and who show clinically relevant depressive symptoms but who do not meet the diagnostic criteria for depression at that time. An example is the "Coping with depression" course for people with subclinically depressive symptoms (Allart-Van Dam, Hosman, Hoogduin, \& Schaap 2007).

Research has shown that indicated prevention is the most effective and the most fruitful (Beekman, Smit, Stek, Reynolds, \& Cuijpers, 2010; Jané-Llopis, Hosman, Jenkins, $\&$ Andersson, 2003). The most important risk factor for developing a major depression is the presence of clinically relevant depressive symptoms (Cuijpers \& Smit, 2004). In recent years some effective indicated preventive interventions have been developed. Metaanalyses have shown that these interventions are effective in reducing depressive symptoms and in preventing the onset of depression. The risk of developing a depression in people who receive such intervention is $22 \%$ lower than people who did not receive an intervention (Cuijpers, Van Straten, Smit, Mihalopoulos, \& Beekman, 2008). Most of the indicated preventive courses in the Netherlands are based on cognitive behavioural techniques. In the Netherlands, the psycho-educational group course and self-help course "Coping with depression" is one of the widely available courses for adults with subclinical depressive symptoms. Offered by prevention departments at 25 mental health institutions in the Netherlands (Van den Berg, 2010), this course has proved to be effective in preventing and reducing depressive symptomatology (Allart-Van Dam et al., 2007).

Despite the wide availability and effectiveness of preventive services in the Netherlands, the impact on public mental health is low. In 2009, around 7,500 adults participated in (online) prevention interventions offered at mental health institutions in the Netherlands (Van den Berg, 2010). In 2009, 920,215 adults of the Dutch population suffered from subthreshold depression (CBS, 2009). This means that less than $1 \%$ of the whole target group is reached by indicated preventive services. There could be several reasons for these low participation rates. One reason might be that some of the people with clinically relevant depressive symptoms do not see themselves as having symptoms of depression and are in need of a preventive intervention (Cuijpers, Van Straten, 
Warmerdam, Van Rooy, 2010). Other reasons are that some people think that mental health services are not effective, that they want to deal with their problems themselves, or that they are afraid to ask for help (Beljouw et al., 2010; Ten Have et al., 2010). Due to the low impact on public mental health of indicated prevention, there is a need for a new approach to public mental health promotion. One solution may be to focus more on the promotion of positive mental health.

\section{New approach to public mental health promotion}

The field of public mental health widely uses a an illness ideology within a medical model (Maddux, 2009). The focus is mainly on what is going wrong with people. Mental health is generally defined as the absence of psychological complaints and mental illnesses. In the recent years there has been a increasing interest in a more positive approach to mental health. Positive mental health promotion is an important new goal for public health (Slade, 2010; World Health Organization, 2005). Positive mental health is not merely the absence of psychological complaints and mental illness but is defined as the presence of positive feelings (emotional well-being) and positive functioning in individual life (psychological well-being) and community life (social well-being) (Keyes, 2005; 2006). This is in line with the definition of the World Health Organization (2005) that defines mental health as a positive state, namely 'a state of well-being in which the individual realizes his or her own abilities, can cope with the normal stresses of life, can work productively and fruitfully, and is able to make a contribution to his or her community' (Herrman, Saxena, \& Moodie, 2005, p. 12). Positive mental health and mental illness in the population belong to two separate but correlated dimensions. An individual suffering from much distress has a higher chance of experiencing low well-being, such as few positive emotions or low life satisfaction. However, this relation is not perfect. An individual may be suffering from mental illness yet have a relatively high positive mental health at the same time. Conversely, the absence of psychopathology is neither necessary nor sufficient to ensure an individual has a good positive mental health (Lamers, Westerhof, Bohlmeijer, Ten Klooster, \& Keyes, 2011). To illustrate, in a representative sample of 1,227 Dutch adults it was estimated in 2007 that $34.9 \%$ had good positive mental health but that $6.7 \%$ of them probably suffered from a mental illness (Westerhof \& Keyes, 2008). This illustrates that by curing mental illness, it does not necessarily automatically lead to positive mental health and vice versa. Positive mental health does have important individual, societal and economic consequences though. Even when one controls for symptoms of mental illness, mental health has an independent relation with psychosocial adaptation, work productivity, physical disease, health care utilization and even mortality (Chida \& Steptoe, 2008; Keyes, 2002; 2004; 2005). Recent studies have shown that having positive mental health protects against the risk of mental illnesses (Keyes, Dhingra, \& Simoes, 2010; Wood \& Joseph, 2010). Furthermore, Fava et al. (2001) found that even when clinical symptoms are absent, low mental health can be seen as a risk factor for future relapse among recovering patients. A recent meta-analysis also showed that higher levels of emotional well-being of physically 
diseased patients predicted better recovery and survival rates than patients with lower levels of emotional well-being (Lamers, Bolier, Westerhof, Smit, \& Bohlmeijer, 2011).

Mental health promotion is therefore an important and complementary activity with mental illness prevention. Both activities have an important but different role (Power, 2010). Prevention of mental illness is mainly based on targeting generic risk factors. By targeting generic risk factors, multiple mental illnesses can be prevented and may thus have a broad trans-diagnostic impact (Hosman et al., 2005). Mental health promotion aims to enhance generic positive competences which make an individual able to cope with stressors in daily life, give meaning to life, work productively and to participate in his or her community (Herrman et al., 2005).

In our opinion Acceptance and Commitment Therapy is particularly suitable for positive mental health promotion. In this thesis an intervention based on ACT was developed. For understanding what ACT entails, a short description of its theoretical background is given below.

\section{Acceptance and Commitment Therapy}

\section{Theoretical background}

ACT is a new form of behavioural therapy. Its philosophical and theoretical roots are based on functional contextualism and Relational Frame Theory (RFT). Although a short introduction is given below, see for a more detailed review Törneke (2010). In ACT, how behaviour is changed is always related to understanding the context of behaviour, instead of changing the content of thoughts or the form of feelings (Dahl, Plumb, Stewart, \& Lundgren, 2009). This assumption is based on functional contextualism which consists of two elements. First, behaviour must always be understood in relation to the setting or context in which it takes place. Second, in order to understand and influence behaviour, the function of behaviour must be studied, i.e. what it is aimed at (Törneke, 2010).

ACT is also based on RFT, which explains how human language influences our thoughts and behaviour. An important process in RFT is stimulus equivalence, which means that humans are capable of relating stimuli by deriving and combining relations between them. Stimuli can be objects or the written forms, sounds, pictures of these objects and their corresponding thoughts, emotions and feelings. When a human learns that stimulus $\mathrm{A}$ is equal to stimulus $\mathrm{B}$, and stimulus $\mathrm{B}$ is equal to stimulus $\mathrm{C}$, he/she can directly deduce that stimulus $\mathrm{A}$ is equal to stimulus $\mathrm{C}$. This is also possible with other relationships, for example "before-after" and "if-then". All these different ways of relating and combining stimuli is defined in RFT as "relational framing". Relational framing means that humans not only learn directly from experiences or model learning but also indirectly from verbal instructions. For example, learning to ride a bike is done by experience and model learning. However, learning that it is dangerous to cross a busy crossroads by bike can be learned with verbal instructions. Continued verbal interactions produce a complex and multirelated network involving vast numbers of different objects and events and the relations between 
them. Everything a human learn, thinks and feels about himself, his environment or others becomes part of this elaborate verbal relation network (Dahl et al., 2009). With relational framing, humans are able to plan for the future, learn from the past, maintain knowledge and evaluate (Hayes, Strosahl, \& Wilson, 1999).

These verbal processes also play an enormous role in psychopathology (Tull, Gratz, Salters, \& Roemer, 2004). Humans can be anxious about something even without direct experience. Humans can make an impression about problems that might occur in the future. With relational framing an elaborate network arises of various associations and rules. That is why a single stimulus cannot cause this problem on its own but that many stimuli together can. An example of such a rule is: 'If I could get rid of my anxiety, I would like to travel to another country.' With relational framing this rule can be interpreted as absolute reality. The words and thoughts cannot harm a person but the behaviour in response to these words and thoughts may indeed do just that. By following this rule, a person would not travel abroad, even if friends asked him to go with them, because he thinks he must first feel less anxious. As a consequence, a person does not do what he really wants to (in this case: travel), and this might evoke more unpleasant thoughts. One of the assumptions of ACT is that it is difficult to change or erase these verbal rules and associations, because they can easily be activated by the elaborate network of the related stimuli. ACT is aimed at not changing the client's experiences directly, but rather at helping the client to relate his/her experiences in a different way so that he/she can engage more fully in value-based and meaningful life (Dahl et al., 2009). This is achieved by targeting different processes as described below.

\section{Processes of $A C T$}

A verbal rule that leads to much psychopathology is that negatively evaluated personal events are harmful and must be controlled. This could lead to experiential avoidance (EA). EA has been defined as the reluctance to remain in contact with personal experiences such as feelings, thoughts and bodily sensations, and attempts to alter, control, predict or avoid the form, the frequency or the contexts in which these experiences arise (Hayes, Luoma, Bond, Masuda, \& Lillis, 2006; Hayes, Wilson, Gifford, Follette, \& Strosahl, 1996). Avoidance strategies can be thought suppression, distraction or avoiding certain situations. Avoidance strategies can be useful and temporarily effective to reduce distress, for example to suppress one's anxiety during a presentation (Hayes et al., 1996). Paradoxically, over the long term, attempts to avoid negative personal experiences increase the frequency, severity and accessibility of these experiences and this could lead to diverse psychopathology. EA then becomes a disordered process when a person devotes an excessive amount of time, effort and energy to controlling the unwanted experiences. This process results in narrowing a person's repertoire of behaviour for dealing with his or her environment, since many behaviours can cause such unwanted experiences (Hayes et al., 2006). As a consequence, a person has less contact with present experiences and EA gets in the way of long-term desired qualities or values in a persons life. Many studies have shown that EA is 
related to diverse psychopathology, such as depression, anxiety, post-traumatic stress disorder and borderline personality disorder (Hayes et al., 2006; Chawla \& Ostafin, 2008) and can be seen as a risk factor for psychopathology (Biglan, Hayes, \& Pistorello, 2008; Kashdan, Barrios, Forsyth, \& Steger, 2006).

The main aim of ACT is to reduce EA by enhancing psychological flexibility. A psychologically flexible person is willing to remain in contact with unwanted personal experiences, rather than trying to avoid, alter or control them. When this struggle and attempt to control or avoid these unwanted personal experiences is relinquished, an individual can shift his/her energy to long-term desired qualities or values in life, even in the presence of unwanted private events (Ciarrochi, Billich, \& Godsell, 2010). A person can then be in contact with present experiences and choose or persist in behaviour that is in line with important values and goals. Studies have shown that psychological flexibility is related to higher quality of life, emotional well-being and job satisfaction (Butler \& Carriochi, 2007; Kashdan et al., 2006). Psychological flexibility is promoted by six processes. There is no order of rank with these processes, because they are all interrelated and support one another (Ciarrochi et al., 2010). See below for a short description of each process.

Acceptance: Acceptance is learned as the alternative of EA. The process is aimed at enhancing clients' awareness to embrace and accept their personal experiences. Clients explore the ineffectiveness of emotional control and avoidance, which are often counterproductive and even increase the client's level of distress and will lead them away from value-based behaviour. Instead, clients are encouraged to accept their personal experiences and to choose or persist in behaviour that is in line with important values and goals (Ciarrochi et al., 2010; Hayes et al., 2006).

Cognitive defusion: Cognitive defusion is a process that involves weakening the language processes that promote fusion. Fusion is a process whereby thoughts are regarded as true and placed in a literal context. Defusion exercises attempt to change the undesirable functions of private events, rather than trying to alter their form or frequency. This is done by creating context in which their unhelpful functions are diminished. Examples of excises are to repeatedly say a thought out loud until only its sound remains, or to speak a thought out loud in a strange voice. Cognitive defusion leads to less belief or attachment to personal experiences rather than a direct change in the frequency of these thoughts (Hayes et al., 2006).

Contact with the present moment: With this process clients learn to be present in the moment and have non-judgmental contact with psychological events that occur. When clients have contact with the present moment, their behaviour will be more flexible and they can perform actions that are in line with their values (Brown, Ryan, \& Creswell, 2007). Participants learn to develop a decentered perspective with regard to feelings and thoughts. Instead of identifying with 
negative emotions and thoughts, patients learn to experience them as passing mental events.

Self-as-context: In this process clients learn to detect and to be aware of the difference between "self-as-context" or "observing self"and their attachment to a conceptualized self (i.e. I am a bad person). Since statements such as "I am bad person" and "I am male" have the same form, people tend to interpret both statements as literally true (Biglan et al., 2008; Hayes et al., 2006). Clients practise with letting the attachment with this conceptualized self go. They learn that there is always a constant and stable "I", even in the face of any self-evaluation. From the perspective of "self-as-context" clients start to realize that an "I" always can obvert these statements and they can let these unhelpful self-evaluations go and retain a sense of self (Ciarrochi et al., 2010).

Values: In this process clients are encouraged to choose and discover values. Values are important chosen life directions, for example in the domain of family, work and social life. Values are not the same as goals, because they are never really achieved or obtained. Clients are encouraged to engage in valued behaviour, regardless of what emotions or thoughts might occur (Hayes et al., 1999).

Committed Action. In this process client are encouraged to actually live according to their chosen values by undertaking effective action (Fletcher \& Hayes, 2005; Hayes et al., 2006). This might evoke distress and sometimes several barriers have to be overcome. ACT helps prepare people with possible negative feelings or thoughts that might occur when a person commits to an action and is willing to have those negative feelings and thoughts in order to move in the desired direction (Ciarrochi et al., 2010).

Meta-analyses have shown that ACT is effective in the treatment of psychopathology, such as borderline personality disorder, depression and social anxiety (Powers, Zum Vörde Sive Vörding, \& Emmelkamp 2009, Hayes et al., 2006). Although discussed in the study of Biglan et al. (2008) that ACT is suitable for prevention, its application as a preventive intervention has hardly been studied.

\section{The "Living to the full" programme}

The indicated intervention "Living to the full" is based on the six processes of the ACT treatment model and is aimed at people with mild to moderate depressive symptomatology. The intervention suits the new approach to public mental health promotion. It is aimed at the promotion of positive mental health and at the reduction of mental illnesses. Positive mental health is promoted by enhancing the competences psychological flexibility and mindfulness, because both competences focus on enhancing a positive, meaningful and 
engaged life. Earlier research has already shown that positive mental health is related to mindfulness and psychological flexibility (Baer, Smith, Hopkins, Krietemeyer, \& Toney, 2006; Josefsson, Larsman, Broberg, \& Lundh, 2011). The intervention also targets experiential avoidance (EA) that can be considered a generic risk factor for mental illnesses (Biglan et al., 2008).

The programme consist of eight sessions. In the first session, the basic principles and visions of ACT are explained and participants have to think about what they really want in life. This is a first exploration of their values. In the second and third sessions, the participants reflect on the avoidance and control strategies they use and whether these are effective in the long run. In the next three sessions, the participants learn how to come into contact with their present experiences without trying to avoid or control them. Participants practise with the willingness to experience negative emotions, cognitive defusion and self as context. In the last two sessions, the focus is on becoming aware of the most important personal values and making decisions on the basis of these values. All sessions use experiential exercises and metaphors for illustrating the processes of ACT.

An important innovation in the traditional ACT treatment model is that the mindfulness exercises are augmented with short meditational exercises based on mindfulness-meditational courses, such as Mindfulness-Based Cognitive Therapy (Teasdale et al., 2000, Ma \& Teasdale, 2004) and Mindfulness-based Stress Reduction (Kabat-Zinn, 1990, 1994). This combination of ACT and mindfulness meditation has also proven to be very effective in the context of treating generalized anxiety disorder (Roemer, Orsillo, \& Salters-Pedneault 2008). In all sessions, participants are asked to do daily mindfulness mediation exercises.

\section{Group course and self-help}

In this thesis, we studied the effectiveness of both the group and the self-help course of the "Living to the full" programme. The group course is offered by the prevention departments of mental health services in the Netherlands. On average the groups consist of about six to ten participants and the course is provided by licensed psychologists and preventive workers with experience in ACT and mindfulness. The group course consists of eight twohour weekly sessions. The self-help course is a book that consists of nine chapters. The extra chapter (week 9) consists of a summary of all the processes learned and ends with some extra advice and information on how to abide by their values. Each chapter can be performed in one week. In this thesis we evaluated the self-help course with e-mail counselling because previous studies have shown that self-help with minimal counselling is more effective for depression than no counselling at all (Cuijpers, Donker, Straten, Li, Andersson, 2010). 


\section{Outline of the thesis}

The second chapter addresses the examination of the psychometric properties of the Acceptance and Action Questionnaire-II (AAQ-II). This questionnaire measures psychological flexibility. This study is the first to use more advanced methods for in-depth analyses on the psychometric properties of the AAQ-II in a sample of people with mild to moderate depressive symptomatology. With this questionnaire it can be examined whether psychological flexibility is an important process of change during an ACT intervention on psychological distress. Therefore, it is important that this takes place with a proper and well-validated questionnaire.

The third chapter examines how EA is related to several maladaptive coping styles, because both EA and aforementioned coping styles include strategies to avoid or control negative internal experiences. In earlier studies it was found that EA mediated the effects of maladaptive coping styles on psychological distress and emotional and psychological well-being (Kashdan et al., 2006). We were able to replicate these findings in this study. More knowledge on how experiential avoidance is related to coping styles can clarify the differences and possible overlap.

The fourth and fifth chapter present the results of a randomized controlled trial on the effects of the group course based on the "Living to the full" programme. The effects on depression, anxiety and fatigue and psychological flexibility are described in chapter four and the effects on positive mental health in chapter five. Also the mediating role of psychological flexibility was investigated in both chapters. These studies are the first to investigate whether a preventive ACT intervention is effective.

The sixth chapter presents the effectiveness of the self-help course based on the "Living to the full" programme with e-mail counselling in a randomized controlled trial on depression, anxiety, fatigue, psychological flexibility, positive mental health and mindfulness. In the seventh chapter it was examined how and when psychological flexibility was related to depression and anxiety in the self-help programme. The role of psychological flexibility was investigated with different methods of analysis and by using many measurement points. Understanding how and when psychological flexibility changes can potentially optimize ACT treatments. 


\section{References}

Allart-Van Dam, E., Hosman, C. M. H., Hoogduin, C. A. L., \& Schaap, C. P. D. R. (2007). Prevention of depression in subclinically depressed adults: Follow-up effects on the 'Coping with Depression' course. Journal of Affective Disorders, 97, 219-228.

Andrews, G., Issakidis, C., Sanderson, K., Corry, J., \& Lapsley, H. (2004). Utilizing survey data to inform public policy: comparison of the cost-effectiveness of treatment of ten mental disorders. British Journal of Psychiatry, 184, 526-533.

Aromaa, E., Tolvanen, A., Tuulari, J., \& Wahlbeck, K. (2011). Personal stigma and use of mental health services among people with depression in a general population in Finland. BMC psychiatry, 11, 52.

Baer, R. A., Smith, G. T., Hopkins, J., Krietemeyer, J., \& Toney, L. (2006). Using selfreport assessment methods to explore facts of mindfulness. Assessment, 13, 27-45.

Beekman, A. T. F., Penninx, B. W. J. H, Deeg, D. J. H, de Beurs, E., Geerlings, S. W., \& van Tilburg, W. (2002). The impact of depression on the well-being, disability and use of services in older adults: a longitudinal perspective. Acta Psychiatrica Scandinavica, 105, 20-27.

Beekman, A. T., Smit, F., Stek, M. L., Reynolds, C. F., \& Cuijpers, P. (2010). Preventing depression in high-risk groups. Current Opinion in Psychiatry, 23, 8-11.

Biglan, A., Hayes, S. C., \& Pistorello, J. (2008). Acceptance and commitment: implications for prevention science. Prevention Science, 9, 139-152.

Bijl, R. V., Ravelli, A., \& van Zessen, G. (1998). Prevalence of psychiatric disorder in the general population: results of The Netherlands Mental Health Survey and Incidence Study (NEMESIS). Social Psychiatry and Psychiatric Epidemiology, 33, 587-95.

Bijl, R. V., \& Ravelli, A. (2000). Current and residual functional disability associated with psychopathology: findings from the Netherlands Mental Health Survey and Incidence Study (NEMESIS). Psychological Medicine, 30, 57-668.

Bond, F. W., \& Bunce, D. (2003). The role of acceptance and job control in mental health, job satisfaction, and work performance. Journal of Applied Psychology, 88, 10571067.

Bosmans, J. E., de Bruijne, M. C., de Boer, M. R., van Hout, H., van Steenwijk, P., \& van Tulder, M. W. (2010). Health care costs of depression in primary care patients in the Netherlands. Family practice, 27, 542-548.

Brown, K. W., Ryan, R. M., \& Creswell, J. D. (2007). Mindfulness:Theoretical foundations and evidence for its salutary effects. Psychological Inquiry, 18, 211-237.

Butler, J., \& Ciarrochi, J. (2007). Psychological acceptance and quality of life in the elderly. Quality of Life Research, 16, 607-615.

CBS, Centraal Bureau voor de Statistiek. StatLine. 2009a [www.statline.nl]. 
Chawla, N., \& Ostafin, B. (2007). Experiential avoidance as a functional dimensional approach to psychopathology: an empirical review. Journal of Clinical Psychology, 63, 871-890.

Ciarrochi, J., Billich, L., \& Godsell, C. (2010). Psychological flexibility as a mechanism of change in acceptance and commitment therapy. In R. Baer (Ed.), Assessing mindfulness and acceptance processes in clients: Illuminating the theory and practice of change (pp. 51-75). Oakland, CA: Context Press/New Harbinger Publications.

Chida, Y., \& Steptoe, A. (2008). Positive psychological well-being and mortality: a quantitative review of prospective observational studies. Psychosomatics Medicine, 70, 741-756.

Cuijpers, P., Donker, T., van Straten, A., Li, J., Andersson, G. (2010). Is guided self-help as effective as face-to-face psychotherapy for depression and anxiety disorders? A systematic review and meta-analysis of comparative outcome studies. Psychological Medicine, 40, 1943-1957.

Cuijpers, P., \& Smit, F. (2002). Excess mortality in depression: a meta-analysis of community studies. Journal of Affective Disorders, 72, 227-236.

Cuijpers, P., van Straten, A., Warmerdam, L., \& van Rooy, M. J. (2010). Recruiting participants for interventions to prevent the onset of depressive disorders: Possible ways to increase participation rates. BMC Health Services Research, 10, 181.

Cuijpers, P., \& Smit, F. (2004). Subthreshold depression as a risk indicator for major depressive disorder, a systematic review of prospective studies. Acta Psychiatrica Scandinavica, 109, 325-331.

Cuijpers, P., Smit, F., \& van Straten, A. (2007). Psychological treatments of subthreshold depression, a meta-analytic review. Acta Psychiatrica Scandinavica, 115, 434-441.

Cuijpers, P., van Straten, A., Smit, F., Mihalopoulos, C., \& Beekman, A. (2008). Preventing the onset of depressive disorders, a meta-analytic review of psychological interventions. American Journal of Psychiatry, 65, 1272-1280.

Dahl, J. C., Plump, J. C., Stewart, I., \& Lundgren, T. (2009). The art and science of valuing in psychotherapy. Helping clients discover, explore and commit to valued action usingacceptance and commitment therapy. Oakland: New Harbinger.

de Graaf, R., ten Have, M., \& van Dorsselaer, S. (2010). De psychische gezondheid van de Nederlandse bevolking. NEMESIS-2: Opzet en eerste resultaten. Utrecht: Trimbos Institute.

Diagnostic and Statistical Manual of Mental Disorders, Fourth Edition Text Revised. Washington, DC: American Psychiatric Association; 2000.

Fava, G. A., Rafanelli, C., Ottolini, F., Ruini, C., Cazzaro, M., \& Grandi, S. (2001). Psychological well-being and residual symptoms in remitted patients with panic disorder and agoraphobia. Professional Psychology, Research and Practice, 31, 899905 . 
Fletcher, L., \& Hayes, S. C. (2005). Relational Frame Theory, Acceptance and commitment Therapy, and a functional analytic definition of mindfulness. Journal of RationalEmotive and Cognitive-Behavioral Therapy, 23, 315-336.

Greenspoon, P. J., \& Saklofske, D. H. (2001). Toward an integration of subjective wellbeing and psychopathology. Social Indicators Research, 54, 81-108.

Hayes, S. C., Luoma, J. B., Bond, F. W., Masuda, A., \& Lillis, J. (2006). Acceptance and commitment therapy: model, processes and outcomes. Behaviour Research Therapy, 44, 1-23.

Hayes S. C., Strosahl, K, \& Wilson, K. G. (1999). Acceptance and Commitment Therapy: An Experiential Approach to Behavior Change. New York, NY: Guilford.

Hayes, S. C., Wilson, K. G., Gifford, E. V., Follette, V. M., \& Strosahl, K. (1996). Experiential avoidance and behavioral disorders: A functional dimensional approach to diagnosis and treatment. Journal of Consulting and Clinical Psychology, 64, 1152-1168.

Herrman, H. S., Saxena, S., Moodie, R., eds. (2005). Promoting mental health: concepts, emerging evidence, practice. A WHO report in collaboration with the Victorian Health Promotion Foundation and the University of Melbourne. Geneva, Switzerland: World Health Organization; 2005. Available at: http://www.who.int/mental_health/evidence/ MH_Promotion_Book.pdf. Accessed January 22, 2010.

Hosman, C., Jane-Llopis, E., \& Saxena, S. (Eds.). (2005). Prevention of mental disorders: Effective interventions and policy options. Oxford: Oxford University Press.

Jané-Llopis, E., Hosman, C., Jenkins, R., \& Anderson, P. (2003). Predictors of effectiveness in depression prevention programmes: Meta-analysis. British Journal of Psychiatry, 83, 384-397.

Josefsson, T., Larsman, P., Broberg, A., \& Lundh, L. G. (2011). Self-reported mindfulness mediates the relation between meditation experience and psychological well-being. Mindfulness, 2, 49-58.

Kabat-Zinn, J. (1990). Full Catastrophe Living: Using the Wisdom of Your Body and Mind to Face Stress, Pain, and Illness. New York, NY: Delacorte.

Kabat-Zinn, J. (1994). Wherever You Go, There You Are: Mindfulness Meditation in Everyday Life. New York, NY: Hyperion.

Keyes, C. L. M. (2005). Mental illness and/or mental health? Investigating axioms of the complete state model of health. Journal of Consulting and Clinical Psychology, 73, 539-548.

Keyes, C. L. M., Dhingra, S. S., \& Simoes, E .J. (2010). Change in level of positive mental health as a predictor of future risk of mental illness. American Journal of Public Health, 100, 2366-2371.

Keyes, C. L. M. (2002). The mental health continuum: from languishing to flourishing in life. Journal of Health Social Behavior, 43, 207-222. 
Keyes, C. L. M. (2004). The nexus of cardiovascular disease and depression revisited: the complete mental health perspective and the moderating role of age and gender. Aging and Mental Health, 8, 266-274.

Keyes, C. L. M. (2006). Mental health in adolescence: is America's youth flourishing? American Journal of Orthopsychiatry, 76, 395-402.

Lamers, S. M. A., Bolier, L., Westerhof, G .J., Smit, F., Bohlmeijer, E. T. (2011). The impact of emotional well-being on long-term recovery and survival in physical illness: a meta-analysis. Journal of Behavioral Medicine, doi: 10.1007/s10865-0119379-8

Lamers, S. M. A., Westerhof, G. J., Bohlmeijer, E. T., ten Klooster, P. M., \& Keyes, C. L. M. (2011). Evaluating the psychometric properties of the Mental Health ContinuumShort Form (MHCSF). Journal of Clinical Psychology, 67, 99-110.

Ma, S. H., \& Teasdale, J. D. (2004). Mindfulness-based cognitive therapy for depression: Replication and exploration of differential relapse prevention effects. Journal of Consulting and Clinical Psychology, 72, 31-40.

Maddux, J. E. (2009). Stopping the "madness": positive psychology and deconstructing the illness ideology and the DSM. In: Lopez, S.J., Snyder, C.R., eds. (2009). Oxford Handbook of Positive Psychology. New York; Oxford University Press, 61-69.

Mrazek, P. J., \& Haggerty, R. J. (1994). Reducing risks for mental disorders. Washington, DC: National Academy Press.

Pitceathly, C., Maguire, P., Fletcher, I. Parle, M., Tomenson, B., \& Creed, F. (2009). Can a brief psychological intervention prevent anxiety or depressive disorders in cancer patients? A randomised controlled trial. Annals of Oncology, 20, 928-934.

Powers, M. B., Zum Vörde Sive Vörding, M. B., \& Emmelkamp, P. M. (2009). Acceptance and commitment therapy: a meta-analytic review. Psychotherapy and Psychosomatics, 78,73-80.

Poos, M. J. J. C., Smit, J. M., Groen, J., Kommer, G. J., \& Slobbe, L. C. J. (2008). Kosten van ziekten in Nederland 2005. Bilthoven: RIVM.

Power, A. K. (2010) Transforming the nation's health: Next steps in mental health promotion. American Journal of Public Health ,100, 2343-2346.

Powers, M. B., Zum Vörde Sive Vörding, M. B., \& Emmelkamp, P. M. G. (2009) Acceptance and commitment therapy: A meta-analytic review. Psychotherapy and psychosomatics, 78, 73-80.

Roemer, L., Orsillo, S. M., \& Salters-Pedneault, K. (2008). Effectiveness of an acceptancebased behavior therapy for generalized anxiety disorder: evaluation in a randomized controlled trial. Journal Consulting and Clinical Psychology, 76, 1083-1089.

Slade, M. (2010). Mental illness and well-being: the central importance of positive psychology and recovery approaches. BMC Health Services research, 10, 26.

Smit, F., Cuijpers, P., Oostenbrink, J., Batelaan, N., de Graaf, R., \& Beekman, A. (2006). Costs of nine common mental disorders: Implications for curative and preventive psychiatry. Journal of Mental Health Policy and Economics, 9, 193-200. 
Stewart, W. F., Ricci, J. A., Chee, E., Hahn, S. R., \& Morganstein, D. (2003). Cost of lost productive work time among US workers with depression. JAMA, 289, 3135-3144.

ten Have, M., de Graaf, R., Ormel, J., Vilagut, G., Kovess, V., \& Alonso, J. (2010). Are attitudes towards mental health help-seeking associated with service use? Results from the European Study of Epidemiology of Mental Disorders. Social Psychiatry Epidemiology, 45, 153-163.

Teasdale, J. D., Moore, R. G., Hayhurst, H., Pope, M., Williams, S., \& Segal, Z. V. (2002). Metacognitive awareness and prevention of relapse in depression: Empirical evidence. Journal of Consulting and Clinical Psychology, 70, 275-287

Törneke, N. (2010). Learning RFT: An introduction to relational frame theory and its clinical applications. Oakland, CA: New Harbinger Publications, Inc.

Tull, M. T., Gratz, K., Salters, K., \& Roemer, L. (2004). The role of experiential avoidance in posttraumatic stress symptoms and symptoms of depression, anxiety, and somatization. Journal of Nervous and Mental Disease, 192, 754-761.

van Beljouw, I., Verhaak, P., Prins, M., Cuijpers, P., Penninx, B., \& Bensing, J. (2010). Reasons and Determinants for Not Receiving Treatment for Common Mental Disorders. Psychiatric Services, 61, 250-257.

van de Berg, M. (2010). Effecten van preventieve interventies voor lokaal gezondheidsbeleid. Een overzicht op basis van de leeflijnen uit de handleidingenvoor roken, alcohol, overgewicht en depressie. Bilthoven: RIVM.

Westerhof, G. J., \& Keyes, C. L. M. (2008). Geestelijke gezondheid is meer dan de afwezigheid van geestelijke ziekte. Maandblad Geestelijke Volksgezondheid, 63 (10), 808-820.

Wood, A.M., \& Joseph, S. (2010). The absence of positive psychological (eudemonic) well-being as a risk factor for depression, a ten year cohort study. Journal of Affective Disorders, 122, 213-217.

Wolfe, V. V., Dozois, D., Fisman, S., \& DePace, J. (2008). Preventing depression among adolescent girls: Pathways toward effective and sustainable programs. Cognitive and Behavioral Practice, 15, 36-46.

World Health Organization. (2008). The global burden of disease: 2004 update. Geneva; WHO.Available at www.who.int/healthinfo/global_burden_ disease/GBD_report_2004update_full.pdf. 


\section{Further evaluation of the psychometric properties of the Acceptance and Action Questionnaire-II}

Fledderus, M., Oude Voshaar, M. A. H., ten Klooster, P. M., \& Bohlmeijer, E. T. Further Evaluation of the Psychometric Properties of the Acceptance and Action Questionnaire-II. Under revision for publication in Psychological Assessment. 


\section{Abstract}

The Acceptance and Action Questionnaire-II (AAQ-II) is a self-report measure designed to assess experiential avoidance as conceptualized in Acceptance and Commitment Therapy (ACT). The current study is the first to evaluate the psychometric properties of the AAQ-II in a large sample of adults $(n=376)$ with mild to moderate levels of depression and anxiety who participated in a study on the effects of an ACT intervention. The internal construct validity and local measurement precision were investigated by fitting the data to a unidimensional item response theory (IRT) model and the incremental validity of the AAQII beyond mindfulness, as measured by the Five Facet Mindfulness Questionnaire, was assessed. Results of the IRT analyses suggest that the AAQ-II is a unidimensional measure of experiential avoidance and has satisfactory reliability for group comparisons in mild to moderately depressed and anxious populations. Item functioning was found to be independent of gender and slightly dependent on age. Furthermore, the AAQ-II showed incremental validity beyond five mindfulness facets in explaining depression, anxiety and positive mental health. This study suggests the AAQ-II shows promise as a useful tool for the measurement of experiential avoidance in mild to moderately depressed and anxious populations. 


\section{Introduction}

There is growing interest in experiential avoidance (EA) as a risk factor for psychopathology (Biglan, Hayes, \& Pistorello, 2008). EA has been defined as the unwillingness to remain in contact with experiences such as feelings, thoughts, and bodily sensations, as an attempted means of behavioral regulation (Hayes et al., 2004). As a consequence, a person will try to use methods that alter, control, predict, or avoid the form, the frequency, or the contexts in which these experiences arise, even when these methods lead to behaviors that cause harm to physical, emotional or psychological well-being (Hayes, Luoma, Bond, Masuda, \& Lillis, 2006). A behavior therapy that is focused on decreasing EA is Acceptance and Commitment Therapy (ACT; Hayes et al., 2006). In $\mathrm{ACT}$, clients are encouraged to accept their private experiences when these experiences help them in engaging in value-based behavior. Studies have shown that ACT is effective in reducing depression and anxiety (e.g., Forman, Herbert, Moitra, Yeomans, \& Geller, 2007; Bohlmeijer, Fledderus, Rokx, \& Pieterse, 2011; Fledderus, Bohlmeijer, Pieterse, \& Schreurs, 2011) and chronic pain (e.g., Vowles \& McCracken, 2008) and in increasing positive mental health (Fledderus, Bohlmeijer, Smit, \& Westerhof, 2010). Meta-analyses have shown medium to large effect sizes of ACT interventions on different symptoms of psychological distress (Hayes et al., 2006; Powers, Zum Vörde Sive Vörding, \& Emmelkamp, 2009). Recently, more studies have shown that reducing EA (or enhancing acceptance) is an important process of change through which ACT leads to observed improvements in mental health (Carriochi, Billich, \& Godsell, 2010). For example, two studies have provided preliminary evidence that changes in EA mediated the effect of an ACT intervention on social anxiety (Dalrymple \& Herbert, 2007; Kocovski, Fleming, \& Rector, 2009).

For examining the effects and the mediating role of EA, is it important that the assessment of EA is carried out with a proper and well-validated general questionnaire. The Acceptance and Action Questionnaire (AAQ) is the most frequently used measure of EA and available in versions of 9 or 16 items (Bond \& Bunce, 2003; Hayes et al., 2004). The AAQ measures various theoretically linked aspects of EA including the need for emotional and cognitive control, avoidance of negative private events, inability to take needed action in the face of private events, and forms of cognitive entanglement (Hayes et al., 2004). Both versions of the AAQ have shown their usefulness in assessing EA in psychopathology (see for reviews Hayes et al., 2006; Chawla \& Ostafin, 2007). Moreover, several versions have been developed that are tailored to populations with specific problems such as chronic pain (McCracken, Vowles, \& Eccleston, 2004), smoking (Gifford et al., 2004), and weightrelated difficulties (Lillis \& Hayes, 2008). Although these questionnaires have shown their usefulness in predicting relevant outcomes of ACT interventions in these areas or populations (e.g., Gifford et al., 2004; Lillis \& Hayes, 2008), a general measure of EA that 
can be used in any context is important for studying the processes underlying ACT interventions (Bond et al., 2011).

Although the AAQ is widely used, it has demonstrated two important limitations (Chawla \& Ostafin, 2007). First, the AAQ has shown problems with its factor structure and internal consistency. Due to the broad item content of the different related constructs, it is unclear whether the AAQ measures one overarching construct or a multidimensional construct (Chawla \& Ostafin, 2007). To illustrate this problem, the 9-item AAQ showed a one-factor solution (Hayes et al., 2004), while the 16-item AAQ showed a two-factor solution of EA, consisting of willingness and overt action (Bond \& Bunce, 2003). Furthermore, internal consistency of the scale is often low, which is probably a result of the complex items (Bond et al., 2011). In the study of Hayes et al. (2004), Cronbach's alpha barely reached an acceptable level $(\alpha=.70)$, while other studies found even lower internal consistency (e.g., Boelen \& Reijntjes, 2008).

Second, there is uncertainty about the incremental validity of the AAQ, because it is unclear what the AAQ adds to other theoretically related measures that also address motivation to accept or avoid aversive private experiences, such as mindfulness and thought-suppression scales (Chawla \& Ostafin, 2007). To overcome these limitations, the AAQ-II was developed from an item-pool generated by ACT researchers and therapists (Bond et al., 2011). It is the current form for assessing acceptance (e.g., Costa \& PintoGouveia, 2011; Wheaton, Berman, \& Abramowith, 2010) and measures the ability to accept aversive internal experiences and to pursue goals and values in the presence of these experiences.

To date, only a few studies have assessed the psychometric properties of the AAQ-II. Confirmatory factor analyses (CFAs) in three different samples, including university students $(n=433)$, financial services workers $(n=583)$, and people seeking treatment for substance misuse $(n=290)$, indicated that the 10-item AAQ-II had a onefactor solution. Furthermore, it showed good internal consistency (Cronbach's $\alpha=.78-.88$ ). Also, the AAQ-II was related to theoretically linked constructs such as depression, anxiety and thought suppression, showing adequate construct validity (Bond et al., 2011). The psychometric properties of the AAQ-II were further examined in a sample of people seeking treatment for chronic pain $(n=144)$ (McCracken \& Zhao-O'Brien, 2010). CFA demonstrated that the AAQ-II had a unitary factor structure in this population as well. The AAQ-II showed good internal consistency (Cronbach's $\alpha=.89$ ) and construct validity as it was associated with pain-related anxiety, depression and mindfulness. The Dutch translation of the AAQ-II was tested in a general sample $(n=374)$ and in a sample of patients in psychiatric hospitals $(n=124)$. In both samples, a one-factor structure was found using principal component analyses and the scale demonstrated good internal consistency (Cronbach's $\alpha=.89$ in both samples) and satisfactory construct validity (Jacobs, Kleen, De Groot, \& A-Tjak, 2008). The incremental validity of the AAQ-II has been investigated in two studies. McCracken and Zhao-O'Brien (2010) found that the AAQ-II added significant variance to the prediction of the quality of daily patient functioning, above and beyond 
acceptance of pain and general mindfulness. Karekla and Panayiotoua (2011) showed that the AAQ-II explained unique variance in psychological distress and quality of life above and beyond various coping styles (e.g., active coping, emotional support) in a general sample of 197 adults. The added variance was small, indicating that the AAQ-II and the coping styles are largely overlapping, but not identical constructs (Karekla \& Panayiotoua, 2011). Taken together, these studies provide promising support for the psychometric qualities of the AAQ-II. However, all studies used classical test theory (CTT) based approaches only for examining the internal construct validity of the scale. Moreover, the incremental validity of the AAQ-II over closely related aspects of mindfulness has yet to be established.

Further empirical support for the internal construct validity of the AAQ-II can be obtained by showing that the responses to the AAQ-II fit a unidimensional item response theory (IRT) model. Fitting an IRT-model can validate the scoring rule of the AAQ-II by verifying that the variance in observed responses can be attributed to both item and person parameters that are related to a single underlying trait of EA (Glas, 1998). Construct validity further implies that expected scores on items should not differ between subpopulations (e.g., gender, age) when their overall level of EA is the same (Chang \& Mazzeo, 1994). This dependence of item response on background variables is known as differential item functioning (DIF). IRT provides the possibility to thoroughly investigate if DIF is present and if so, it can be investigated if the same latent trait of EA still applies to all groups, despite observed differences in response behavior (Geberhardt \& Adams, 2007; Glas, 1998). Although CFA and IRT models are closely related (Reise, Widaman, \& Pugh, 1993), IRT is a stronger model than CFA with more parameters (location parameters for the items in addition to factor loadings, i.e., item discrimination parameters) allowing stronger conclusions regarding DIF (Fischer \& Molenaar, 1995). Furthermore, the test information curve (TIC) can be evaluated in an IRT-model. This is a more advanced method for assessing the reliability of the AAQ-II than classical approaches that summarize the average measurement precision of a scale in a single index score (such as Cronbach's alpha). This feature of IRT is especially relevant for the analysis of self-report measures, because it is a common feature of the items of such instruments to differentiate best between respondents at a specific level of the latent trait (Embretson \& Reise, 2000). If, for example, relative item difficulties would cluster together at a narrow range in the middle of the latent trait scale, the measure would perform poorly in differentiating between persons at the extreme ends of the latent trait.

Further support for the incremental validity would be obtained by demonstrating that the AAQ-II contributes to information beyond that which is attained by a comprehensive measure of mindfulness in a sample eligible for ACT. Especially, because mindfulness is incorporated in ACT and acceptance is included in most definitions of mindfulness (Fletcher \& Hayes, 2005). For instance, Bishop et al. (2004) defined mindfulness as "an orientation that is characterized by curiosity, openness and acceptance" (p. 232). They described acceptance as being in the present moment and open 
to experiences (Bishop et al., 2004). This is in accordance with the ACT theory on the definition of acceptance (Fletcher \& Hayes, 2005). The only previous study that assessed the incremental validity of the AAQ-II over mindfulness used a unidimensional measure of mindfulness (McCracken \& Zhao-O'Brien, 2011). A comprehensive multifaceted and often used measure of mindfulness is the Five Facet Mindfulness Questionnaire (FFMQ; Baer, Smith, Hopkins, Krietemeyer, \& Toney, 2006). The FFMQ consists of five facets of mindfulness: (1) observing, defined in terms of noticing or attending to internal and external experiences, (2) describing, defined in terms of labeling internal experiences with words, (3) acting with awareness, defined in terms of attending to one's activities of the moment (opposite of acting on automatic pilot), (4) nonjudging of inner experience, defined in terms of taking a non-evaluative stance toward thoughts and feelings, and (5) nonreactivity to inner experience, defined in terms of allowing thoughts and feelings to come and go, without getting caught up in or carried away by them. Baer et al. (2006) stated that nonreactivity and nonjudging may be seen as ways of operationalizing acceptance. They found a high correlation $(r=.49)$ between the AAQ-II and the nonjudging facet. Although the AAQ-II and FFMQ are not meant to measure to same construct it is important to examine whether the AAQ-II adds additional variance in explaining relevant outcomes such as depression, anxiety, and positive mental health, given the possible overlap acceptance and several aspects of mindfulness.

Finally, this is the first study aimed at assessing these psychometric properties of the AAQ-II in a sample with mild to moderate depression and anxiety. As many people suffer from mild to moderate depression and anxiety (World Health Organization, 2008), there is a growing implementation of ACT and mindfulness-based interventions in this population. Although the efficacy of these treatments has been established (e.g., Forman et al., 2007; Segal, Williams, \& Teasdale, 2002), it is increasingly important to study the underlying processes of change for understanding how and why these treatments work to allow further optimisation. In ACT and mindfulness-based treatments for depression and anxiety, acceptance is considered an important process of change (Carriochi et al., 2010). Therefore, it is important that this process is assessed with a reliable and valid measure for this population.

Therefore, the current study had two aims. The first aim was to use IRT based methods to further assess the internal construct validity of the AAQ-II and to provide insight in its local measurement precision using IRT-based methods in sample of adults with mild to moderate depression and anxiety. The second aim was to further examine whether the AAQ-II has additional variance in explaining depression, anxiety and positive mental health over the mindfulness facets as measured by the FFMQ. 


\section{Methods}

\section{Participants}

Baseline data were used from a randomized controlled trial of the effects of a guided selfhelp ACT intervention on psychological distress and positive mental health (Fledderus et al., 2011). In September 2009, participants were recruited through advertisements in Dutch newspapers for a study on the effects of guided self-help based on ACT. In the advertisement, the target group of the intervention was described as people who wanted to get more out of their life but who were hindered by depressive or anxiety symptoms.

Inclusion criteria were an age of 18 years or older and mild to moderate depressive symptoms (>10 and $<39$ on the Center of Epidemiological Studies-Depression Scale (CES-D; Radloff, 1977) and anxiety symptoms (> 3 and <15 on the Hospital Anxiety and Depression Scale-Anxiety (HADS-A; Zigmond \& Snaith, 1983). People with severe depressive symptomatology and/or anxiety (more than 1 standard deviation above the population mean on the CES-D (cut-off score $\geq 39$; Bouma, Ranchor, Sanderman, \& Van Sonderen, 1995) and/or HADS-A (cut-off score $\geq 15$; Olssøn, Mykletun, \& Dahl, 2005) were excluded, because severe distress would require more intensive individual diagnostics and treatment. For the remaining participants it was checked who were still responding positively to a screener for a depressive disorder (Web Screening Questionnaire (WSQ) Q1 $\geq 6$ and Q2 = 1) (Donker, Van Straten, Marks, \& Cuijpers, 2009). As the WSQ yields a high number of false positives (Donker et al., 2009) those who were screened as having a depressive disorder underwent a telephone interview that employed the depressive episode module of the Mini International Neuropsychiatric Interview (MINI; Sheehan et al., 1998). People whom the MINI diagnosed as having a severe depressive episode were excluded.

Other exclusion criteria were: (a) few depressive ( $\leq 10$ on the CES-D) and/or anxiety symptoms ( $\leq 3$ on the HADS-A), (b) receiving psychological or psychopharmacological treatment within the last three months, and (c) high suicide risk (Q15 = 3 on the WSQ).

\section{Procedure}

A total of 625 people responded to the advertisements and received an information sheet explaining the study and an informed consent form. This was signed by 507 people who then received an e-mail with a screening questionnaire comprising the CES-D, HADS-A, WSQ and demographic items. First, 54 respondents were excluded because they had severe depression and/or anxiety according to the scores on the CES-D and HADS-A. They were advised to contact their general practitioner. Second, 44 respondents were diagnosed by the WSQ as having a depressive disorder and subsequently underwent a telephone interview using the MINI. These interviews were conducted by Master students of psychology who were trained and supervised by a clinical psychologist. Of the 43 respondents (one respondent could not be contacted), two were diagnosed with a severe depressive episode 
and were excluded and advised to contact their general practitioner. In all, 56 respondents were excluded because they had severe depression or anxiety. A further 75 respondents were excluded because they had few depression and/or anxiety symptoms $(n=58)$, did not complete the screening questionnaire $(n=15)$, could not be contacted for the interview ( $n$ $=1$ ), or currently received psychological treatment $(n=1)$. In total, 376 participants were included in the study and were randomly assigned to the ACT intervention with minimal email support $(n=125)$, the same intervention with extensive email support $(n=125)$ or to a waiting list $(n=126)$. The waiting list group received the intervention after the intervention period of 9 weeks. More detailed information about the study can be found in Fledderus et al. (2011). Table 1 shows an overview of the participants' characteristics. Their mean age was 42 years (range $=18-73$ ). The majority was female $(70 \%)$ and of Dutch origin (93\%). Most of the participants had a high level of education (86\%), a paid job $(76 \%)$ and were not married $(47 \%)$.

Table 1. Respondents characteristics and scores on AAQ-II, CES-D, HADS-A, MHC-SF and FFMQ

\begin{tabular}{|c|c|}
\hline Age, years $(n=376) ; M, S D$ & $42.49(11.09)$ \\
\hline \multicolumn{2}{|l|}{ Age groups $(n=376) ; n(\%)$} \\
\hline $18-36$ years & $116(30.9)$ \\
\hline $37-48$ years & $132(35.1)$ \\
\hline 49 and older & $128(34.0)$ \\
\hline Gender $(n=376) ; \%$ female & 69.7 \\
\hline \multicolumn{2}{|l|}{ Marital status $(n=375) ; n(\%)$} \\
\hline Married & 164 (43.7) \\
\hline Divorced & $32(8.5)$ \\
\hline Widowed & $4(1.1)$ \\
\hline Never married & 175 (46.7) \\
\hline \multicolumn{2}{|l|}{ Race $(n=376) ; n(\%)$} \\
\hline Dutch & $349(97.8)$ \\
\hline Other & $27(2.2)$ \\
\hline \multicolumn{2}{|l|}{ Educational level $(n=376) ; n(\%)$} \\
\hline Low (primary school, lower vocational education) & $19(5.1)$ \\
\hline Intermediate (secondary school, vocational education) & $62(16.5)$ \\
\hline High (higher vocational education, university) & $295(78.5)$ \\
\hline Acceptance (AAQ-II) $(n=372) ; M, S D$ & $40.72(8.59)$ \\
\hline Depression (CES-D) $(n=364) ; M, S D$ & $22.70(6.63)$ \\
\hline Anxiety (HADS-A) $(n=373) ; M, S D$ & $9.47(2.50)$ \\
\hline Positive mental health (MHC-SF) $(n=362) ; M, S D$ & $3.13(.76)$ \\
\hline \multicolumn{2}{|l|}{ Mindfulness (FFMQ); $M, S D$} \\
\hline Observe $(n=372)$ & $25.09(5.17)$ \\
\hline Describe $(n=373)$ & $25.69(6.23)$ \\
\hline ActAware $(n=375)$ & $20.94(4.96)$ \\
\hline NonJudge $(n=374)$ & $22.98(5.38)$ \\
\hline NonReact $(n=372)$ & $19.18(3.78)$ \\
\hline
\end{tabular}




\section{Measures}

All participants completed online measures at baseline and directly after the intervention (nine weeks). Those assigned to the experimental conditions completed a third assessment at five months after baseline. For this study, the baseline data were used. The internal consistency of the used measures was examined by Cronbach's alpha coefficients, where values above .70 were considered acceptable and values of .80 or higher as good (George \& Mallery, 2003). Only fully completed questionnaires were used in the analysis.

The AAQ-II (Bond et al., 2011) is a 10-item questionnaire. Participants were asked to rate on a 7-point Likert-scale the degree to which each statement is true for them. A total score, ranging from 10 to 70 , was computed by summing the scores on the individual items. Higher scores indicate higher levels of general acceptance and less experiential avoidance. The Dutch AAQ-II (Jacobs et al., 2008) showed good internal consistency in the current study $(\alpha=.85)$.

The FFMQ (Baer et al., 2006) is a 39-item questionnaire that measures five facets of mindfulness: observing ( 8 items), describing ( 8 items), acting with awareness ( 8 items), nonjudging ( 8 items) and nonreactivity ( 7 items). Participants were asked to rate the degree to which each statement is true for them on a 5-point Likert scale ranging from 1 (never or very rarely true) to 5 (very often or always true). Facet scores were computed by summing the scores on the individual items. Facet scores range from 8 to 40 (except for the nonreactivity facet which ranges from 7 to 35), with higher scores indicating more mindfulness. The Dutch FFMQ was developed by translation and back-translation of the original FFMQ and has shown adequate construct validity and test-retest reliability in patients with fibromyalgia (Veehof, Ten Klooster, Taal, Westerhof, \& Bohlmeijer, 2011) and factorial validity in people with depressive symptomatology (Bohlmeijer, Ten Klooster, Fledderus, Veehof, \& Baer, 2011). All five facets showed acceptable to good internal consistency in this study, ranging from .70 for observing to .91 for describing.

The CES-D (Radloff, 1977) is a 20-item questionnaire that measures depressive symptoms in the general population. Respondents rated on a 4-point scale ranging from hardly ever (less than 1 day) to predominantly (5-7 days) to what extent they had experienced depressive symptoms in the previous week. Summation of the scores results in a total score ranging from 0 to 60 . A score of 16 or higher is considered to indicate the presence of clinically relevant depressive symptoms. The CES-D has shown good psychometric properties in a general sample (Radloff, 1977). The Dutch translation demonstrated similar psychometric properties in a group of elderly people in the Netherlands (Haringsma, Engels, Beekman, \& Spinhoven, 2004). In this study, the scale showed acceptable internal consistency $(\alpha=.78)$.

The HADS-A (Zigmond \& Snaith, 1983) was used to measure the presence and severity of anxiety symptoms. Participants were asked to rate the degree to which they experienced several emotions in the past week. All items were rated on a 4-point scale. Scale scores were computed by summing the scores on the individual items. Scale scores 
range from 0 to 21 with higher scores indicating more anxiety. The Dutch HADS has shown good psychometric properties across diverse general and clinical populations (Spinhoven, Ormel, Sloekers, Kempen, Speckens, Van Hemert, 1997). In this study, the scale showed low internal consistency at baseline $(\alpha=.56)$.

The Mental Health Continuum-Short Form (MHC-SF) was used to measure positive mental health (Keyes, 2002). The MHC-SF is a 14-item questionnaire that measures three dimensions of mental health: (1) emotional well-being ( 3 items), defined in terms of positive feelings and satisfaction with life; (2) psychological well-being (6 items), defined in terms of positive functioning in individual life (self-realization); and (3) social well-being ( 5 items), defined in terms of positive functioning in community life (being of social value). Participants were asked to rate the frequency of feelings they experienced in the past month. Items were scored on a 6-point scale ranging from 1 (never) to 6 (every day). A total score was computed by summing the scores on the individual items and dividing these by the number of items. Higher scores indicate better positive mental health. The Dutch MHC-SF has shown good construct validity and test-retest reliability in the general adult population (Lamers, Westerhof, Bohlmeijer, Ten Klooster \& Keyes, 2011) and good internal consistency in this study $(\alpha=.88)$.

\section{Statistical analysis}

For assessing the internal construct validity and local measurement precision of the AAQII, the 2-parameter generalized partial credit model (GPCM; Muraki, 1992) was estimated using MIRT (Glas, 2010). The GPCM pertains to polytomously scored items, such as the items of the AAQ-II. In this model, each item is described by a number of category intersection parameters equal to the number of response options minus 1 and one discrimination parameter. Category intersection parameters indicate the location on the latent EA continuum where two consecutive response options are equally likely to be endorsed by respondents. Discrimination parameters represent the degree to which an item discriminates between persons with different levels of the latent trait and can be interpreted like factor loadings in factor analysis, i.e. they represent the strength of the association of the item with the latent trait. The item parameters were estimated using the marginal maximum likelihood (MML) procedure. MML is the most commonly used estimation procedure in IRT. In contrast to other methods (for instance, joint maximum likelihood) it produces consistent estimates of the structural model parameters (Bock \& Aitkin, 1982). Response options 1 and 2 and response options 6 and 7 of the AAQ-II were collapsed to obtain stable category intersection parameters.

The first step of the IRT analysis was to evaluate the presence of DIF across gender and age in the items of the AAQ-II. To optimize the stability of the resulting parameters, three equally large age groups were created for this analysis, resulting in the following groups: 18-36 years, 37-48 years and 49 years and older. Age and gender are important background variables that might confound the outcomes of effectiveness studies if the items of the instrument used are biased against subgroups, especially in smaller trials. 
Analysis of DIF is therefore an important step in ascertaining the external construct validity of the AAQ-II for depressed and anxious populations. Items show DIF if the probability of choosing a given response option differs between groups with the same level of EA. The presence of DIF and the unidimensionality of the AAQ-II were evaluated with Lagrange Multiplier (LM) tests (Glas, 1998). Although relatively new in the personality assessment literature, LM tests are more widespread in other areas of research (e.g., Van Groen, Ten Klooster, Taal, Van de Laar, \& Glas, 2010; Weisscher, Glas, Vermeulen, \& De Haan, 2010; Glas, Geerlings, Van de Laar, \& Taal, 2009). The LM test is asymptotically equivalent to the likelihood ratio test, but has some computational advantages (Glas, 1998; Glas, 1999). From a practical point of view, the LM statistics are useful item-oriented diagnostic tools, which give an indication of the source of model violations. They are based on a difference between observed and expected frequencies, so the importance of a significant DIF finding can be assessed in a framework that is directly related to observed data. Another advantageous aspect of the LM statistics is that they offer the possibility of directed model relaxation to obtain sufficient model fit.

The LM statistics are accompanied by effect size statistics which show the seriousness of model violation. These statistics are the absolute difference between observed average item scores minus average item scores expected by the model. Because response options were collapsed, the effect size statistics theoretically range from 0 to 4 . We evaluated whether the DIF effect sizes were significant, correcting for multiple comparisons $(p<.01)$ and considered significant effects sizes $>0.10$ indicative of substantial DIF. If DIF is not present, unambiguous support for the construct validity of the AAQ-II is obtained. If DIF is found, this indicates that response behavior is inconsistent across groups. This could indicate that an item is systematically more difficult for one group. It may also indicate that the same latent dimension of EA does not apply to one of the groups at all, which is a more serious violation of construct validity (Glas, 1998). When a limited number of items show substantial DIF, construct validity may still be defendable if it can be explicitly shown that the same underlying latent variable EA pertains to both groups. That is, the same IRT model should hold for the entire set of response data, after assigning separate item parameters to the items that show substantial DIF (Geberhardt \& Adams, 2007; Glas, 1998; Fischer \& Molenaar, 1995). The second step of the IRT analysis was therefore to investigate whether the same latent scale, with gender or age specific parameters where necessary, still applied. To this end, LM statistics pertaining to the form of the item response curves were calculated after assigning separate parameters to items with substantial DIF (Glas, 1999). Because in this analysis, LM statistics are computed within groups for each of the items, corrected $p$ values $<.01$ were, again, considered to indicate significant misfit.

After the data were adequately modeled, the TIC was calculated to provide insight into the local measurement precision of the AAQ-II. The TIC is calculated from the item parameters and provides information about the range of latent scores where the AAQ-II is best at discriminating among individuals. The height of the curve (denoting the amount of 
information at a given point of the latent scale) is a function of the discrimination parameters and the threshold parameters of the items making up the scale. To better interpret the outcomes of this analysis, the amount of information provided by the AAQ-II for relevant ranges along the latent metric of EA, was also converted to reliability coefficients ( $r=1-1 /$ information) (Reeve \& Fayers, 2005).

For examining the incremental validity of the AAQ-II, Pearson's correlation coefficients were first calculated between acceptance (AAQ-II) and depression (CES-D), positive mental health (MHC-SF) and mindfulness facets (FFMQ). In line with previous studies (e.g., Hayes et al., 2006; Fledderus, Bohlmeijer, \& Pieterse, 2010a) negative correlations between the AAQ-II and anxiety and depression and a positive correlation with positive mental health were expected. Based on previous studies (Baer et al., 2006; Baer et al., 2008; Veehof et al., 2011) positive correlations were expected between the mindfulness facets (except for observing) and the AAQ-II. Nonjudging was predicted to show the strongest correlation with the AAQ-II. Furthermore, at least moderate negative correlations were predicted between the mindfulness facets (except observing) and anxiety and depression. Also, moderate positive correlations between the mindfulness facets (except observing) with positive mental health were predicted. Hierarchical multiple regression analyses were then conducted to examine the incremental validity of AAQ-II beyond the facets of the FFMQ in explaining depression, anxiety and positive mental health. In the first block, the facets of the FFMQ were entered that were univariately significantly related to the dependent variables depression (CES-D), anxiety (HADS-A) and positive mental health (MHC-SF). In the second block, acceptance (AAQ-II) was included. The change in variance accounted for from block 2 served as a test for the incremental validity of the AAQ-II $(p<.05)$. We also performed reversed hierarchical multiple regression analyses in which the AAQ-II was entered in the first block and the mindfulness facets were added in the second block.

\section{Results}

\section{Internal construct validity}

LM tests indicated no substantial DIF for gender for any of the items of the AAQ-II ( i.e. all $p$ 's $>.01$ ). In Table 2, the results for DIF for age are shown. Substantial age DIF was found in item 9 ("Worries get in the way of my success") of the AAQ-II. Because the presence of DIF may bias the parameter estimates of the other items, the presence of DIF was reevaluated after assigning age specific parameters to item 9 (Glas, 1998; Fischer \& Molenaar, 1995). In the re-specified model with age-specific parameters for item 9, the DIF in item 4 ("I worry about not being able to control my worries and feelings") became more pronounced $(L M=12.39, p<.01, E . S .=0.13)$. Therefore, item 4 was assigned age specific parameters as well. After these re-specifications no more significant LM tests were found (i.e., all $p$ 's > .01). 
The three panels in Table 3 contain the DIF statistics of the items with substantial DIF separately for each age group. In each panel the observed average score and the expected average score of the age group are compared to the observed and expected averages of the other age groups together. Table 3 illustrates the nature of DIF present in item 4. The first panel shows that the observed score on item 4 in the age group of 18 to 36 years was 2.00 compared to an average observed score in the other groups of 2.30. Because people aged 18 to 36 years were expected to score 2.20 according to the model (see Table 2 ), this results in a DIF effect size of -0.20 , reflecting the fact that these respondents scored lower than expected. Likewise, it can be seen that the average observed score of the respondents in the age group 49+ years was 0.11 points higher than expected under the model. The same pattern was noticed for item 9. In the next step of the analysis it was examined whether the re-specified model, with age-group specific item parameters for item 4 and 9, fitted the data. The results for age group 18-36 years are shown in Table 4. The results for the two other age groups were analogous (i.e., range of $p$ 's $=.08$-.98). Note that none of the outcomes of the LM tests were below the significance level of $1 \%$, indicating that all items adequately fitted to the re-specified model. So, although younger respondents scored systematically worse on items 4 and 9 than is to be expected based on their total score, this analysis showed that both items still relate to the same latent trait of EA and that the observed bias is relatively minor.

In the final step of the IRT-analysis, the test information curve was calculated from the resulting item parameters. Because age-group specific item parameters were assigned to two items of the AAQ-II, the test information curve was plotted for the three age-groups separately, with age-group specific parameters for items 4 and 9. In Figure 1 it can be seen that measurement precision is somewhat lower across the range of latent scores for age group 2. This is because the discrimination parameters of items 4 and 9 in age group 2 were lower than for the other age groups, indicating a less strong association with EA for both items within age group 2. Overall, between -2 and 1.6, the measurement precision of the AAQ-II exceeded 4, which corresponds to $r=0.75$. This indicates that with collapsed response options, the AAQ-II is reliable for inferences at the group level within this range. $93.5 \%$ of respondents in our sample fell within this range. 
Table 2. Differential Item Functioning across Age Groups

\begin{tabular}{llll}
\hline Item & L.M.* & $p$ & E.S. \\
\hline 1 & 4.48 & .11 & 0.10 \\
2 & 7.04 & .03 & 0.10 \\
3 & 0.18 & .92 & 0.01 \\
4 & 9.76 & .01 & 0.12 \\
5 & 4.82 & .09 & 0.08 \\
6 & 1.31 & .52 & 0.04 \\
7 & 5.97 & .05 & 0.08 \\
8 & 5.94 & .05 & 0.09 \\
9 & 16.39 & .00 & 0.14 \\
10 & 2.32 & .31 & 0.07 \\
\hline
\end{tabular}

Note. L.M. = Lagrange Multiplier; E.S. $=$ effect size; $* \mathrm{Df}=2$.

Table 3. Age Based Differential Item Functioning for Items with Substantial DIF

\begin{tabular}{|c|c|c|c|c|c|c|c|}
\hline & \multicolumn{2}{|c|}{ Focal group } & \multicolumn{2}{|c|}{ Reference group } & \multirow[b]{2}{*}{ E.S. } & \multirow[b]{2}{*}{ L.M.* } & \multirow[b]{2}{*}{$p$} \\
\hline & Obs & Exp & Obs & Exp & & & \\
\hline \multicolumn{8}{|c|}{ Age group } \\
\hline \multicolumn{8}{|l|}{$18-36$} \\
\hline Item 4 & 2.00 & 2.20 & 2.30 & 2.30 & -0.20 & 10.59 & .03 \\
\hline Item 9 & 1.40 & 1.58 & 1.65 & 1.65 & -0.18 & 14.32 & .01 \\
\hline \multicolumn{8}{|c|}{ Age group } \\
\hline \multicolumn{8}{|c|}{$37-48$} \\
\hline Item 4 & 2.27 & 2.21 & 2.17 & 2.20 & 0.06 & 4.10 & .39 \\
\hline Item 9 & 1.53 & 1.57 & 1.59 & 1.57 & -0.03 & 1.91 & .75 \\
\hline \multicolumn{8}{|l|}{ Age group } \\
\hline \multicolumn{8}{|l|}{$49+$} \\
\hline Item 4 & 2.32 & 2.21 & 2.15 & 2.21 & 0.11 & 4.41 & .35 \\
\hline Item 9 & 1.77 & 1.57 & 1.47 & 1.57 & 0.20 & 16.21 & .00 \\
\hline
\end{tabular}

Note. Obs $=$ Observed average score; Exp $=$ Expected average score; E.S. $=$ Effect Size

L.M. = Lagrange Multiplier; $*$ Df $=4$.

Table 4. Outcomes of Tests for Model Fit in Score Level Groups for Respondents in Age Group 18-36 Years

\begin{tabular}{|c|c|c|c|c|c|c|c|c|c|}
\hline \multirow[b]{2}{*}{ Item } & \multirow[b]{2}{*}{ L.M.* } & \multirow[b]{2}{*}{$p$} & \multirow[b]{2}{*}{ E.S. } & \multicolumn{2}{|c|}{$18-36$ years } & \multicolumn{4}{|c|}{ Other age groups } \\
\hline & & & & Obs & Exp & Obs & $\operatorname{Exp}$ & Obs & Exp \\
\hline 1 & 3.52 & .17 & 0.14 & 1.94 & 1.69 & 2.21 & 2.22 & 2.92 & 2.76 \\
\hline 2 & 3.69 & .16 & 0.10 & 1.49 & 1.46 & 2.58 & 2.36 & 3.21 & 3.28 \\
\hline 3 & 0.09 & .96 & 0.05 & 1.41 & 1.39 & 2.17 & 2.20 & 3.08 & 3.16 \\
\hline 4 & 5.73 & .06 & 0.10 & 1.41 & 1.26 & 1.81 & 1.93 & 2.77 & 2.80 \\
\hline 5 & 0.85 & .65 & 0.05 & 1.67 & 1.66 & 2.76 & 2.66 & 3.49 & 3.52 \\
\hline 6 & 3.50 & .17 & 0.11 & 2.05 & 1.90 & 2.25 & 2.41 & 2.95 & 2.92 \\
\hline 7 & 1.11 & .57 & 0.07 & 1.18 & 1.08 & 1.65 & 1.62 & 2.55 & 2.48 \\
\hline 8 & 1.26 & .53 & 0.10 & 0.82 & 0.92 & 1.62 & 1.67 & 2.54 & 2.67 \\
\hline 9 & 7.28 & .03 & 0.07 & 0.73 & 0.62 & 1.18 & 1.25 & 2.26 & 2.28 \\
\hline 10 & 0.21 & .90 & 0.09 & 0.74 & 0.78 & 1.29 & 1.28 & 1.82 & 2.02 \\
\hline
\end{tabular}


Figure 1. Test information curves of the AAQ-II. Age group $1=18-36$ years; Age group 2 $=37-48$ years; Age group $3=49$ years and older.

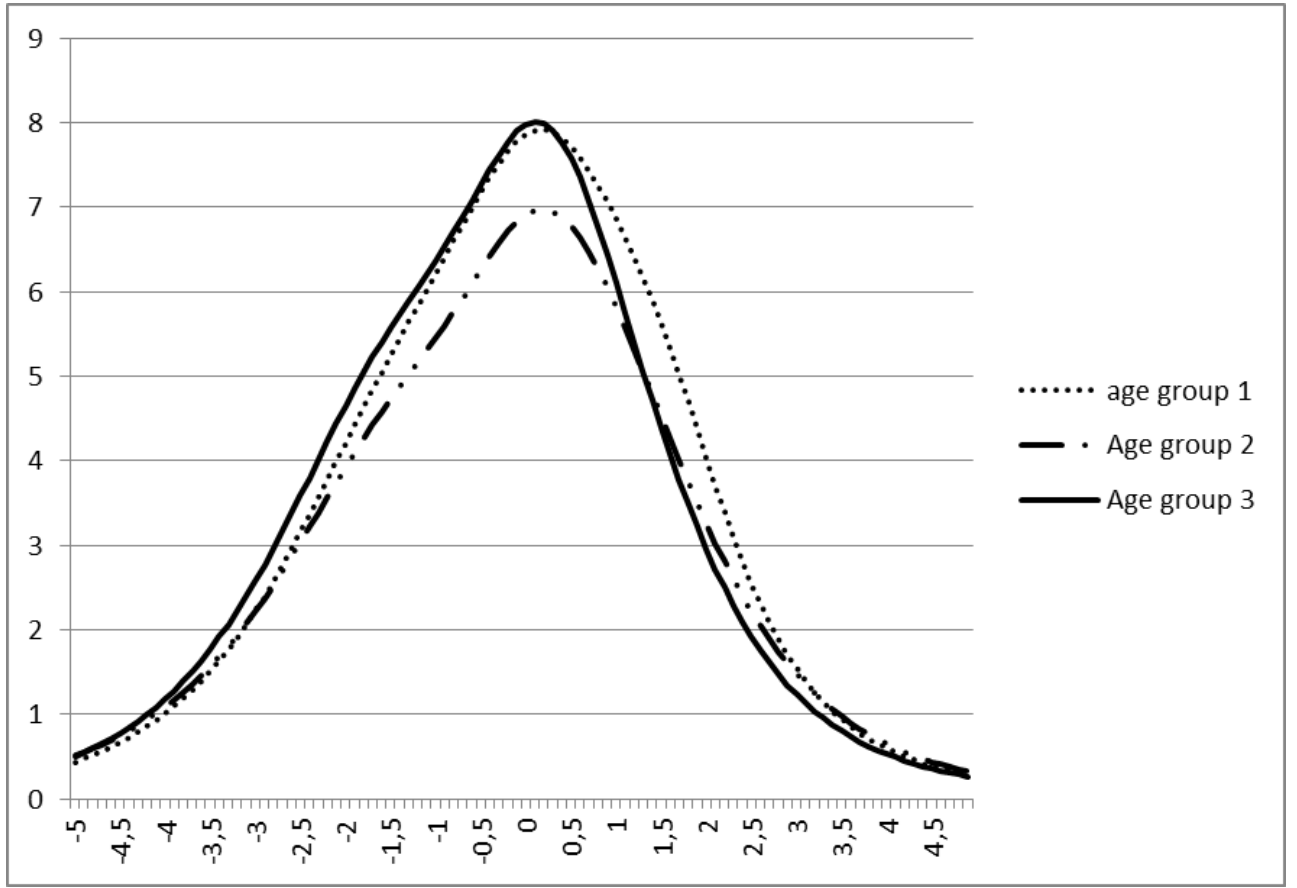

\section{Correlations between the AAQ-II and other measures}

The correlations between AAQ-II and the other constructs can be found in Table 5. As predicted, the AAQ-II correlated moderately negatively with depression and anxiety. The AAQ-II correlated positively with positive mental health. As expected, no significant relation was found between the AAQ-II and the observing facet of the FFMQ. The highest significant relation was found between the AAQ-II and nonjudging. For the other facets of the FFMQ, moderate correlations were found. Depression and anxiety were, as predicted, not related to the observing and significantly related to acting with awareness, nonjudging and nonreacting. Depression was, as expected, also related to the facet describing, but no relation was found between anxiety and this facet. As predicted, positive mental health was significantly related to four of the mindfulness facets, but also to observing. 
Table 5. Correlations between AAQ-II and Depression (CES-D), Anxiety (HADS-A), Positive Mental Health (MHC-SF) and Five Facets of Mindfulness (FFMQ)

\begin{tabular}{lllllllll}
\hline & CES-D & HADS-A & MHC-SF & $\begin{array}{c}\text { FFMQ- } \\
\text { Observe }\end{array}$ & $\begin{array}{c}\text { FFMQ- } \\
\text { Des } \\
\text { cribe }\end{array}$ & $\begin{array}{c}\text { FFMQ- } \\
\text { Acta } \\
\text { ware }\end{array}$ & $\begin{array}{c}\text { FFMQ- } \\
\text { Non } \\
\text { judge }\end{array}$ & $\begin{array}{c}\text { FFMQ- } \\
\text { Non } \\
\text { react }\end{array}$ \\
\hline AAQ-II & $-.40^{* *}$ & $-.31^{* *}$ & $.45^{* *}$ & .10 & $.31^{* *}$ & $.30^{* *}$ & $.54 * *$ & $.37 * *$ \\
$n$ & 360 & 371 & 359 & 368 & 369 & 371 & 370 & 368 \\
CES-D & & $-.47 * *$ & $-.34 * *$ & -.03 & $-.11^{*}$ & $-.20 * *$ & $-.25 * *$ & $-.16 * *$ \\
$n$ & & 361 & 350 & 360 & 361 & 363 & 362 & 360 \\
HADS-A & & & .06 & -.03 & -.02 & $-.22 * *$ & $-.24 * *$ & $-.20^{* *}$ \\
$n$ & & & 360 & 369 & 370 & 372 & 371 & 369 \\
MHC-SF & & & & $.30 * *$ & $.38^{* *}$ & $.20 * *$ & $.20 * *$ & $.22 * *$ \\
$n$ & & & & 358 & 359 & 361 & 360 & 358 \\
\hline
\end{tabular}

Note. AAQ-II $=$ Acceptance and Action Questionnaire-II; CES-D = Center for Epidemiological Studies Depression Scale; HADS-A = Hospital Anxiety and Depression Scale-Anxiety; MHC-SF = Mental Health Continuum-Short Form; FFMQ $=$ Five Facet Mindfulness Questionnaire; $*=p<.05 ; * *=p<.01$.

\section{Increment validity of the AAQ-II}

In Table 6, the hierarchical regressions for examining the incremental validity of the AAQII can be found. In the first step, the mindfulness facets that correlated significantly with depression were included. Table 6 shows that the mindfulness facets acting with awareness and nonjudging significantly explained variance in depression. In the second step, when the AAQ-II was entered as well, only the AAQ-II was significantly related to depressive symptoms. The AAQ-II explained a significant proportion of the variance in depressive symptoms beyond the contribution of the mindfulness facets (adjusted $\mathrm{R}^{2}$ change $=.07, p<$ .001).The same procedure was repeated with anxiety as the outcome measure. As with depression, the facets acting with awareness and nonjudging significantly explained variance in anxiety. After including the AAQ-II, acting with awareness and AAQ-II were significantly related to anxiety. The AAQ-II again explained a significant proportion of variance beyond the contribution of the mindfulness facets (adjusted $\mathrm{R}^{2}$ change $=.02, p<$ $.001)$. Finally, the same procedure was repeated with positive mental health as outcome. In the first step, the facets observing, describing and nonjudging were significantly related to positive mental health. After adding the AAQ-II, the mindfulness facets observing and describing and the AAQ-II were significantly related to positive mental health. Again the AAQ-II made a significant contribution to the explained variance (adjusted $\mathrm{R}^{2}$ change = $.08, p<.001)$. The reversed hierarchical analyses revealed the same results, indicating that the AAQ-II adds something unique beyond the mindfulness facets in explaining depression, anxiety and positive mental health. 
Table 6. Hierarchical Regression Analyses for Depression (CES-D), Anxiety (HADS-A) and Positive Mental Health (MHC-SF) with the Facets of Mindfulness (FFMQ)

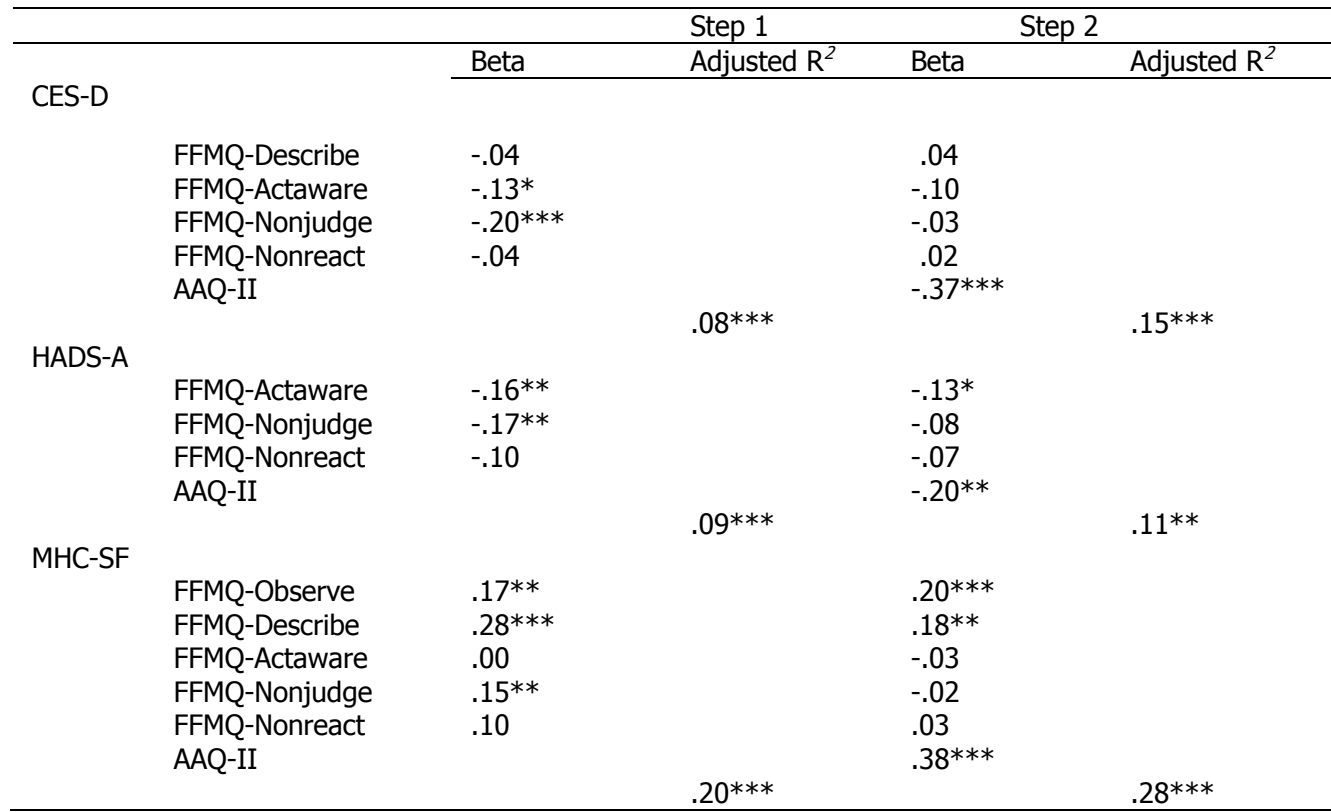

Note. AAQ-II = Acceptance and Action Questionnaire-II; FFMQ = Five Facet Mindfulness Questionnaire; CES-D $=$ Center for Epidemiological Studies Depression Scale; MHC-SF = Mental Health Continuum-Short Form; $*=p$ $<.05 ; * *=p<.01 ; * * *=p<.001$.

\section{Discussion}

In this study the psychometric properties of the Acceptance and Action Questionnaire-II (AAQ-II) were investigated in a sample of adults with mild to moderate depression and anxiety $(n=376)$. The first aim of the study was to use IRT based methods to examine the internal construct validity. Specifically, differential item functioning (DIF) across age and gender and local measurement precision were assessed. The results showed no DIF for gender and only two items of the AAQ-II showed DIF across age. These results indicate that most items function equivalently across the variables gender and age and the items have the same meaning for men and women and across different age groups. However, items 4 and 9 both showed that the youngest age group scored lower and the highest age group higher than expected on acceptance. Since there are only age differences in these two items, the DIF may be related to differences in interpreting these particular items. In both items "worry" is the subject; worrying about not having worries under control, and that worries get in the way of a successful life. This indicates that older people might worry less compared with younger people. Earlier research has shown that older and younger people differ in their worry content and that worries decline with age (Diefenback, McCarthyLarzelere, Williamson, Mathews, Manguno-Mire, \& Bentz, 2001; Lindesay et al., 2006). For example, Lindesay et al. (2006) found that older people worried less about 
relationship/family, finances/housing and work compared with younger people. So maybe different ideas of what worrying means and the frequency of worries could explain these differences. On the other hand, although these two items were found to exhibit statistically significant DIF, subsequent analysis indicated that a model with age-group specific parameters for items 4 and 9 fitted the unidimensional GPCM. These findings indicate that the same underlying latent variable of EA applies to all age groups, but that the overall level of EA required for a respondent to endorse a specific response option differs systematically. Considering that the absolute magnitude of observed DIF was relatively minor, the results suggest that the measurement model of the AAQ-II is valid for people with mild to moderate anxious and depressive symptoms and that the AAQ-II can reasonably be considered a unidimensional scale in this population.

The analysis of the test information curve (TIC) suggests that the AAQ-II is a reliable instrument for measuring EA in adults with mild to moderate depression and anxiety. However, it should be noted that the response options were collapsed to five instead of seven response options. So the results of our analysis pertain to the AAQ-II with five response options. Collapsing response options leads to loss of variability and consequent loss of measurement precision. The average reliability of the AAQ-II with seven response options will therefore exceed the reliability of the AAQ-II with five response options. However, as very few respondents in our sample elected response options 1 and 2 and response options 6 and 7, it was not possible to estimate stable threshold parameters for these response options. Although having many response options is an appealing feature of a scale for reasons mentioned above, it is vital for the validity of inferences drawn from the total score that respondents can consistently distinguish between response options, especially since the sum score of AAQ-II is used. Previous research has shown that respondents find it difficult to discriminate between more than 6 response options (Lopez, 1996). Therefore, it would be worthwhile to further investigate the utility of the current response format in different settings with larger samples.

Another point of interest are the three positively framed items. Bond et al. (2011) found in an exploratory factor analysis (EFA) that these items loaded on a second factor. They concluded that these three items should be deleted and a seven-item version of the AAQ-II should be used. However, using EFA, it is difficult to distinguish between true multidimensionality and method effects stemming from negatively and positively framed items. The IRT analysis carried out in this study is more sensitive in assessing multidimensionality and revealed no problems with multidimensionality after the DIF for age was taken into account. Furthermore, in McCracken and Zhao-O'Brien (2010) a unitary factor structure was found as well. Future research could examine whether it is necessary to delete these three items.

The second aim of the study was to examine whether the AAQ-II adds additional variance to mindfulness facets as measured with the Five Facet Mindfulness Questionnaire (FFMQ; Baer et al., 2006) in explaining depression, anxiety and positive mental health. Results showed that the AAQ-II was negatively related to depression and anxiety, and 
positively related to mindfulness facets (except for the facet observing) and positive mental health. We found no relation with the AAQ-II and the mindfulness facet observing. The other facets correlated significantly with the AAQ-II, with the strongest relation between AAQ-II and nonjudging. These findings correspond to earlier research (e.g. Baer et al., 2006; Veehof et al., 2011). The facet nonjudging is also theoretically the most closely related to the AAQ-II. Both measure the willingness to accept private experiences in the present moment without trying to avoid or change these experiences. Furthermore, the AAQ-II accounts for a higher proportion of variance in depression, anxiety and positive mental health when added to the mindfulness facets. This finding corroborates earlier research that showed that the AAQ-II had incremental validity beyond mindfulness in predicting chronic pain (McCracken \& Zhao-O'Brien, 2010). This earlier study used a unidimensional measure of mindfulness, while the current study used a multifaceted measure of mindfulness and looked in more detail to the separate facets of mindfulness. When the AAQ-II was added, the mindfulness facets acting with awareness and nonjudging were no longer related to depression and only the facet acting with awareness was still related to anxiety. When the AAQ-II was included, observing and describing were still related to positive mental health, but nonjudging was no longer significant. This implies that the AAQ-II has a unique role in predicting these outcomes above and beyond these mindfulness facets which justifies its use in ACT and mindfulness-based intervention studies. An explanation of this finding is that although both questionnaires assess the ability to contact the present moment and to accept private experiences, the AAQ-II also assesses taking value-based actions even in the face of unwanted thoughts, feelings and other private events that might occur. Besides acceptance of experiences, value-based behavior is important for the enhancement of psychological flexibility which is a core process of ACT (Hayes et al., 2006). Value-based behavior might be particularly important in individuals experiencing significant levels of depression and anxiety. This relevance is already underscored by earlier research that has shown that improved value-based actions at the end of an ACT treatment for chronic pain patients were associated with less pain and depression after the treatment (Vowles \& McCracken, 2008). More research is needed to investigate whether value-based living is an important predictor of depression, anxiety and positive mental health, beyond acceptance and mindfulness. Furthermore, future research could further examine the incremental validity of the AAQ-II with other closely related constructs, such as thought suppression.

Although this study provided robust IRT analyses and a more detailed insight into the incremental validity of AAQ-II, there are several limitations as well. First, the psychometric properties were analyzed cross-sectionally and no longitudinal analyses were done. Future research could examine DIF for the items of the AAQ-II over a longer time period, to investigate the stability of the parameters over time. Second, the DIF analyses were performed with age and gender. Future research could examine other demographic variables, such as education or ethnicity. In our sample our participants were mainly Dutch and highly educated, so generalization of the present results should be made with prudence. 
Third, although it was the first time that the AAQ-II was assessed in a sample with mild to moderate depressive and anxiety symptoms, generalization to other samples (e.g., major depression) have to be made with care. Finally, future latent trait studies of the AAQ-II would probably benefit from larger sample sizes. Although small sample sizes (e.g., $n$ < 200) generally argue for simple models (e.g., the Rasch model), Lord (1983) argues that this is mainly the case if the discrimination parameters are difficult to estimate. In our sample, the discrimination parameters fell within reasonable limits (i.e. small S.D.'s) indicating that this was not the case in our sample. Considering this result, we believe that our sample size of 376 is sufficiently larger than 200 to justify the use of the generalized partial credit model.

To conclude, this study confirmed that the AAQ-II is a valid and reliable measure to assess experiential avoidance or its reverse acceptance in people with mild to moderate depression and anxiety. This study expands previous evaluations of the psychometric properties of the AAQ-II by using more advanced and robust IRT methods. Furthermore, the AAQ-II showed incremental validity in explaining depression, anxiety and positive mental health over different mindfulness facets. An important research question for future studies is to examine whether changes in acceptance mediate the effects of an ACT intervention on depression and anxiety. 


\section{References}

Baer, R. A., Smith, G. T., Hopkins, J., Krietemeyer, J., \& Toney, L. (2006). Using selfreport assessment methods to explore facts of mindfulness. Assessment, 13, 27-45.

Baer, R. A.,. Smith, G. T., Lykins, E., Button, D., Krietemeyer, J., Sauer, S., Walsh, E., Duggan, D., \& Williams, J. M. G. Construct Validity of the Five Facet Mindfulness Questionnaire in Meditating and Nonmeditating Samples. Assessment, 15, 329-342.

Biglan, A., Hayes, S. C., \& Pistorello, J. (2008). Acceptance and commitment: Implicationsfor prevention science. Prevention Science, 9, 139-152.

Bishop, S. R., Lau, M., Shapiro, S., Carlson, L., Anderson, N. D., Carmody, J., Segal, Z. V. Abbey, S., Speca, M., Velting, D., \& Devins, G. (2004). Mindfulness: A proposed operational definition. Clinical Psychology: Science and Practice, 11, 230-241.

Bock, R. D., \& Aitkin, M. (1981). Marginal maximum likelihood estimation of item parameters: Application of an EM algorithm. Psychometrika, 46, 443-459.

Boelen, P. A., \& Reijntjes, A. (2008). Measuring experiential avoidance: Reliability and validity of the Dutch 9-item acceptance and action questionnaire (AAQ). Journal of Psychopathology and Behavioral Assessment, 30, 241-251.

Bohlmeijer, E. T., Fledderus, M., Rokx, T. A. J. J., \& Pieterse, M. E. (2011). Efficacy of an Early intervention based on acceptance and commitment therapy for adults with depressive symptomatology: Evaluation in a randomized controlled trial. Behaviour Research and Therapy, 49, 62-67.

Bohlmeijer, E. T., ten Klooster, P. M., Fledderus, M., Veehof, M., \& Baer, R. (2011). Psychometric properties of the Five Facet Mindfulness Questionnaire in depressed adults and development of a short form. Assessment, 18, 308-320.

Bond, F. W., \& Bunce, D. (2003). The role of acceptance and job control in mental health,job satisfaction, and work performance. Journal of Applied Psychology, 88, 1057-1067.

Bond, F. W., Hayes, S. C., Baer, R. A., Carpenter, K. C., Guenole, N., Orcutt, H. K., Waltz, T., \& Zettle, R. D. (2011). Preliminary psychometric properties of the Acceptance and Action Questionnaire - II: A revised measure of psychological flexibility and acceptance. Behavior Therapy, 42, 676-688.

Bouma, J., Ranchor, A. V., Sanderman, R., \& van Sonderen, E. (1995). Het meten van symptomen van depressie met de CES-D, een handleiding [Measuring symptoms of depression with the CES-D, a guide]. Noordelijk Centrum voor Gezondheidsvraagstukken: Groningen.

Chang, H. H., \& Mazzeo, J. (1994). The unique correspondence of the item response function and item category response functions in polytomously scored item response models. Psychometrika, 59, 391-404. 
Chawla, N., \& Ostafin, B. (2007). Experiential avoidance as a functional dimensional approach to psychopathology: An empirical review. Journal of Clinical Psychology, 63, 871-890.

Ciarrochi, J., Billich, L., \& Godsell, C. (2010). Psychological flexibility as a mechanism of change in acceptance and commitment therapy. In R. Baer (Ed.), Assessing mindfulness and acceptance processes in clients: Illuminating the theory and practice of change (51-75). Oakland, CA: Context Press/New Harbinger Publications.

Costa, J., \& Pinto-Gouveia, J. (2011). The mediation effect of experiential avoidance between coping and psychopathology in chronic pain. Clinical Psychology \& Psychotherapy, 18, 34-47.

Dalrymple, K. L., \& Herbert, J. D. (2007). Acceptance and Commitment Therapy for generalized social anxiety disorder: A pilot study. Behavior Modification, 31, $543-$ 568.

Diefenbach, G., McCarthy-Larzelere, M., Williamson, D., Mathews, A., Manguno-Mire, G. \& Bentz, B. (2001). Anxiety, depression and the content of worries. Depression and Anxiety, 14, 247-250.

Donker, T., van Straten, A., Marks, I., \& Cuijpers P. (2009). A brief web-based screening questionnaire for common mental disorders: development and validation. Journal of Medical Internet Research, 11, 19.

Embretson, S. E., \& Reise, S. P. (2000). Item response theory for psychologists. New Jersey: Lawrence Erlbaum Associates, Inc.

Fledderus, M., Bohlmeijer, E. T., \& Pieterse, M. E. (2010a). Does experiential avoidance mediate the effects of maladaptive coping styles on psychopathology and mental health? Behavior Modification, 34, 503-519.

Fledderus, M., Bohlmeijer, E. T., Smit, F., \& Westerhof, G. J. (2010b). Mental health promotion as a new goal in public mental health care: A randomized controlled trial of an intervention enhancing psychological flexibility. American Journal of Public Health, 100, 2372-2378.

Fledderus, M., Bohlmeijer, E. T., Pieterse, M. E., \& Schreurs, K. M. G. (2012). Acceptance and commitment therapy as guided self-help for psychological distress and positive mental health: randomized controlled trial. Psychological Medicine, 42, 485-496.

Fletcher, L., \& Hayes, S. C. (2005). Relational Frame Theory, Acceptance and Commitment Therapy, and a functional analytic definition of mindfulness. Journal of Rational-Emotive and Cognitive-Behavioral Therapy, 23, 315-336.

Fischer, G. H., \& Molenaar, I. W. (1995). Rasch models: Foundations, recent developments and applications. New York, NY: Springer Verlag.

Forman, E. M., Herbert, J. D., Moitra, E., Yeomans, P. D., \& Geller, P. A. (2007). A randomized controlled effectiveness trial of acceptance and commitment therapy and cognitive therapy for anxiety and depression. Behavior Modification, 31, 772-99. 
Glas, C. A. W. (1998). Detection of differential item functioning using Lagrange multiplier tests. Statistica Sinica, 8, 647-668. Available at: www3.stat.sinica.edu.tw/ statistica/j8n3/j8n32/j8n32.htm

Glas, C. A. W. (1999). Modification indices for the 2-pl and the nominal response model. Psychometrika, 64, 273-294.

Glas, C. A. W., Geerlings, H., van de Laar, M. A. F. J, \& Taal, E. (2009). Analysis of longitudinal randomized clinical trials using item response models. Contemporary Clinical Trials, 30, 158-170.

Glas, C. A. W. (2010). Preliminary Manual of the software program Multidimensional Item Response Theory (MIRT). Available at: www.utwente.nl/gw/omd/afdeling/Glas/.

Gebhardt, E., \& Adams, R. J. (2007). The influence of equating methodology on reported trends in PISA. Journal of Applied Measurement, 8, 305.

George, D., \& Mallery, P. (2003). SPSS for Windows step by step: A simple guide and reference. 11.0 update (4th ed.). Boston: Allyn \& Bacon.

Gifford, E. V., Kohlenberg, B. S., Hayes, S. C., Antonuccio, D. O., Piasecki, M. M., Rasmussen-Hall, M. L., \& Palm, K. M. (2004). Acceptance-based treatment for smoking cessation. Behavior Therapy, 35, 689-705.

Haringsma, R., Engels, G. I., Beekman, A. T. F., \& Spinhoven, P. (2004). The criterion validity of the Center for Epidemiological Studies Depression Scale (CES-D) in a sample of self-referred elders with depressive symptomatology. International Journal of Geriatric Psychiatry, 19, 558-563.

Hayes, S. C., Luoma, J. B., Bond, F. W., Masuda, A., \& Lillis, J. (2006). Acceptance and commitment therapy: Model, processes and outcomes. Behaviour Research and Therapy, 44, 1-25.

Hayes, S. C., Strosahl, K. D., Wilson, K. G., Bissett, R. T., Pistorello, J., Toarmino, D., ...McCurry, S. M. (2004). Measuring experiential avoidance: A preliminary test of a working model. The Psychological Record, 54, 553-578.

Jacobs, N., Kleen, M., de Groot, F., \& A-Tjak, J. (2008). Het meten van experiëntiële vermijding. De Nederlandstalige versie van de Acceptance and Action Questionnaire-II (AAQ-II ). [Measuring experiential avoidance. Dutch translation of the Acceptance and Action questionnaire-II (AAQ-II) ]. Gedragstherapie, 41, 349361.

Karekla, M., \& Panayiotoua, G. (2011). Coping and experiential avoidance: Unique or overlapping constructs? Journal of Behavior Therapy and Experimental Psychiatry, 42, 163-170.

Keyes, C. L. M. (2002). The mental health continuum: From languishing to flourishing in life. Journal of Health and Social Behavior, 43, 207-222.

Kocovski, N. L., Fleming, J., \& Rector, N. A. (2009). Mindfulness and acceptance-based group therapy for social anxiety disorder: An open trial. Cognitive and Behavioral Practice, 16, 276-289. 
Lamers, S. M. A., Westerhof, G. J., Bohlmeijer, E. T., ten Klooster, P. M., \& Keyes, C. L. M. (2011). Evaluating the psychometric properties of the Mental Health ContinuumShort Form (MHC-SF). Journal of Clinical Psychology, 67, 99-110.

Lillis, J., \& Hayes, S. C. (2008). Measuring avoidance and inflexibility in weight related problems. International Journal of Behavioral Consultation and Therapy, 4, 372 378.

Lindesay, J., Baillon, S., Brugha, T., Dennis, M., Stewart, R., Araya, R., \& Meltzer, H. (2006). Worry content across the lifespan: an analysis of 16- to 74-year-old participants in the British National Survey of Psychiatric Morbidity 2000. Psychological Medicine, 36, 1625-1633.

Lopez, W. (1996). Communication validity and rating scales. Rasch Measurement Transactions, 10(1), 482.

Lord, F. M. (1984). Small N justifies Rasch model. In D. J. Weiss (Ed.), New horizons in testing: Latent trait test theory and computerized adaptive testing. New York: Academic Press.

McCracken, L. M., \& Zhao-O'Brien, J. (2010). General psychological acceptance and chronic pain: there is more to accept than the pain itself. European Journal of Pain, 14, 170-175.

McCracken, L. M., Vowles K. E., \& Eccleston C. (2004). Acceptance of chronic pain: component analysis and a revised assessment method. Pain, 107, 159-166.

Muraki, E. (1992). A generalized partial credit model: Application of an EM algorithm. Applied psychological measurement, 16, 159.

Olssøn, I., Mykletun, A., \& Dahl, A. A. (2005). The Hospital Anxiety and Depression rating scale: A cross-sectional study of psychometrics and case findings abilities in general practice. BMC Psychiatry, 5, 46.

Powers, M. B ., Zum Vörde Sive Vörding, M. B., \& Emmelkamp, P. M. G. (2009). Acceptance and Commitment Therapy: a meta-analytic review. Psychotherapy and psychosomatics, 78, 73-80.

Radloff, L. S. (1977). The CES-D scale: A self-report depression scale for research in thegeneral population. Applied Psychological Measurement, 1, 385-401.

Reeve, B. B., \& Fayers, P. (2005). Applying item response theory modelling for evaluating questionnaire item and scale properties. In: Fayers P, Hays RD, eds. Assessing Quality of Life in Clinical Trials: Methods of Practice (2nd ed. ed.). Oxford, NY: Oxford University Press.

Reise, S. P., Widaman, K. F., \& Pugh, R. H. (1993). Confirmatory factor analysis and item response theory: two approaches for exploring measurement invariance. Psychological Bulletin, 114, 552-566.

Sheehan, D. V., Lecrubier, Y., Sheehan, K. H., Amorim, P., Janav, J., Weiller, E., Hergueta, T., Baker, R., \& Dunbar, G. C. (1998). The Mini-International Neuropsychiatric Interview (MINI): The development and validation of a structured 
diagnostic psychiatric interview for DSM-IV and ICD-10. Journal of Clinical Psychiatry, 59, 22-3.

Spinhoven, P. H., Ormel, J., Sloekers, P. P. A, Kempen, G. I. J. M., Speckens, A. E. M., \& van Hemert, A. M. (1997). A validation study of the Hospital Anxiety and Depression Scale (HADS) in different groups of Dutch subjects. Psychological Medicine, 27, 363-370.

van Groen, M. M, ten Klooster, P. M., Taal, E., van de Laar, M. A., Glas, C. A. (2010). Application of the health assessment questionnaire disability index to various rheumatic diseases. Quality of Life Research, 19, 1255-1263.

Veehof, M.M., ten Klooster, P.M., Taal, E., Westerhof, G.J., \& Bohlmeijer, E.T. (2011). Psychometric properties of the Dutch Five Facet Mindfulness Questionnaire (FFMQ) in patients with fibromyalgia. Clinical Rheumatology, 30, 1045-1054.

Vowles, K. E., \& McCracken, L. M. (2008). Acceptance and values-based action in chronic pain: A study of treatment effectiveness and process. Journal of Consulting and Clinical Psychology, 76, 397-407.

Weisscher, N., Glas, C. A., Vermeulen, M, \& de Haan, R. J. (2010). The use of an item response theory based disability item bank across diseases: accounting for differential item functioning. Journal of Clinical Epidemiology, 63, 543-549.

Wheaton, M. G., Berman, N. C, \& Abramowitz, J. S. (2010). The contribution of experiential avoidance and anxiety sensitivity in the prediction of health anxiety. Journal of Cognitive Psychotherapy, 24, 229-239.

World Health Organization. (2008). The global burden of disease: 2004 Update. Geneva: World Health Organization. Geneva; WHO. Available at www.who.int/healthinfo/global_burden_disease/GBD_report_2004update_full.pdf.

Zigmond, A. S. \& Snaith, R. P. (1983). The Hospital Anxiety and Depression Scale. Acta psychiatrica Scandinavica, 67, 361-370. 


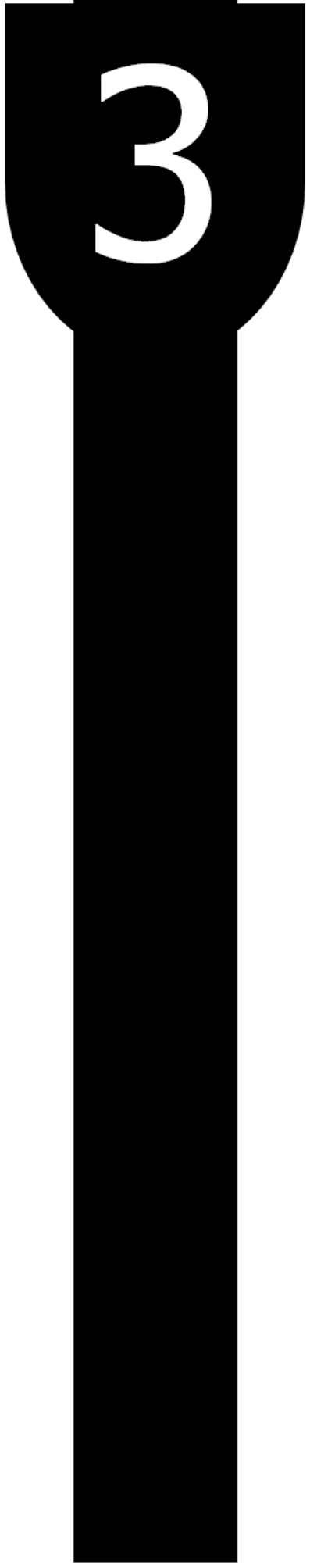

\section{Does experiential avoidance mediate the effects of maladaptive coping styles on psychopathology and mental health?}

Fledderus, M., Bohlmeijer, E. T., \& Pieterse, M. E. (2010). Does Experiential Avoidance Mediate the Effects of Maladaptive Coping Styles on Psychopathology and Mental Health? Behavior Modification, 34(6), 503-519. 


\section{Abstract}

Experiential avoidance (EA) is considered a risk factor for psychopathology. This study explores whether EA mediates the relationship between maladaptive coping styles (palliative, avoidance, and passive coping) and psychopathology and positive mental health. A total of 93 adults with mild to moderate psychological distress completed measures assessing coping styles, psychopathology (depression, anxiety, and alcohol use), and mental health (emotional, psychological, and social well-being). Results showed that EA mediated the effects of passive coping on both increased anxiety and depression and decreased emotional and psychological well-being. These results suggest that a person who is prone to use EA or has learned EA in stressful situations has a higher risk of developing psychopathology and lower mental health. This indicates that early interventions that aim at people with high levels of EA are highly relevant. 


\section{Introduction}

There is growing interest in experiential avoidance (EA) as a risk factor for psychopathology. EA has been defined as the reluctance to remain in contact with experiences such as feelings, thoughts, and bodily sensations, and attempts to alter, control, predict, or avoid the form, the frequency or the contexts in which these experiences arise (Hayes et al., 2004; Hayes, Wilson, Gifford, Follette, \& Strosahl, 1996). EA can be temporarily effective in reducing the experience of unwanted emotions, feelings, and thoughts. However, EA is often counterproductive in the long run, because attempts to avoid private events create or even increase the frequency, severity, and accessibility of the private event that one who wants to avoid (Gold \& Wegner, 1995). This struggle with and controlling or avoiding of the unwanted private events predominate and interfere with the movement toward long-term desired qualities or values in life, and results in ineffective functioning and in less contact with present experiences (Hayes, Luoma, Bond, Masuda, \& Lillis, 2006; Hayes, Strosahl, \& Wilson, 1999; Kashdan, Barrios, Forsyth, \& Steger, 2006).

It has been found in various studies that EA positively correlates with various forms of psychopathology, including depression and anxiety (Kashdan et al., 2006; Roemer, Salters, Raffa, \& Orsillo, 2005; Tull, Gratz, Salters, \& Roemer, 2004), posttraumatic stress (Marx \& Sloan, 2005), and substance abuse (Stewart, Zvolensky, \& Eifert, 2002). A recent meta-analysis (Hayes et al., 2006) of 32 studies that examined the relationship between EA as measured by the Acceptance and Action Questionnaire (AAQ) and psychopathology (e.g., anxiety, post-traumatic stress disorder, pain, and depression) found a weighted effect size of $r=.42$ (95\% CI: .40-.44). Longitudinal studies have found that EA predicts the future symptoms of post-traumatic stress disorder in trauma survivors (Marx \& Sloan, 2005), quality of life in students (Hayes et al., 2004), and the absence of mental illness in customer service workers (Bond \& Bunce, 2003).

An important question is how EA is related to other coping styles that involve action to change aversive private experiences, such as avoidance coping, wishful thinking, or distancing? These coping styles have also been found to be related to negative psychological outcomes (Penley, Tomaka, \& Wiebe, 2002). Although EA at first glance may appear rather similar to these coping styles, an important difference is revealed when looking at the way these construct are operationalized. EA assesses whether a person engages in attempts to change the form, frequency, or situational sensitivity of unwanted private events. Coping styles are measured in terms of how often a strategy is used and what the content of the actual behavior is to cope with stressful situations. EA is thus more focused on the function and context of behavior, whereas coping styles are focused on the frequency and content of behavior (Hayes et al., 1996; Kashdan et al., 2006). A coping style may or may not be used to avoid personal emotions, feelings, and thoughts. Due to this difference, EA possibly mediates the effect of coping styles on mental health (Biglan, Hayes, \& Pistorello, 2008; Kashdan et al., 2006). This was corroborated in a study by 
Kashdan et al., who found that EA mediated the effects of maladaptive coping styles on anxiety-related stress. Using an experience-sampling method, they also found that EA mediated the effects of emotional suppression and cognitive reappraisal on positive psychological functioning in students. Positive psychological functioning was assessed with measures of daily positive affect, frequency of positive events, life satisfaction, and purpose in life. EA even predicted positive psychological functioning (e.g., life satisfaction ES $r=$ .55) better than cognitive reappraisal (ES $r=.20$ ) (Kashdan et al., 2006). EA is thus considered to be a predisposition to make people more vulnerable for developing psychopathology and reduced positive psychological functioning in reaction to various stressors (Biglan et al., 2008; Kashdan et al., 2006). However, more studies using different instruments and different settings are needed to shed light on the distinction between EA and other avoidance strategies (Chawla \& Ostafin, 2007) and on the relation between EA and psychological well-being.

Therefore, this study first examines three coping styles, measured with the aid of the Utrecht coping list (UCL; Schreurs, Tellegen, \& Van de Willige, 1984), that have not been examined previously within this context. The UCL is the most widely used coping inventory in the Netherlands. In the UCL, coping is seen as a disposition, and a total of seven subscales are discerned. It measures how frequently each of these coping styles are used in response to "problems or unpleasant situations in general." For the current study three UCL subscales were selected that may be expected to be closely related to EA: palliative, avoidance, and passive coping. Palliative coping is seeking distraction or good company. Avoidance coping is shunning situations or problems and "letting go." Passive coping is being overwhelmed by problems, such as ruminating about the past. Higher scores on these three ways of coping are related to psychopathology, such as anxiety and depression (Schreurs, Van de Willige, Brosschot, Tellegen, \& Graus, 1993). In line with Kashdan et al. (2006), we expect that the coping styles themselves are not problematic unless they are used as rigid and inflexible methods for avoiding or controlling unwanted thoughts or emotions. We predict that coping styles have an influence on psychopathology, such as depression, anxiety, and alcohol use but that EA mediates this association.

Secondly, we want to pay more attention to the role of EA in positive mental health. Mental health, according to Keyes (2002), is not only the absence of mental illness but also the presence of positive feelings and optimal functioning in private and public life. Keyes (2007) showed that adults with complete mental health missed the fewest days of work, had the healthiest psychosocial functioning, and had the fewest health limitations on activities in daily life. Mental health is defined as symptoms of emotional well-being (happiness and life satisfaction), psychological well-being (striving to become a better person), and social well-being (striving to contribute to society) (Keyes, 2002). The existing literature provides a good deal of information on the role of EA and emotional well-being (e.g., Hayes et al., 2006), but if EA prevents people from committing to value-based actions, it may also have a significant effect on positive psychological and social well- 
being. We therefore hypothesize that EA also mediates the effects of the coping styles on positive mental health.

In summary, the results of a study into the relationship between EA, maladaptive coping styles, psychopathology (anxiety, depression, and alcohol use), and mental health in a cross-sectional dataset of adults with mild to moderate psychological distress are presented.

\section{Method}

\section{Participants}

This study included 93 participants. Inclusion criteria were people of 18 years and older with mild to moderate anxiety or depressive symptoms. Exclusion criteria were (a) severe psychopathology requiring immediate treatment, (b) currently undergoing treatment at a mental health institution or recently started on pharmacological treatment, or (c) reporting few psychological complaints or symptoms. Table 1 shows an overview of the participants' characteristics. The mean age of the participants was 49 years $(S D=10.7$; range $=24-71)$. The majority of the participants were women $(81.7 \%)$ and Dutch $(91.4 \%)$. Of the participants $46.2 \%$ were married, $39.8 \%$ had a higher education, followed by $33.3 \%$ with a secondary education, and $52.7 \%$ had a paid job.

Table 1. Characteristics of Participants

\begin{tabular}{|c|c|c|}
\hline & $n$ & $\%$ \\
\hline \multicolumn{3}{|l|}{ Gender } \\
\hline Female & 76 & $81.7 \%$ \\
\hline Male & 17 & $18.3 \%$ \\
\hline Age (M, SD) & $49.02(10.70)$ & \\
\hline \multicolumn{3}{|l|}{ Marital status } \\
\hline Married & 43 & $46.2 \%$ \\
\hline Divorced & 18 & $19.4 \%$ \\
\hline Widowed & 3 & $3.2 \%$ \\
\hline Never married & 29 & $31.2 \%$ \\
\hline \multicolumn{3}{|l|}{ Race } \\
\hline Dutch & 85 & $91.4 \%$ \\
\hline Other & 8 & $8.6 \%$ \\
\hline \multicolumn{3}{|l|}{ Education } \\
\hline Low education & 25 & $26.9 \%$ \\
\hline Middle education & 31 & $33.3 \%$ \\
\hline High education & 37 & $39.8 \%$ \\
\hline \multicolumn{3}{|l|}{ Daily activities } \\
\hline Paid job & 49 & $52.7 \%$ \\
\hline No job & 44 & $47.3 \%$ \\
\hline
\end{tabular}




\section{Procedure}

Participants in this study were participants who signed up for a group intervention (comprising 8 2-hr sessions) based on acceptance and commitment therapy (ACT) developed by the University of Twente. ACT is a form of behavioral therapy that focuses on diminishing EA and increasing value-based behavior (Hayes et al., 1999). Participants were randomized into the intervention or to a waiting list. This study analyzed only the data from the baseline assessment.

The participants were recruited through press articles, leaflets, and posters, and through psychologists at seven mental health institutions in the Netherlands. In total, 140 individuals responded and were assessed for eligibility. Assessment of these criteria was carried out by trained psychologists in clinical face-to-face interviews. Of the 140 respondents, 93 were included in this study. These participants received an information sheet to read, and on agreement to participate in this study, they signed an informed consent form. This study was approved by a local ethical committee. After receiving informed consent, the questionnaires were sent by mail to the respondents' home address and subsequently returned. Respondents were also asked to provide demographic variables such as gender, age, marital status, race, education, and daily activities.

\section{Measures}

Acceptance and Action Questionnaire-II (AAQ-II). The AAQ-II (Bond et al., 2011) is a 10item measure of EA. The AAQ-II assesses on a 7-point Likert-type scale ranging from $1=$ never true to 7 = always true the subject's unwillingness to be in contact with negative private events, the need to control these events, and the effect of controlling their negative private experiences on their lives. Summation of the scores results in a total score ranging from 10 to 70 whereby a higher score indicates higher acceptance and less EA. The Dutch AAQ-II showed a good factor structure in a general and clinical population in the Netherlands and good internal consistency in the current study ( $\alpha=.86$ ) (Jacobs, Kleen, De Groot, \& A-Tjak, 2008).

Utrecht coping list (UCL). The UCL (Schreurs et al., 1984) measures that coping style people use in various unpleasant situations or problems using a 4-point scale ranging from 1 = seldom or never to $4=$ very often. Three out of seven subscales are used in this study: palliative coping (eight items) measures to what extent people are looking for distraction, avoidance coping (eight items) measures to what extent people avoid difficult situations or problems, passive coping (seven items) measures to what extent people feel overwhelmed by their problems. The UCL has proven to be a reliable and valid instrument (Schaufeli \& Van Dierendonck, 1992). The internal consistency in this study was moderate to good $(\alpha=.78)$. In a Dutch reference group of female nurses and a random sample of the Dutch population between 18 and 65 years old $(n=712)$, the average scores on palliative coping are 14 to 19,12 to 16 on avoidance and 9 to 11 on passive coping (Schreurs et al., 1993). 
Center for Epidemiologic Studies Depression Scale (CES-D). The CES-D (Radloff, 1977) is a 20-item questionnaire that measures depressive symptoms in the general population. Respondents rate on a 4-point scale ranging from $0=$ hardly ever (less than 1 day) to 3 = predominantly (5-7 days) to what extent they had experienced depressive symptoms in the previous week. Summation of the scores result in a total score ranging from 0 to 60 . A score of 16 or higher is considered indicative of clinically relevant depressive symptoms. The CES-D showed adequate psychometric properties. The Dutch translation showed similar psychometric properties in a group of eldery people in the Netherlands (Haringsma, Engels, Beekman, \& Spinhoven, 2004). The scale shows high internal consistency in this study $(\alpha=.88)$.

Hospital Anxiety and Depression Scale-Anxiety Subscale (HADS-A). The HADSA (Zigmond \& Snaith, 1983) is a 7-item questionnaire that assesses the presence and severity of anxious symptoms. Respondents rate on a 4-point scale ranging from $0=$ not at all to $3=$ often to what extent they had experienced anxiety symptoms in the previous week. The total HADS-A scores range from 0 to 21 . The Dutch translation showed good psychometric properties in six different groups of Dutch participants (Spinhoven et al., 1997). Bjelland, Dahl, Haug, and Neckelmann (2002) showed that among the general population and in somatic patients samples, an optimal balance between sensitivity and specificity was achieved when caseness was defined by a score of 8 or above. The scale showed high internal consistency in this study $(\alpha=.83)$.

Alcohol use. This measure assesses the number of alcoholic beverages consumed in the preceding week. Respondents rate how many beverages they drank during each of the last 7 days. With the summation of the beverages consumed over the previous week, the weekly consumption of alcoholic beverages was calculated.

Mental health continuum-short form (MHC-SF). The MHC-SF (Keyes, 2005, 2006; Keyes et al., 2008) is a 14-item questionnaire that measures three dimensions: emotional well-being (three items), social well-being (five items), and psychological wellbeing (six items). Respondents rate on a 6 -point scale ranging from $1=$ never to $6=$ every day to what extent they had experienced a feeling of well-being in the previous month. A total score was computed by summing the scores on the individual items and dividing these by the number of items. The Dutch MHC-SF is validated in a representative study among Dutch adults and showed good psychometric properties (Westerhof \& Keyes, 2008). The MHC-SF showed good internal consistency in this study $(\alpha=.91)$.

\section{Statistical analyses}

All measures had a normal distribution except for the measure of alcohol use. Therefore, alcohol use was transformed into a dichotomous variable using current Dutch guidelines according to which a weekly alcohol consumption of less than 21 standard glasses of alcohol for men and 14 for women is considered safe (Health Council of the Netherlands, 2006). Pearson correlations were calculated for bivariate associations between EA and coping styles, depression, anxiety, alcohol use, and mental health. A correlation of $r=.1$ to 
.3 is considered as low, $r=.3$ to .5 as medium, and $r=.5$ to 1 as high conform Cohen's taxonomy (1992). Mediation analyses were performed using multiple regression analyses with procedures defined by Baron and Kenny (1986). To check whether EA fully mediates the effect between the independent variable and the dependent variables, the Sobel test was used.

\section{Results}

\section{Baseline characteristics}

The means and standard deviations for the measures of acceptance (AAQ-II), palliative coping (UCL-palliative), avoidance coping (UCL-avoidance), passive coping (UCLpassive), depression (CES-D), anxiety (HADS-A), alcohol use, and mental health are presented in Table 2. The scores on acceptance are lower $(M=36.76, S D=10.07)$ than was found in a general Dutch population $(M=52.03, S D=9.30)$ (Jacobs et al., 2008), meaning that the participants score high on EA. With regard to the coping styles, the participants achieved average scores on the palliative coping, high scores on avoidance coping, and very high scores on passive coping in comparison with Dutch nurses and a random sample of the Dutch population (Schreurs et al., 1993). Of the participants, $72.0 \%$ scored above the cutoff score of anxiety (8 or higher) (Bjelland et al., 2002) and $78.5 \%$ of the participants scored above the cut-off score (16 or higher) that is indicative of clinically relevant depressive syndromes (Radloff, 1977). The participants drank about 8.5 alcoholic beverages per week (15.4 for men and 7 for women), indicating that the alcohol consumption can be considered safe. There were 18 participants ( 5 men and 13 women) for whom the alcohol consumption can be considered unsafe. The scores on emotional wellbeing are lower $(M=3.36, S D=1.11)$ than was found in a general Dutch population $(M=$ 4.67, $S D=.94)$. Also psychological well-being $(M=3.32, S D=1.03)$ and social well-being $(M=2.84, S D=.98)$ are lower than that was found in a general Dutch population $(M=$ $4.18, S D=.99 ; M=3.33, S D=1.01$, respectively; Westerhof \& Keyes, 2008).

\section{Correlational analyses}

Correlations between the measures are presented in Table 3. Results show that lower levels of EA (or high levels of acceptance) are strongly related to reduced passive coping, $r(92)=$ $-.56, p<.01$. For the other two coping styles, palliative coping and avoidance, no significant relations could be found. Results show that lower levels of EA are strongly related to decreased anxiety, $r(93)=-.60, p<.01$, and moderately related to decreased depression, $r(93)=-.47, p<.01$. Lower levels of EA are also moderately related to increased emotional, $r(93)=.36, p<.01$, and psychological well-being, $r(93)=.38, p<.01$ and weakly related to increased social well-being, $r(93)=.25, p=.02$. Alcohol use is not related to EA. The only coping style that is related with psychopathology and mental health is passive coping, which is moderately related to four health outcomes: depression, $r(92)=$ 
$.41, p<.01$; anxiety, $r(92)=.33, p<.01$; emotional well-being, $r(92)=-.29, p<.01$; and psychological well-being $r(92)=-.37, p<.01$.

Table 2. Means and Standard Deviations of Measures

\begin{tabular}{llll}
\hline Measure & $n$ & $M$ & $S D$ \\
\hline AAQ-II & 93 & 36.76 & 10.07 \\
UCL-Palliative & 93 & 16.65 & 3.93 \\
UCL-Avoidance & 93 & 16.58 & 3.89 \\
UCL-Passive & 92 & 16.32 & 3.61 \\
CES-D & 93 & 24.96 & 9.55 \\
HADS-A & 93 & 10.34 & 4.21 \\
Number of alcoholic beverages & 90 & 8.50 & 13.50 \\
MHC-SF-Emotional & 93 & 3.36 & 1.11 \\
MHC-SF-Psychological & 93 & 3.32 & 1.03 \\
MHC-SF-Social & 93 & 2.84 & 0.98 \\
\hline
\end{tabular}

Note. AAQ-II = Acceptance and Action Questionnaire-II; UCL = Utrecht Coping List (palliative, avoidance and passive coping are subscales); CES-D = Center for Epidemiologic Studies Depression Scale, HADS-A = Hospital Anxiety and Depression Scale-Anxiety subscale; MHC-SF = Mental Health Continuum-Short Form (emotional, psychological and social well-being are subscales).

Table 3. Correlations Between Experiential Avoidance, Coping Styles, Psychopathology and Mental Health

\begin{tabular}{|c|c|c|c|c|c|c|c|c|c|c|}
\hline & 1 & 2 & 3 & 4 & 5 & 6 & 7 & 8 & 9 & 10 \\
\hline AAQ-II & - & -.10 & -.02 & $-.56 * *$ & $-.47 * *$ & $-.60 * *$ & .02 & $.36 * *$ & $.38^{* *}$ & $.25^{*}$ \\
\hline $\begin{array}{l}\text { UCL- } \\
\text { Palliative }\end{array}$ & & - & $.35^{* *}$ & .13 & -.13 & .01 & -.14 & $.21 *$ & .16 & .15 \\
\hline $\begin{array}{l}\text { UCL- } \\
\text { Avoidance }\end{array}$ & & & - & $.30 * *$ & .19 & .02 & -.19 & -.12 & -.18 & -.10 \\
\hline $\begin{array}{l}\text { UCL- } \\
\text { Passive }\end{array}$ & & & & - & $.41^{* *}$ & $.33 * *$ & .04 & $-.29 * *$ & $-.37 * *$ & -.17 \\
\hline CES-D & & & & & - & $.55^{* *}$ & .06 & $-.77 * *$ & $-.70 * *$ & $-.55^{* *}$ \\
\hline HADS-A & & & & & & - & -.08 & $-.42 * *$ & $-.38 * *$ & $-.34 * *$ \\
\hline Alcohol use & & & & & & & - & .01 & -.04 & .03 \\
\hline $\begin{array}{l}\text { MHC-SF- } \\
\text { Emotional }\end{array}$ & & & & & & & & - & $.79 * *$ & $.64 * *$ \\
\hline $\begin{array}{l}\text { MHC-SF- } \\
\text { Psychological }\end{array}$ & & & & & & & & & - & $.74 * *$ \\
\hline $\begin{array}{l}\text { MHC-SF- } \\
\text { Social }\end{array}$ & & & & & & & & & & \\
\hline
\end{tabular}




\section{Mediational analyses}

Regression analyses were conducted to examine whether EA mediates the effects between the maladaptive coping styles (independent variable) on one hand, and psychopathology and mental health (dependent variables) on the other. Results from the correlations correspond with the results of the regression analyses. The first series of regression analyses showed that only passive coping as the predictor yielded a significant relation with EA (the mediator) $(\beta=-.56, p<.01)$. The second series of regression analyses showed that passive coping as a predictor yielded a significant positive relation with depression and anxiety, and a negative relation with emotional well-being and psychological well-being. The third series of regression analyses were performed with passive coping and EA simultaneously as predictors of each of the four dependent variables, respectively: depression, anxiety, psychological, and emotional well-being.

Table 4. Regression Analyses with Passive Coping (UCL-passive) and EA (AAQ-II) Simultaneously as Predictors of the Four Dependent Variables and the Sobel z to Test if EA is a Mediator

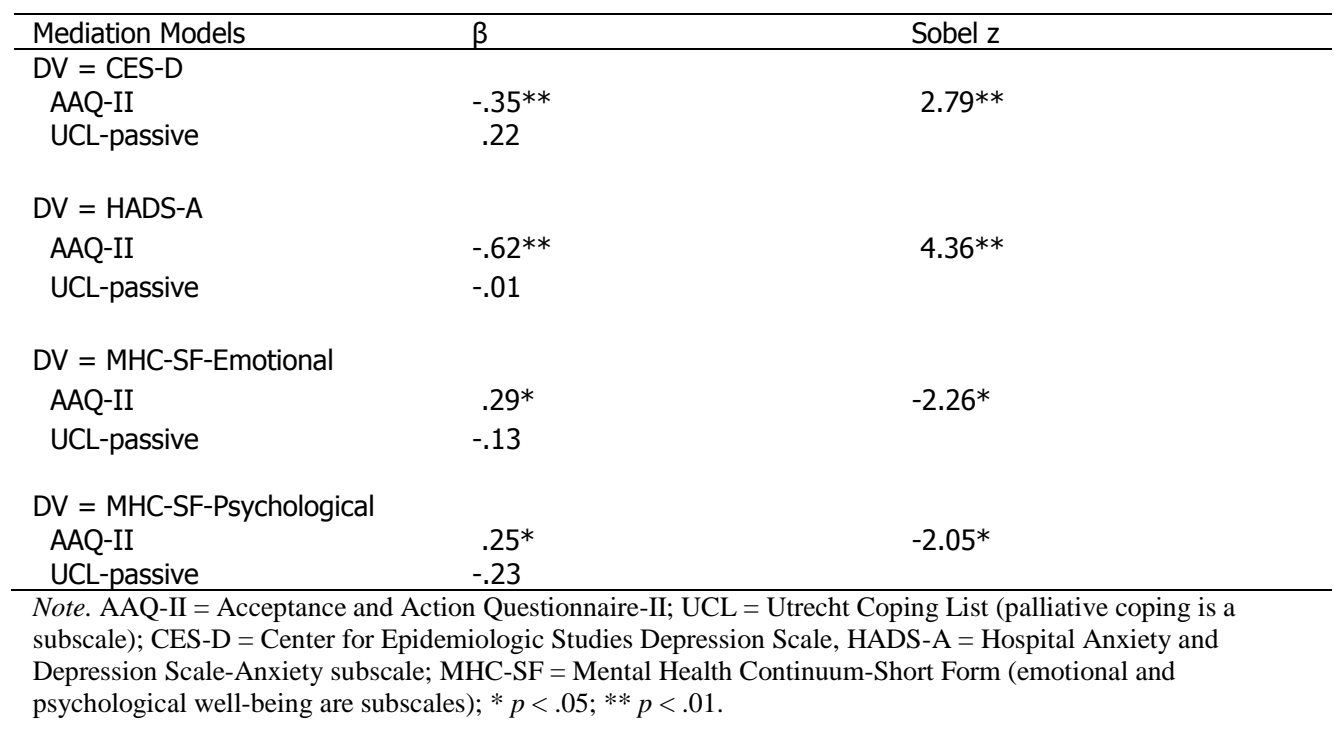

To achieve full mediation, the previously found relation in the second regression analyses should become nonsignificant, whereas the mediator should retain its significance. The results of these regression analyses (Table 4) show full mediation, confirmed by significant Sobel tests, on all four dependent variables. EA mediated the effects of passive coping on depression (initial $\beta=.41$, final $\beta=.22$ ), anxiety (initial $\beta=.33$, final $\beta=-.01$ ), emotional well-being (initial $\beta=-.29$, final $\beta=-.13$ ), and psychological well-being (initial $\beta=-.37$, final $\beta=-.23)$. 


\section{Discussion}

In this cross-sectional study, we explored whether three dispositional coping styles, that is, palliative coping, avoidance, and passive coping, were related to psychopathology and positive mental health and whether EA would mediate these relationship, in a sample of 93 adults with mild to moderate psychological distress. This mediational role of EA has not been studied in clinical samples before.

Only one of the three coping styles, passive coping, was (strongly) correlated with EA. This indicates that people with high levels of EA tend to become easily overwhelmed by their problems and unpleasant situations, worry about the past, feel incapable of doing something, or escape into a fantasy world. In turn, both passive coping and EA showed a moderately strong relationship with increased depression and anxiety, which corroborates the results of earlier studies (Hayes et al., 2006; Muris, Schmidt, Lambrichs, \& Meesters, 2001; Norberg, Lindblad, \& Boman, 2005). More importantly, this study suggests that the association between passive coping and depression and anxiety is mediated by EA. This finding may implicate that passive coping only leads to psychological distress when a person is not willing to experience certain private events and is therefore trying to control and avoid them. These efforts of control and avoidance unfortunately increase and exacerbate the distress the individual is trying to reduce. Passive coping thus appears to lead to more depressive symptomatology and anxiety by the inflexible and rigid use of EA. This study is in line with the hypothesis by Kashdan et al. (2006), that is, EA can be considered as a learned and underlying predisposition for diverse psychopathology, such as anxiety and depression. An individual who is prone to using EA or who has learned EA in stressful situations has a higher risk of developing psychopathology.

Another interesting finding in this study is that EA also mediates the relationship between passive coping and emotional and psychological well-being. The relationship between EA and emotional well-being corresponds with the finding of Kashdan et al. (2006) that EA diminishes positive affect and life satisfaction. For people who devote an excessive amount of time, effort, and energy to control unwanted experiences, it may be more difficult to live according to their values and to live the life they really want. EA narrows down the behavior repertoire of people and prevents them from participating in meaningful and value-based actions (Hayes et al., 1999). As a result EA can be expected to be related to less psychological well-being. Indeed, this study shows that EA is not only related to less emotional well-being but also to less autonomy, self acceptance, personal growth, purpose in life, positive relationship with others and environmental mastery. In addition, the results showed that passive coping is related to lower emotional and psychological well-being as well but that this relationship is mediated by the wish to avoid or control unpleasant experiences. This is a relevant finding, because there is growing evidence that mental health is more than just the mere absence of psychopathology and that higher levels of emotional and psychological well-being protect against psychological disorders (Keyes, 2002). 
We found that EA was not associated with avoidant and palliative coping. This finding corroborates the importance of distinguishing between the two constructs. Avoidant coping, such as reconciling oneself to the situation or avoiding difficult situations, and palliative coping, such as trying to relax or looking for distraction, may not necessarily be used as attempts to change the form, frequency, or situational sensitivity of unwanted private events. We also found no relationship between EA and alcohol use in this study. Possibly, these results can be explained by the alcohol consumption level of the participants that can be considered as within the safe range (Health Council of the Netherlands, 2006). This study population probably does not use alcohol as an avoidance strategy.

Unexpectedly, we only found a weak relationship between social well-being and EA. An explanation could be that the difference in domains that are involved in both constructs. EA measures the influence of unwanted thoughts and experiences on a person's private life, whereas social well-being considers the functioning of a person in public life by assessing how a person is contributing to the society in general.

Two limitations in this study need to be addressed. First, due to the crossectional nature of this study, causal interpretations need to be made with the utmost care. This specifically applies to the mediational effects of EA presented in this article. However, as this is one of the first attempts to empirically test these assumptions, these data do augment our understanding of processes involved in mental health. The results certainly justify future longitudinal research. Second, the relatively small sample size, especially the number of male participants obviously limits generalization to other samples. At the same time, as large effect sizes are needed to reach statistical significance in small samples, the results found here can be considered as relatively robust. Moreover, in many previous studies the participants consisted of undergraduate students or people with a specific disorder (Chawla \& Ostafin, 2007). In this study there was a considerable diversity in age, education, and daily activities, and there was a broad range of psychological distress.

Our findings further corroborate the concept of EA as an important construct that differs from the way people cope with their problems or unpleasant situations. Our study suggests that the unwillingness to be in contact with unwanted private experiences and the effort to control these experiences are directly related to depressive symptomatology and anxiety and thus mediate the relationship between coping styles and psychological distress. In addition, the findings from this study suggest that EA is also a risk factor for not only reduced emotional well-being but also for reduced psychological well-being. These findings implicate that people with high levels of EA could profit from early interventions that target EA as a broad risk factor. Therapies that integrate acceptance and mindfulness with behavioral therapy are promising. Acceptance and commitment therapy (ACT; Hayes et al., 1999) was found to be effective with people with depression and anxiety (Forman, Herbert, Moitra, Yeomans, \& Geller, 2007) and with many other illnesses (see Powers, Zum Vörde Sive Vörding, \& Emmelkamp, 2009). Mindfulness-based cognitive therapy (MBCT) was found to be effective in patients with recurrent depression (Ma \& Teasdale, 2004; Teasdale et al., 2002). Preliminary studies suggest that MBCT is also effective in 
patients with depression or anxiety disorders without a history of psychological distress (e.g., Evans et al., 2008; Finucane \& Mercer, 2006; Kim et al., 2009). Roemer, Orsillo, and Salters-Pedneault (2008) developed acceptance-based behavioral therapy and found promising effects in people with generalized anxiety disorder.

The results of this study suggest that acceptance-based interventions may not only increase the efficacy of reducing the incidence of mental disorders (Biglan et al., 2008) but may also help people to live more satisfying lives. 


\section{References}

Baron, R. M., \& Kenny, D. (1986). The moderator-mediator variable distinction in socialpsychological research: Conceptual, strategic, and statistical considerations. Journalof Personality and Social Psychology, 51, 1173-1182.

Biglan, A., Hayes, S. C., \& Pistorello, J. (2008). Acceptance and commitment: Implications for prevention science. Prevention Science, 9, 139-152.

Bjelland, I., Dahl, A. A., Haug, T. T., \& Neckelmann, D. (2002). The validity of the Hospital Anxiety and Depression Scale. An updated literature review. Journal of Psychosomatic Research, 52, 69-77.

Bond, F. W., \& Bunce, D. (2003). The role of acceptance and job control in mental health, job satisfaction, and work performance. Journal of Applied Psychology, 88, $1057-$ 1067.

Bond, F. W., Hayes, S. C., Baer, R.A., Carpenter, K. C., Guenole, N., Orcutt, H. K., Waltz, T., \& Zettle, R. D. (2011). Preliminary psychometric properties of the Acceptance and Action Questionnaire-II: a revised measure of psychological flexibility and acceptance. Behavior Therapy, 42, 676-688.

Chawla, N., \& Ostafin, B. (2007). Experiential avoidance as a functional dimensional approach to psychopathology: An empirical review. Journal of Clinical Psychology, 63, 871-890.

Cohen, J. (1992). A power primer. Psychological Bulletin, 112, 155-159.

Evans, S., Ferrando, S., Findler, M., Stowell, C., Smart, C., \& Haglin, D. (2008). Mindfulness-based cognitive therapy for generalized anxiety disorder. Journal of Anxiety Disorders, 22, 716-721.

Finucane, A., \& Mercer, S. W. (2006). An exploratory mixed methods study of the acceptability and effectiveness of mindfulness-based cognitive therapy for patients with active depression and anxiety in primary care. BMC Psychiatry, 6, 1-14.

Forman, E. M., Herbert, J. D., Moitra, E., Yeomans, P. D., \& Geller, P. A. (2007). A randomized controlled effectiveness trial of acceptance and commitment therapy and cognitive therapy for anxiety and depression. Behavior Modification, 31, 772-779.

Gold, D. B., \& Wegner, D. M. (1995). Origins of ruminative thought: Trauma, incompleteness, nondisclosure, and suppression. Journal of Applied Social Psychology, 25, 1245-1261.

Haringsma, R., Engels, G. I., Beekman, A. T. F., \& Spinhoven, P. H. (2004). The criterion validity of the Center for Epidemiological Studies Depression Scale (CES-D) in a sample of self-referred elders with depressive symptomatology. International Journal of Geriatric Psychiatry, 19, 558-563.

Hayes, S. C., Luoma, J. B., Bond, F. W., Masuda, A., \& Lillis, J. (2006). Acceptance and commitment therapy: Model, processes and outcomes. Behaviour Research and Therapy, 44, 1-25. 
Hayes, S. C., Strosahl, K., \& Wilson, K. G. (1999). Acceptance and commitment therapy: An experiential approach to behavior change. New York, NY: Guilford.

Hayes, S. C., Strosahl, K. D., Wilson, K. G., Bissett, R. T., Pistorello, J., Toarmino, D., ... McCurry, S. M. (2004). Measuring experiential avoidance: A preliminary test of a working model. Psychological Record, 54, 553-578.

Hayes, S. C., Wilson, K. G., Gifford, E. V., Follette, V. M., \& Strosahl, K. (1996). Experiential avoidance and behavioral disorders: A functional dimensional approach to diagnosis and treatment. Journal of Consulting and Clinical Psychology, 64, 1152-1168.

Health Council of the Netherlands. (2006). Richtlijnen goede voeding 2006 [Guidelines for a healthy diet]. The Hague: Health Council of the Netherlands.

Jacobs, N., Kleen, M., de Groot, F., \& A-Tjak, J. (2008). Het meten van experiëntiële vermijding. De Nederlandstalige versie van de Acceptance and Action Questionnaire-II (AAQ-II ). [Measuring experiential avoidance. Dutch translation of the Acceptance and Action questionnaire-II (AAQ-II)]. Gedragstherapie, 41, 349361.

Kashdan, T. B., Barrios, V., Forsyth, J. P., \& Steger, M. F. (2006). Experiential avoidance as a generalized psychological vulnerability: Comparisons with coping and emotion regulation strategies. Behaviour Research and Therapy, 44, 1301-1320.

Keyes, C. L. M. (2002). The mental health continuum: From languishing to flourishing in life. Journal of Health and Social Behavior, 43, 207-222.

Keyes, C. L. M. (2005). Mental illness and/or mental health? Investigating axioms of the complete state model of health. Journal of Consulting and Clinical Psychology, 73, 539-548.

Keyes, C. L. M. (2006). Mental health in adolescence: Is America's youth flourishing? American Journal of Orthopsychiatry, 76, 395-402.

Keyes, C. L. M. (2007). Promoting and protecting mental health as flourishing: A complementary strategy for improving national mental health. American Psychologist, 62, 95-108.

Keyes, C. L. M., Wissing, M., Potgieter, J., Temane, M., Kruger A., \& van Rooy, S. (2008). Evaluation of the mental health continuum-Short form (MHC-SF) in Swetsana-speaking South Africans. Clinical Psychology and Psychotherapy, 15, 181-192.

Kim, Y. W., Lee, S., Choi, T. K., Suh, S. Y., Kim, B., Kim, C. M., ... Yook, K. (2009). Effectiveness of mindfulness-based cognitive therapy as an adjuvant to pharmacotherapy in patients with panic disorder or generalized anxiety disorder. Depression and Anxiety, 26, 601-606.

Ma, S. H., \& Teasdale, J. D. (2004). Mindfulness-based cognitive therapy for depression: Replication and exploration of differential relapse prevention effects. Journal of Consulting and Clinical Psychology, 72, 31-40. 
Marx, B. P., \& Sloan, D. M. (2005). Peritraumatic dissociation and experiential avoidance as predictors of posttraumatic stress symptomatology. Behaviour Research and Therapy, 43, 569-583.

Muris, P., Schmidt, H., Lambrichs, R., \& Meesters, C. (2001). Protective and vulnerability factors of depression in normal adolescents. Behaviour Research and Therapy, 39, 555-565.

Norberg, A. L., Lindblad, F., \& Boman, K. K. (2005). Coping strategies in parents of children with cancer. Social Science \& Medicine, 60, 965-975.

Penley, J. A., Tomaka, J., \& Wiebe, J. S. (2002). The association of coping to physical and psychological health outcomes: A meta-analytic review. Journal of Behavioral Medicine, 25, 551-603.

Powers, M. B., Zum Vörde Sive Vörding, M. B., \& Emmelkamp, P. M. G. (2009) Acceptance and commitment therapy: A meta-analytic review. Psychotherapy and psychosomatics, 78, 73-80.

Radloff, L. S. (1977). The CES-D scale: A self-report depression scale for research in the general population. Applied Psychological Measurement, 1, 385-401.

Roemer, L., Orsillo, S. M., \& Salters-Pedneault, K. (2008). Efficacy of an acceptance based behavior therapy for generalized anxiety disorder: Evaluation in a randomized controlled trial. Journal of Consulting and Clinical Psychology, 72, 1083-1089.

Roemer, L., Salters, K., Raffa, S., \& Orsillo, S. M. (2005). Fear and avoidance of internal experiences in GAD: Preliminary tests of a conceptual model. Cognitive Therapy and Research, 29, 71-88.

Schaufeli, W., \& van Dierendonck, D. (1992). De betrouwbaarheid en validiteit van de Utrechtse Coping Lijst. Een longitudinaal onderzoek bij schoolverlaters. [The reliability and validity of the Utrecht Coping List: A longitudinal study among schoolleavers]. Gedrag en Gezondheid, 20, 38-45.

Schreurs, P. J. G., Tellegen, B., \& van de Willige, G. (1984). Gezondheid, stress en coping: De ontwikkeling van de Utrechtse Coping Lijst [Health, stress and coping: The development of the UCL]. Gedrag, Tijdschrift voor Psychologie, 12, 107-117.

Schreurs, P. J. G., van de Willige, G., Brosschot, J. F., Tellegen, B., \& Graus, G. M. H. (1993). De Utrechtse Coping Lijst (UCL). Omgaan met problemen en gebeurtenissen. Herziene handleiding 1993 [Manual of UCL]. Lisse: Swets \& Zeitlinger.

Spinhoven, P. H., Ormel, J., Sloekers, P. P. A, Kempen, G. I. J. M., Speckens, A. E. M., \& van Hemert, A. M. (1997). A validation study of the Hospital Anxiety and Depression Scale (HADS) in different groups of Dutch subjects. Psychological Medicine, 27, 363-370.

Stewart, S. H., Zvolensky, M. J., \& Eifert, G. H. (2002). The relations of anxiety sensitivity, experiential avoidance, and alexithymic coping to young adults' motivations for drinking. Behavior Modification, 26, 274-296. 
Teasdale, J. D., Moore, R. G., Hayhurst, H., Pope, M., Williams, S., \& Segal, Z. V. (2002). Metacognitive awareness and prevention of relapse in depression: Empirical evidence. Journal of Consulting and Clinical Psychology, 70, 275-287.

Tull, M. T., Gratz, K. L., Salters, K., \& Roemer, L. (2004). The role of experiential avoidance in posttraumatic stress symptoms and symptoms of depression, anxiety, and somatization. Journal of Nervous and Mental Disease, 192, 754-761.

Westerhof, G. J., \& Keyes, C. L. M. (2008). Geestelijke gezondheid is meer dan de afwezigheid van geestelijke ziekte. [Mental health is more than the absence of mental disease]. Maandblad Geestelijke Gezondheidszorg, 10, 808-820.

Zigmond, A. S., \& Snaith, R. P. (1983). The Hospital Anxiety and Depression Scale. Acta Psychiatrica Scandinavica, 67, 361-370. 
$68 \quad$ Chapter 3 


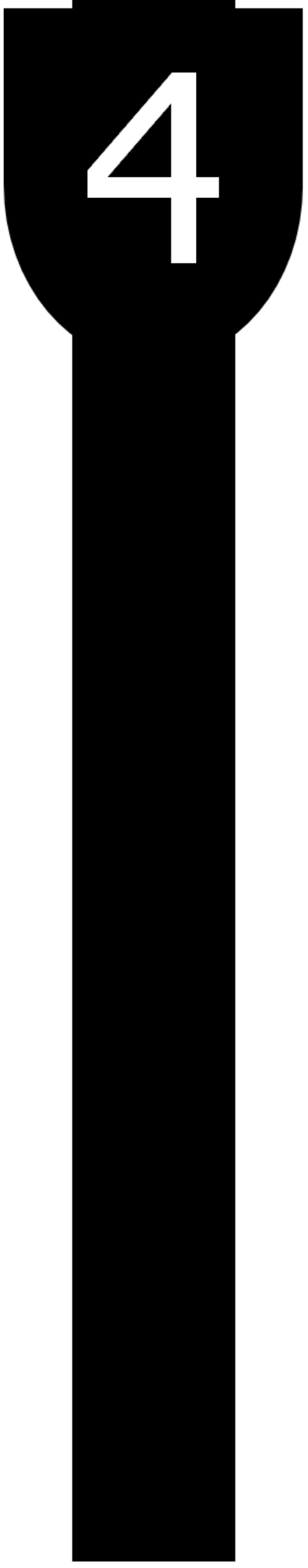

\section{Efficacy of an early intervention based on Acceptance and Commitment Therapy for adults with depressive symptomatology: Evaluation in a randomized controlled trial}

Bohlmeijer, E. T., Fledderus, M., Rokx, T. A. J. J., \& Pieterse, M. E. (2011). Efficacy of an Early Intervention Based on Acceptance and Commitment Therapy for Adults with Depressive Symptomatology: Evaluation in a Randomized Controlled Trial. Behaviour Research and Therapy, 49, 62-67. 


\section{Abstract}

Objective: The current study examined the efficacy of an early intervention based on acceptance and commitment therapy (ACT) for depressive symptomatology. The ACT intervention is aimed at increasing the acceptance of negative thoughts and emotions and living a mindful and value-based life.

Method: Adults with mild to moderate depressive symptomatology were randomly assigned to the ACT intervention $(n=49)$ or to a waiting list $(n=44)$. The mean age of the participants was 49 years. The majority of the participants was female and of Dutch origin. All the participants completed measures before and after the intervention, as well as three months later at follow-up to assess depression (CES-D), anxiety (HADS-A), fatigue (CIS), alcohol use and acceptance (AAQ-II).

Results: The ACT intervention led to statistically significant reduction in depressive symptomatology (Cohen's $d=.60$ ). These reductions were maintained at the three-month follow-up. Also significant reductions in anxiety and fatigue were observed. Moreover, mediational analysis showed that the improvement of acceptance during the intervention mediated the effects of the intervention on depressive symptomatology at follow-up.

Conclusion: These findings suggest that an early intervention based on ACT, aimed at increasing acceptance, is effective in reducing depressive symptomatology. 


\section{Introduction}

Depression makes a large contribution to the burden of disease worldwide and is the leading cause of the burden of disease in middle-and high-income countries (World Health Organization, 2008). Depression is also associated with high economic costs and increased use of health services (e.g., Cuijpers, Smit, Oostenbrink et al., 2007; Von Korff, Ormel, Katon, \& Lin, 1992). In the last decades many effective treatments for depression have been developed (Cuijpers, Van Straten, Smit, Mihalopoulos, \& Beekman, 2008). However, even when the current evidence-based treatments would be optimally implemented, only $40 \%$ of the burden of depression will be avoided (Andrews, Issakidis, Sanderson, Corry, \& Lapsley, 2004). Pro-actively offering preventive interventions to people in the community is therefore a necessary complementary strategy for decreasing the burden of disease (Hosman, Jane-Llopis, \& Saxena, 2005). Particularly indicated preventive or early interventions are promising (Cuijpers, Smit, \& Van Straten, 2007; Cuijpers et al., 2008; Smit, Ederveen, Cuijpers, Deeg, \& Beekman, 2006). These interventions aim at people who suffer from clinically relevant symptoms but who do not meet the criteria of a clinical disorder (Mrazek \& Haggerty, 1994). The presence of depressive symptomatology can be seen as the most important risk factor for developing a clinical depression (Cuijpers \& Smit, 2004). Early interventions in the form of workshops, courses or self-help can be attractive for people who are not in need of psychotherapy or medical treatment as yet (Jorm \& Griffiths, 2006).

In the last years several early interventions have been developed (e.g. Lynch, Tamburrino, \& Nagel, 1997; Willemse, Smit, Cuijpers, \& Tiemens, 2004). Most interventions are based on cognitive behavior therapy and on the 'Coping with Depression' course in particular (Lewinsohn, Antonucci, Breckenridge, \& Munoz, 1984). In this 12 week group course psycho-education is combined with several mood management techniques. Cuijpers, Smit, and Van Straten (2007) found a mean effect size of .42 of seven interventions on depressive symptoms.

For early interventions to be effective, a clear model of risk factors and mechanisms in the development of psychopathology is needed (Rapee, 2008). There is growing evidence that in addition to symptoms of depression, experiential avoidance (EA) is such a mechanism involved in depression and other psychopathology. EA has been defined as the unwillingness to remain in contact with experiences such as feelings, thoughts, and bodily sensations, as an attempted means of behavioral regulation (Hayes et al., 2004). A meta-analysis of 32 studies examining the relationship between EA and psychopathology (e.g., anxiety, posttraumatic stress disorder, pain, depression) found a weighted effect size of $r=.42$ (95\% CI: .40-.44) (Hayes, Luoma, Bond, Masuda, \& Lillis, 2006). Additionally, EA has been found to mediate the effects of maladaptive coping behavior on psychopathology and positive mental health (Fledderus, Bohlmeijer, \& Pieterse, 2010; Kashdan, Barrios, Forsyth, \& Steger, 2006). 
So, early interventions targeting EA and clinically relevant symptoms of depression are warranted from a public mental health perspective (Biglan, Hayes, \& Pistorello, 2008). One intervention that has been specifically developed for targeting EA in patients with depression is acceptance and commitment therapy (ACT). ACT is a form a behavioral therapy that focuses on decreasing EA and increasing value-based behavior (Hayes, Strosahl, \& Wilson, 1999). Several studies have shown medium to large effects of clinical ACT treatments on depression (e.g., Forman, Herbert, Moitra, Yeomans, \& Geller, 2007; Lappalainen et al., 2007).

However, to our knowledge, no studies have been conducted on the efficacy of ACT as an early community intervention for people with clinically relevant depressive symptoms. A group course based on ACT was developed, called "Living to the full" and was pro-actively offered to the general public. This paper presents the results of a randomized controlled trial with a waiting list as a control group, in which the efficacy of this ACT intervention was assessed for reducing depressive symptomatology. In addition, we were also interested in symptoms of anxiety and fatigue, and the degree of alcohol use. A secondary goal of this paper was to test the effects on EA as an important process factor of ACT.

\section{Method}

\section{Procedure and participants}

The group intervention was designed as an early intervention for adults of 18 years and older with mild or moderate psychological distress. Study participants were recruited from March to May 2008 through press articles, leaflets and posters, and through psychologists at seven mental health institutions in the Netherlands. In these advertisements the target group of the intervention was described as people who want to live more fully but who are hindered by depressive symptoms. 140 individuals responded and were assessed for eligibility by trained psychologists in clinical face-to-face interviews. Participants with more severe psychological distress and therefore in need of therapeutic treatment were excluded and referred to a mental health institution. Other exclusion criteria were: (a) currently undergoing treatment at a mental health institution; (b) started less than three months ago with psychopharmacological treatment; (c) reporting no psychological complaints or symptoms; or (d) missing two or more sessions of the intervention. 47 individuals were excluded on the basis of these criteria. After signing informed consent, the remaining 93 participants were randomly assigned to the ACT intervention $(n=49)$ or to a waiting list $(n=44)$. An independent researcher carried out the block randomization for the two groups with stratification on gender and age ( $<50$ and $\geq 50$ years), using a computergenerated random sequence of numbers. Participants completed measures on three occasions: at baseline (T0), post-treatment at two months (directly after the intervention) (T1), and follow-up at 5 months after baseline (T2). Figure 1 provides an overview of the 
flow of participants. There were $75(80.6 \%)$ participants who filled out the questionnaires three times. The drop-out rate for the intervention was $14.3 \%$ ( 7 out of 49). Table 1 shows an overview of the participants' characteristics. The mean age of the study participants was 49 years (range $=24-71)$. The majority was female $(81.7 \%)$ and of Dutch origin $(91.4 \%)$. They varied in education: $26.9 \%$ had less than 13 years of education, $39.8 \%$ more than 16 years and $33.3 \%$ in-between. Furthermore, $46.2 \%$ was married and $52.7 \%$ had a paid job.

\section{Measures}

All assessments included a primary measure of depression, secondary measures of anxiety, fatigue and alcohol use and EA as a process measure.

\section{Primary measure}

Center for Epidemiologic Studies Depression Scale (CES-D). The CES-D (Radloff, 1977) is a 20 -item questionnaire that measures depressive symptoms in the general population. Respondents rate on a 4-point scale ranging from hardly ever (less than 1 day) (0) to predominantly (5-7 days) (3) to what extent they had experienced depressive symptoms in the previous week. Summation of the scores results in a total score ranging from 0 to 60 . A score of 16 or higher is considered to indicate the presence of clinically relevant depressive symptoms. The CES-D showed adequate psychometric properties (Radloff, 1977). The Dutch translation showed similar psychometric properties in a group of elderly people in the Netherlands (Haringsma, Engels, Beekman, \& Spinhoven, 2004). The scale showed high internal consistency in this study $(\alpha=.88$, T0).

\section{Secondary measures}

Hospital Anxiety and Depression Scale-Anxiety subscale (HADS-A). The HADS-A (Zigmond \& Snaith, 1983) is a 7-item questionnaire that assesses the presence and severity of anxious symptoms. Respondents rate on a 4-point scale ranging from not at all (0) to often (3) to what extent they had experienced anxiety symptoms in the previous week. The total HADS-A scores range from 0 to 21. The Dutch translation showed good psychometric properties (Spinhoven et al., 1997). Bjelland, Dahl, Haug, and Neckelmann (2002) showed that an optimal balance between sensitivity and specificity was achieved when caseness was defined by a score of 8 or above. The scale showed high internal consistency in this study $(\alpha=.83, \mathrm{~T} 0)$.

Checklist Individual Strength (CIS). The CIS (Vercoulen, Alberts, \& Bleijenberg, 1999) is a Dutch 20-item questionnaire and measures four aspects of fatigue: subjective fatigue, concentration, motivation and activity. Only the subscale of subjective fatigue ( 8 items) was measured in this study, because this scale indicates the severity of fatigue. Respondents rate on a 7-point scale ranging from yes, that is correct (1) to no, that is not correct (7) to what extent they had felt fatigue in the last two weeks. The summation of the scores gives 
an indication of the severity of fatigue: < 27 indicates normal fatigue, 27-35 indicates heightened fatigue and $>35$ indicates severe fatigue. The CIS showed good convergent and discriminant validity, and showed high internal consistency in this study $(\alpha=.93, \mathrm{~T} 0)$.

Alcohol use. Alcohol use was measured by assessing the number of standard units of alcohol consumed in the preceding week. Respondents rated how many standard units they drank during each of the last 7 days. These were summated to calculate the weekly alcohol consumption.

\section{Process measure}

Acceptance and Action Questionnaire-II (AAQ-II). The AAQ-II (Bond et al., 2011) is a 10item measure of EA. The AAQ-II assesses on a 7-point scale ranging from never true (1) to always true (7) the subject's willingness to be in contact with negative private events, the acceptance of these events, and whether they can live according to their values. Summation of the scores results in a total score ranging from 10 to 70, whereby a higher score indicates higher acceptance and less EA. The Dutch AAQ-II showed a good factor structure in a general and clinical population in the Netherlands and good internal consistency in the current study ( $\alpha=.86$, T0) (Jacobs, Kleen, De Groot, \& A-Tjak, 2008).

\section{Intervention}

$A C T$

The intervention 'Living to the full' consists of eight two-hour weekly sessions. It is a group-based intervention with on average seven participants per group. The intervention was provided by seven teams of two licensed psychologists. These psychologists work at prevention departments of mental health care institutes. All psychologists received a threeday training that was given by two clinical psychologists with ample experience in ACT.

The intervention is based on six core processes of ACT: willingness to experience negative emotions and thoughts, cognitive defusion, contact with the present moment, self as context, values, and committed action (Hayes et al., 2006). In session 1, the basic principles of ACT are explained and participants are encouraged to think about what they really want in life. This is a first exploration of their values. In sessions 2 and 3, the participants reflect on the avoidance and control strategies they are using and whether these strategies are effective in the long run. In sessions 4,5 , and 6, the participants learn how to come into contact with their present experiences, without trying to avoid or control them. Cognitive defusion and experiencing self as context are practised. In the last two sessions, the focus is on becoming aware of the most important personal values and making decisions based on these values. In all sessions participants learn mindfulness skills based on mindfulness-based stress reduction (Kabat-Zinn, 1990, 1994). 


\section{Waiting-list control}

Study participants assigned to the waiting list received no intervention. After the study ended, these participants were invited to take part in the ACT intervention.

Figure 1. Flow of Participants.

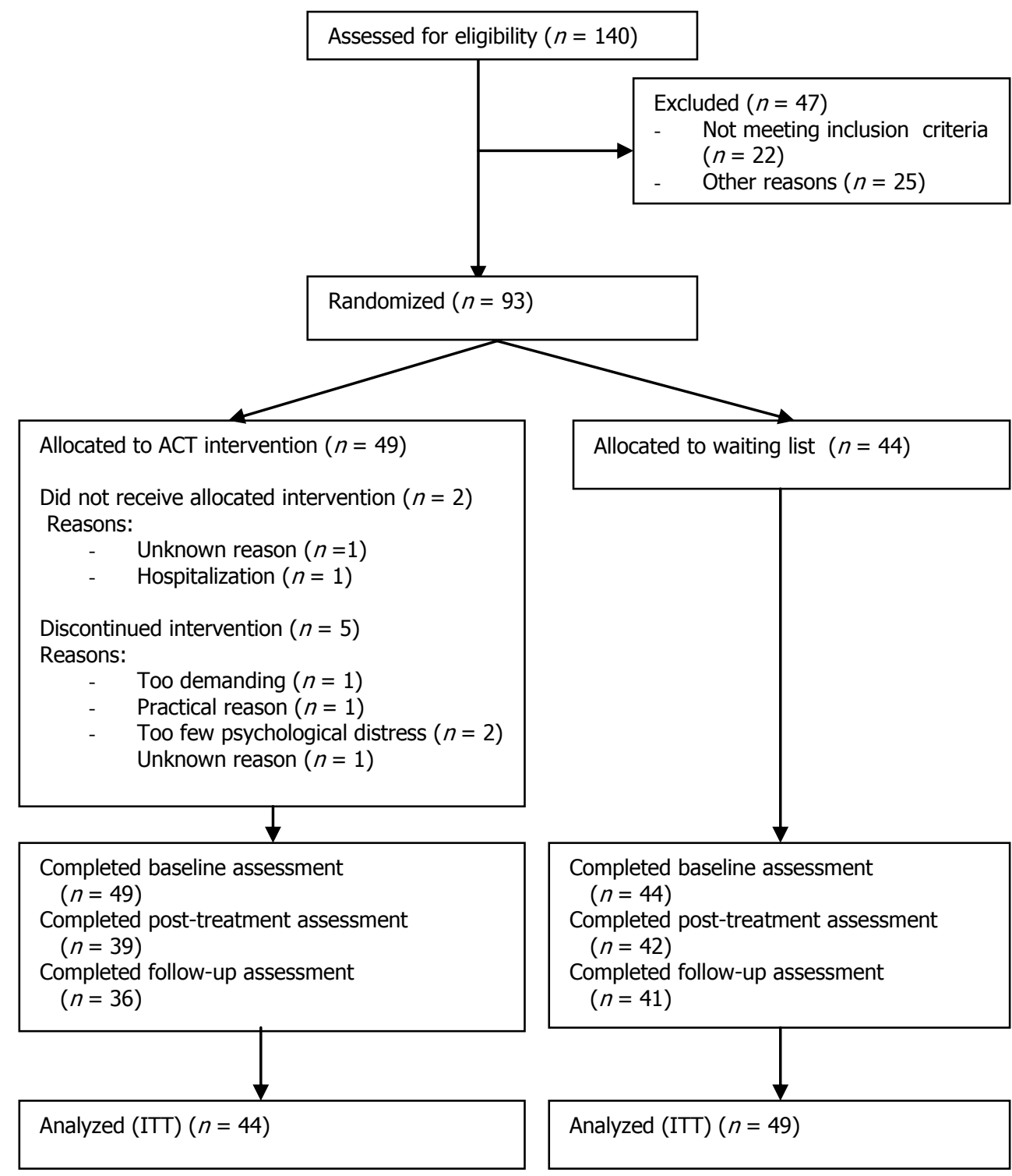


Table 1. Characteristics of Participants

\begin{tabular}{|c|c|c|c|c|c|c|}
\hline Characteristic & $\begin{array}{l}\text { All participan } \\
(n=93)\end{array}$ & & $\begin{array}{l}\text { ACT } \\
(n=49)\end{array}$ & & $\begin{array}{l}\text { Waiting list } \\
(n=44)\end{array}$ & \\
\hline & $n$ & $\%$ & $n$ & $\%$ & $n$ & $\%$ \\
\hline \multicolumn{7}{|l|}{ Gender } \\
\hline Female & 76 & 81.7 & 42 & 85.7 & 34 & 77.3 \\
\hline Male & 17 & 18.3 & 7 & 14.3 & 10 & 22.7 \\
\hline Age $(M, S D)$ & $\begin{array}{r}49.02 \\
(10.70)\end{array}$ & & $\begin{array}{r}48.84 \\
(11.34)\end{array}$ & & $\begin{array}{r}49.23 \\
(10.07)\end{array}$ & \\
\hline \multicolumn{7}{|l|}{ Marital status } \\
\hline Married & 43 & 46.2 & 25 & 51.0 & 18 & 40.9 \\
\hline Divorced & 18 & 19.4 & 10 & 20.4 & 8 & 18.2 \\
\hline Widowed & 3 & 3.2 & 0 & 0 & 3 & 6.8 \\
\hline Never married & 29 & 31.2 & 14 & 28.6 & 15 & 34.1 \\
\hline \multicolumn{7}{|l|}{ Race } \\
\hline Dutch & 85 & 91.4 & 46 & 93.9 & 39 & 88.6 \\
\hline Other & 8 & 8.6 & 3 & 6.1 & 5 & 11.4 \\
\hline \multicolumn{7}{|l|}{ Education } \\
\hline$<13$ years of education & 25 & 26.9 & 14 & 28.6 & 11 & 25.0 \\
\hline $13-16$ years of education & 31 & 33.3 & 16 & 32.6 & 15 & 34.1 \\
\hline$>16$ years of education & 37 & 39.8 & 19 & 38.8 & 18 & 40.9 \\
\hline \multicolumn{7}{|l|}{ Daily activities } \\
\hline Paid job & 49 & 52.7 & 26 & 53.1 & 23 & 52.3 \\
\hline No job & 44 & 47.3 & 23 & 46.9 & 21 & 47.7 \\
\hline
\end{tabular}

\section{Statistical analyses}

The statistical analyses were done using SPSS 17. Independent-samples $t$-tests and chisquare tests were conducted to examine differences between the treatment conditions at baseline. Intention-to-treat analyses were conducted with the use of SPSS Missing Value Analysis to impute all missing data on the continuous measures with the expectationmaximization (EM) method. This method computes missing values based on maximum likelihood estimates using observed data in an iterative process (Dempster, Laird, \& Rubin, 1977). The total percentage of missing data was $10.47 \%$ due to unanswered items $(.43 \%)$ or incomplete assessments (10.04\%). These missing values at baseline, post-treatment and follow-up were imputed. Hence, all participants that were randomized were included in the statistical analyses. A comparison of results based on the imputed intention-to-treat sample versus the observed data revealed similar outcomes. Therefore, only the results from the intention-to-treat analyses are reported.

All measures had a normal distribution, except for the measure of alcohol use. To describe this measure, the measure of alcohol consumption was transformed into a dichotomous variable using the current Dutch guideline (Health Council of the Netherlands, 2006), according to which a weekly alcohol consumption of 21 or more standard units per week (for men) and 14 or more (for women) was defined as alcohol misuse. For analyzing, the difference in reported alcohol use between baseline and post-treatment and follow-up 
was calculated. The non-parametric Mann-Whitney test was used to assess whether this change in alcohol use was different between the ACT group and the waiting-list group. To measure the effects for the other measures, analysis of covariance (ANCOVA) were conducted with the baseline scores as covariates. Comparisons were two-tailed and interpreted with a significance of $p<.05$.

Effect sizes at post-treatment and follow-up were calculated with Cohen's d using the means and the pooled standard deviations of the measurements of the conditions. To interpret Cohen's $d$ an effect size of $d=.2$ was considered small, $d=.5$ was considered medium and $d=.8$ was considered large (Cohen, 1992).

In order to examine whether a reduction in EA (or an improvement in acceptance) during the intervention would mediate the effects of the intervention on depressive symptomatology at follow-up mediational analysis with bootstrapping procedures $(n=$ 5000 bootstrap resamples) were used to assess the indirect effect of the mediational pattern outlined by Preacher and Hayes (2008). As prescribed, an indirect effect was considered significant in the case zero was not contained in the $95 \%$ confidence interval.

\section{Results}

\section{Baseline characteristics}

The means and standard deviations for the measures of depression (CES-D), anxiety (HADS-A), fatigue (CIS) and EA (AAQ-II) are presented in Table 2. There were no significant differences at baseline between the ACT group and the waiting-list group for any of the demographic variables or outcome measures, indicating a successful randomization.

The baseline scores of the participants on depression, anxiety and fatigue consistently show clinically relevant symptoms in at least two-thirds of the sample. The scores on acceptance are considerably lower than was found in a general Dutch population (Jacobs et al., 2008), meaning that the participants score high on EA. Most participants reported a safe use of alcohol, and 29 participants drank no alcoholic beverages. In the ACT intervention 8 participants were reporting alcohol misuse and on the waiting list 10 participants.

\section{Intervention attendance}

The average number of sessions attended by ACT participants that started with the intervention $(n=47)$ was 7.06 , with a range of $2-8$. There were 27 ACT participants that attended all the sessions.

\section{Treatment adherence}

At the time of the study, a standard measure of therapist adherence was not yet available. However, the therapists at every mental health institution were asked to note in a logbook 
after every session whether they performed all parts of the session. In total, $88.1 \%$ of all the exercises and $92.7 \%$ of all the mindfulness exercises were performed in the 8 sessions.

\section{Primary outcome}

The results of the ANCOVA as well as the corresponding effect sizes are presented in Table 2. An ANCOVA covarying the baseline assessment of depression, showed significant differences between the groups at post-treatment and at follow-up with more reduction in depression in the ACT intervention compared to the waiting-list group. Results for Cohen's $d$ showed medium effect sizes at post-treatment and at follow-up.

Table 2. Means and Standard Deviations for Measures (Baseline to Follow-up) and Results of ANCOVA and Cohen's d for Intervention Effects

\begin{tabular}{llllllll}
\hline & $\begin{array}{l}\text { ACT } \\
(n=49)\end{array}$ & \multicolumn{7}{l}{$\begin{array}{l}\text { Waiting list } \\
(n=44)\end{array}$} \\
\hline Measures & $M$ & $S D$ & $M$ & $S D$ & $F(\mathrm{dt})$ & $p$ & $d$ \\
\hline Primary outcome & & & & & & & \\
$\quad$ CES-D baseline & 23.94 & 9.91 & 26.11 & 9.12 & & & \\
CES-D post-treatment & 15.94 & 10.37 & 22.07 & 9.99 & $9.19(1,92)$ & .003 & .60 \\
CES-D follow-up & 14.78 & 9.49 & 21.17 & 10.71 & $9.30(1,92)$ & .003 & .63 \\
& & & & & & & \\
Secondary outcomes & & & & & & & \\
HADS-A baseline & 9.65 & 4.39 & 11.09 & 3.91 & & & \\
HADS-A post-treatment & 7.13 & 4.19 & 9.71 & 3.44 & $7.94(1,92)$ & .006 & .67 \\
HADS-A follow-up & 6.66 & 3.74 & 8.74 & 3.72 & $4.23(1,92)$ & .043 & .56 \\
& & & & & & & \\
CIS baseline & 39.49 & 11.82 & 40.52 & 11.80 & & & \\
CIS post-treatment & 33.80 & 11.85 & 39.85 & 11.31 & $8.24(1,92)$ & .005 & .52 \\
CIS follow-up & 34.52 & 11.94 & 40.32 & 11.89 & $7.84(1,92)$ & .006 & .49
\end{tabular}

Process measure

AAQ-II baseline

36.83

11.29

36.68

8.63

AAQ-II post-treatment

42.98

8.92

37.87

8.54

$10.47(1,92) \quad .002$

.59

AAQ-II follow-up

$\begin{array}{lll}44.66 & 10.27 & 38.39\end{array}$

8.69

$14.17(1,92) \quad .000 \quad .66$

Note. ACT = Acceptance and Commitment Therapy, CES-D = Center for Epidemiologic Studies Depression Scale, HADS-A = Hospital Anxiety and Depression Scale-Anxiety subscale, CIS = Checklist Individual Strength, AAQ-II = Acceptance and Action Questionnaire-II. 


\section{Secondary outcomes}

A significant difference between the groups was observed for anxiety at post-treatment and follow-up with a greater decrease in anxiety in the ACT intervention. Results also showed that the ACT group had more reduction in fatigue at the post-treatment and at follow-up compared to the waiting-list group. Medium effects sizes were found at post-treatment and at follow-up for the secondary outcomes.

A Mann-Whitney test, using the dichotomous criterion for alcohol misuse, showed no effects of the ACT intervention on alcohol misuse from baseline to post-treatment and follow-up.

\section{Process outcome}

Participants in the ACT intervention showed a greater reduction in EA (or improvement in acceptance), both at post-treatment and at follow-up compared to the waiting-list group. Medium effect sizes were found at post-treatment and at follow-up.

\section{Mediational analyses with EA}

The results of the mediational analysis are presented in Table 3. Step 1 in Table 3 shows that, controlling for CES-D and AAQ-II at baseline, the ACT intervention significantly reduced depressive symptomatology at follow-up. Step 2 in Table 3 shows that the improvement of AAQ-II treatment effect is reduced with $43 \%$ and becomes non-significant. Mediational analysis, following Preacher and Hayes (2008) showed that the mediating effect of improvement of AAQ-II from baseline to post-treatment is significant $(p<.05)$, with bootstrapping values between -4.10 and -.67 .

Table 3. Hierarchical Regression Analysis of CES-D at Follow-up on Intervention, Baseline CES-D, Baseline AAQ-II, and Improvement of AAQ-II between Baseline and Post-treatment

\begin{tabular}{lll}
\hline CES-D (T2) & Step 1 Beta & Step 2 Beta \\
\hline Intervention Group (Comp: Control group) & $-.228^{* *}$ & -.130 \\
Baseline CES-D (T0) & $.682^{* * *}$ & $.568^{* * *}$ \\
Baseline AAQ-II (T0) & .117 & -.177 \\
Improvement in AAQ-II (T1-T0) & & $-.419 * * *$ \\
Explained variance (adjusted $\left.\mathrm{R}^{2}\right)$ & .474 & $.568^{\mathrm{a}}$ \\
\hline Note. $* * p<.01 ; * * * p<.001 ;{ }^{\mathrm{a}}$ Significant improvement in $\mathrm{R}^{2}$ Change $(p<.05)$. &
\end{tabular}




\section{Discussion}

Depression is one of the most prevalent disorders in the world. In order to reduce this prevalence, a public mental health approach is needed in addition to effective treatment in clinical settings (Hosman et al., 2005). In this study it was found that a small-group course based on acceptance and commitment therapy (ACT) has beneficial effects on depressive symptoms and may be useful in such a public mental health approach. Among ACT participants the average level of depressive symptomatology decreased significantly to a level below the cut-off score (16) for clinical relevant levels of symptoms (Radloff, 1977), while among the waiting-list control group depressive symptoms remained well above this cut-off score. This effect was maintained at three-month follow-up. As the presence of clinically relevant depressive symptoms is known to be an important risk factor for clinical depression (Cuijpers \& Smit, 2004), this outcome suggests that early treatment with ACT may decrease the risk of developing a (next) full clinical depression. This risk is also associated with experiential avoidance (EA) (Biglan et al., 2008; Hayes et al., 2006; Kashdan et al., 2006). The ACT intervention specifically targeted EA. In this respect it is meaningful that medium effect sizes were found on EA, and that a reduction in EA during the intervention mediated the treatment effect on depressive symptoms at three-month follow-up. This implies that longer term effects of ACT are mediated by the effects on EA. This finding corroborates the underlying theoretical model on which ACT is built.

In addition to depressive symptoms, the intervention showed similar effects on symptoms of anxiety and fatigue. The reduction in fatigue is an important finding, because fatigue is related to both poorer psychological and physical health (Cardol, Bensing, Verhaak, \& de Bakker, 2005). These findings suggest that an early intervention based on ACT may play a role in reducing a broad spectrum of psychological distress. This is consistent with earlier studies that found that EA is related to a wide variety of measures of psycho-pathology (Hayes et al., 2006). No significant reduction in alcohol use was found. Possibly, this outcome is due to low statistical power on this secondary outcome, as 18 of 93 participants reported hazardous alcohol consumption, and a binary outcome measure was used in the analyses.

This study corroborates the findings of earlier studies that showed that ACT is effective in substantially reducing depressive symptomatology of community dwelling people (Forman et al., 2007; Lappalainen et al., 2007). The results also support findings from previous studies that early interventions implemented as a course (e.g. the Coping with depression course) can substantially reduce depressive symptomatology (Cuijpers, Smit, Oostenbrink et al., 2007). To our best knowledge this is the first study that explored the effects of a similar course based on ACT.

It was recently discussed that early interventions, in order to have a large impact on public mental health, should have a number of characteristics (Cuijpers, Van Straten, Warmerdam, \& Van Rooy, 2010). An intervention should be offered in a framework that 
reduces the stigma associated with depression, because this is one of the main reasons people are unwilling to participate. Furthermore, the intervention should also focus on other mental illnesses for reaching larger groups for preventive services. We think that ACT is especially suited for these types of early or indicated preventive interventions. First, ACT is based on a positive health model and not on a disease model (Hayes et al., 1999). This allows an intervention to be framed positively more easily. Second, ACT targets a risk factor, EA that is relevant for various mental illnesses and thus may have a broad transdiagnostic impact (Hosman et al., 2005). This was confirmed by our study. However, more elaborate studies are needed to substantiate this claim. Another interesting focus for future studies is the question whether early treatments are more effective in participants who are at risk of a first-time depressive episode than in participants with a history of chronic or recurrent episodes.

\section{Limitations}

Several important limitations have to be pointed out. First, no diagnostic instruments were used in the study, so it was unclear how many participants suffered from a mental disorder before and after the intervention. Also, our study relied on self-report measures and used no clinician ratings. Second, the number of participants using psychopharmacological treatment longer than three months prior to baseline and changes in psychopharmacological doses was not assessed. Third, the use of a waiting list as a control group is sub-optimal because confounding by nonspecific factors cannot be controlled for. This implies that the effects on the outcome and process measures cannot be assigned to the specific ACT components. Furthermore, we did not assess the outcomes of participants in the waiting list after they had received the intervention because we included a three-month follow-up period for both the intervention group and waiting-list group and because of budgetary restraints. However, performing a post-treatment assessment in the waiting-list group would add further evidence of the efficacy of the intervention if it can be shown that depressive symptoms were reduced to a similar level as the intervention group at posttreatment. Fourth, due to the relative short follow-up period data on sustained effects are not yet available. Fifth, treat ment adherence was not assessed by independent evaluators who have been trained to assess reliability.

\section{Conclusion}

Despite the limitations, it can be concluded that the findings provide initial support for efficacy of an early intervention based on ACT within a public mental health approach. The intervention Living to the full has now been implemented in about $50 \%$ of Dutch mental health care institutes. Further research is needed to determine the efficacy of this intervention, for example among different populations. This research should preferably include the use of diagnostic instruments, an active control group and a longer follow-up period. 


\section{Acknowledgements}

This study was funded by Innovation Fund Health Insurers (Innovatiefonds Zorgverzekeraars). Ethical principles in the country where the study was conducted (the Netherlands) were followed. The study was approved by the Medical-Ethical Review Board for Mental Health Care Institutes (METIGG; number 8203) which is recognized by the Central Committee for Research involving human participants (CCMO). Its activities fall under the Dutch law (WMO). The study has been registered in the "Nederlands Trial Register", the Dutch primary register for clinical trials (NTR1296). 


\section{References}

Andrews, G., Issakidis, C., Sanderson, K., Corry, J., \& Lapsley, H. (2004). Utilizing survey data to inform public policy: comparison of the cost-effectiveness of treatment of ten mental disorders. British Journal of Psychiatry, 184, 526-533.

Biglan, A., Hayes, S. C., \& Pistorello, J. (2008). Acceptance and commitment: implications for prevention science. Prevention Science, 9, 139-152.

Bjelland, I., Dahl, A. A., Haug, T. T., \& Neckelmann, D. (2002). The validity of the Hospital Anxiety and Depression Scale. An updated literature review. Journal of Psychosomatic Research, 52, 69-77.

Bond, F. W., Hayes, S. C., Baer, R. A., Carpenter, K. C., Guenole, N., Orcutt, H. K., Waltz, T., \& Zettle, R. D. (2011). Preliminary psychometric properties of the Acceptance and Action Questionnaire-II: a revised measure of psychological flexibility and acceptance. Behavior Therapy, 42, 676-688.

Cardol, M., Bensing, J., Verhaak, P., \& de Bakker, D. (2005). Moeheid: determinanten, beloop en zorg. [Fatigue: Determinants, development and care]. Utrecht: NIVEL. Cohen, J. (1992). A power primer. Psychological Bulletin, 112, 155-159.

Cuijpers, P., \& Smit, F. (2004). Subthreshold depression as a risk indicator for major depressive disorder: a systematic review of prospective studies. Acta Psychiatrica Scandinavica, 109, 325-331.

Cuijpers, P., Smit, F., Oostenbrink, J., de Graaf, R., ten Have, M., \& Beekman, A. (2007). Economic costs of minor depression: a population-based study. Acta Psychiatrica Scandinavica, 115, 229-236.

Cuijpers, P., Smit, F., \& van Straten, A. (2007). Psychological treatments of subthreshold depression: a meta-analytic review. Acta Psychiatrica Scandinavica, 115, 434-441.

Cuijpers, P., van Straten, A., Smit, F., Mihalopoulos, C., \& Beekman, A. T. F. (2008). Preventing the onset of depressive disorders: a meta-analytic review of psychological interventions. American Journal of Psychiatry, 165, 1272-1280.

Cuijpers, P., van Straten, A., Warmerdam, L., \& van Rooy, M. J. (2010). Recruiting participants for intervention to prevent the onset of depressive disorders: possible ways to increase participation rates. BMC Health Services Research, 10, 181.

Dempster, A. P., Laird, N. M., \& Rubin, D. B. (1977). Maximum likelihood from incomplete data via the EM algorithm. Journal of the Royal Statistical Society, 39, $1-38$.

Fledderus, M., Bohlmeijer, E. T., \& Pieterse, M. E. (2010). Does experiential avoidance mediate the effects of maladaptive coping styles on psychopathology and mental health? Behavior Modification, 34, 503-519.

Forman, E. M., Herbert, J. D., Moitra, E., Yeomans, P. D., \& Geller, P. A. (2007). A randomized controlled effectiveness trial of acceptance and commitment therapy and cognitive therapy for anxiety and depression. Behavior Modification, 31, 772-799. 
Haringsma, R., Engels, G. I., Beekman, A. T. F., \& Spinhoven, P. (2004). The criterion validity of the Center for Epidemiological Studies Depression Scale (CES-D) in a sample of self-referred elders with depressive symptomatology. International Journal of Geriatric Psychiatry, 19, 558-563.

Hayes, S. C., Luoma, J. B., Bond, F. W., Masuda, A., \& Lillis, J. (2006). Acceptance and commitment therapy: model, processes and outcomes. Behaviour Research and Therapy, 44, 1-25.

Hayes, S. C., Strosahl, K., \& Wilson, K. G. (1999). Acceptance and commitment therapy: An experiential approach to behavior change. New York: Guilford.

Hayes, S. C., Strosahl, K. D., Wilson, K. G., Bissett, R. T., Pistorello, J., Toarmino, D., ... McCurry, S. M. (2004). Measuring experiential avoidance: A preliminary test of a working model. Psychological Record, 54, 553-578.

Health Council of the Netherlands. (2006). Richtlijnen goede voeding 2006. [Guide-lines for a healthy diet]. The Hague: Health Council of the Netherlands.

Hosman, C., Jane-Llopis, E., \& Saxena, S. (Eds.). (2005). Prevention of mental disorders: Effective interventions and policy options. Oxford: Oxford University Press.

Jacobs, N., Kleen, M., de Groot, F., \& A-Tjak, J. (2008). Het meten van experiëntiële vermijding. De Nederlandstalige versie van de Acceptance and Action Questionnaire-II (AAQ-II). [Measuring experiential avoidance. Dutch translation of the acceptancemand action questionnaire-II (AAQ-II)]. Gedragstherapie, 41, 349361.

Jorm, A. F., \& Griffiths, K. M. (2006). Population promotion of informal self-help strategies for early intervention against depression and anxiety. Psychological Medicine, 36, 3-6.

Kabat-Zinn, J. (1990). Full catastrophe living: Using the wisdom of your body and mind to face stress, pain, and illness. New York: Delacorte.

Kabat-Zinn, J. (1994). Wherever you go, there you are: Mindfulness meditation in everyday life. New York: Hyperion.

Kashdan, T. B., Barrios, V., Forsyth, J. P., \& Steger, M. F. (2006). Experiential avoidance as a generalized psychological vulnerability: comparisons with coping and emotion regulation strategies. Behaviour Research and Therapy, 44, 1301-1320.

Lappalainen, R., Lehtonen, T., Skarp, E., Taubert, E., Ojanen, M., \& Hayes, S. C. (2007). A preliminary controlled effectiveness trial the impact of CBT and ACT models using psychology trainee. Behavior Modification, 31, 488-511.

Lewinsohn, P. M., Antonucci, D. O., Breckenridge, J. S., \& Munoz, R. F. (1984). The coping with depression course. Eugene, OR: Castalia.

Lynch, D. J., Tamburrino, M. B., \& Nagel, R. (1997). Telephone counseling for patients with minor depression: preliminary findings in a family practice setting. Journal of Family Practice, 44, 293-298.

Mrazek, P., \& Haggerty, R. (1994). Reducing risks for mental disorders: Frontiers for preventive intervention research. Washington, DC: National Academy Press. 
Preacher, K. J., \& Hayes, A. F. (2008). Asymptotic and resampling strategies for assessing and comparing indirect effects in multiple mediator models. Behavior Research Methods, 40, 879-891.

Radloff, L. S. (1977). The CES-D scale: a self-report depression scale for research in the general population. Applied Psychological Measurement, 1, 385-401.

Rapee, R. M. (2008). Prevention of mental disorders: promises, limitations, and barriers. Behavioral Practice, 15, 47-52.

Smit, F., Ederveen, A., Cuijpers, P., Deeg, D., \& Beekman, A. (2006). Opportunities for cost-effective prevention of late-life depression: an epidemiological approach. Archives of General Psychiatry, 63, 290-296.

Spinhoven, P. H., Ormel, J., Sloekers, P. P. A., Kempen, G. I. J. M., Speckens, A. E. M., \& van Hemert, A. M. (1997). A validation study of the Hospital Anxiety and Depression Scale (HADS) in different groups of Dutch subjects. Psychological Medicine, 27, 363-370.

Vercoulen, J. H. M. M., Alberts, M., \& Bleijenberg, G. (1999). The checklist individual strength (CIS). Gedragstherapie, 32, 131-136.

von Korff, M., Ormel, J., Katon, W., \& Lin, E. H. B. (1992). Disability and depression among high utilizers of health care: a longitudinal analysis. Archives of General Psychiatry, 49, 91-100.

Willemse, G. R. W. M., Smit, F., Cuijpers, P., \& Tiemens, B. G. (2004). Minimal-contact psychotherapy for sub-threshold depression in primary care: randomised trial. British Journal of Psychiatry, 185, 416-421.

World Health Organization. (2008). The global burden of disease: 2004 update. Geneva: World Health Organization. Available at www.who.int/healthinfo/ global_burden_disease/GBD_report_2004update_full.pdf.

Zigmond, A. S., \& Snaith, R. P. (1983). The Hospital Anxiety and Depression Scale. Acta Psychiatrica Scandinavica, 67, 361-370. 
86 Chapter 4 


\section{Mental health promotion as a new goal in public mental health care: $\mathbf{A}$ randomized controlled trial of an intervention enhancing psychological flexibility}

Fledderus, M., Bohlmeijer, E. T., Smit, F., \& Westerhof, G. J. (2010). Mental Health Promotion as a New Goal in Public Mental Health Care: A Randomized Controlled Trial of an Intervention Enhancing Psychological Flexibility. American Journal of Public Health, 100, 2372-2378. 


\section{Abstract}

Objectives: We assessed whether an intervention based on acceptance and commitment therapy (ACT) and mindfulness was successful in promoting positive mental health by enhancing psychological flexibility.

Methods: Participants were 93 adults with mild to moderate psychological distress. They were randomly assigned to the group intervention $(n=49)$ or to a waiting-list control group $(n=44)$. Participants completed measures before and after the intervention as well as 3 months later at follow-up to assess mental health in terms of emotional, psychological, and social well-being (Mental Health Continuum-Short Form) as well as psychological flexibility (i.e., acceptance of present experiences and value-based behavior, Acceptance and Action Questionnaire-II).

Results: Regression analyses showed that compared with the participants on the waiting list, participants in the ACT and mindfulness intervention $\mathrm{n}$ had greater emotional and psychological well-being after the intervention and also greater psychological flexibility at follow-up. Mediational analyses showed that the enhancement of psychological flexibility during the intervention mediated the effects of the intervention on positive mental health.

Conclusions: The intervention is effective in improving positive mental health by stimulating skills of acceptance and value-based action. 


\section{Introduction}

Over the past few decades the field of public mental health has undergone a strong professionalization. There is increasing agreement on the classification and diagnosis of mental health problems attributable to the development of common frames of reference (Diagnostic and Statistical Manual of Mental Disorders and International Classification of Diseases) and the increasing availability of valid diagnostic tests. Furthermore, the prevention and treatment of mental illness has profited from the development of standardized protocols and guidelines as well as from rigorous studies on their (cost)effectiveness. Despite the many advantages of such professionalization, however, the process also has resulted in a rather exclusive focus on what is going wrong with people. The field of public mental health widely uses an illness ideology within a medical model (Maddux, 2009). Mental health is generally defined as the absence of psychological complaints and mental illnesses.

In recent years, there has been increasing interest in a more positive approach to mental health. This approach builds on the fundamental assumption that human beings possess an inherent developmental tendency toward personal growth and fulfillment. The World Health Organization has recently defined positive mental health in terms of (1) an individual's well-being, (2) effective individual functioning, and (3) effective social functioning (Herrman, Saxena, Moodie, 2005). Subjective evaluations of these 3 core components can be termed emotional, psychological, and social well-being (Westerhof \& Keyes, 2010). Emotional well-being refers to the experience of feelings of happiness and satisfaction, whereas psychological well-being refers to leading a meaningful life in which one realizes one's own capacities. Social well-being refers to the feeling that one values and is valued by the society in which one lives (Herman, Saxena, Moodie, 2005).

Mental health promotion can be seen as an important new goal for public mental health. The main reason for this new goal is that the absence of mental illness does not necessarily imply the presence of flourishing mental health (Westerhof \& Keyes, 2010; Greenspoon \& Saklofske, 2001; Keyes, 2002; 2005). As a result, traditional public mental health interventions that are effective in alleviating mental illness do not necessarily promote mental health. Furthermore, mental health does have important individual, societal, and economic consequences. Even when one controls for symptoms of mental illness, mental health has an independent relation with psychosocial adaptation, work productivity, physical disease, health care utilization, and even mortality (Keyes, 2002; 2004; 2005; 2006; Chida \& Steptoe, 2008). An important challenge for the coming years is, therefore, to study whether and how mental health can be effectively promoted.

Mental health promotion requires moving from a risk-reduction model (e.g., Mrazek \& Haggerty, 1994) to a competence enhancement model (Barry \& Jenkins, 2007). To effectively promote mental health, interventions should be based on theories and empirical evidence of psychological competences that can explain their effectiveness (Jané- 
Llopis \& Barry, 2005; Sowden et al., 1997; Cowen, 2002). Psychological flexibility is one such competence (Hayes, Luoma, Bond, Masuda, \& Lillis, 2006).

Psychological flexibility includes 2 mutually dependent processes: acceptance of experiences and value-based behavior. A psychologically flexible person is willing to remain in contact with negative experiences rather than trying to avoid, alter, or control negative experiences. This acceptance is facilitated by committing to actions that are based on an individual's authentic values (Hayes et al., 2006) Studies have shown that psychological flexibility is related not only to fewer psychological problems (Hayes et al., 2006; Chawla \& Ostafin, 2007) but also to better quality of life, emotional well-being, and job satisfaction (Bond \& Bunce, 2003; Butler \& Ciarrochi, 2007). Two other studies showed that psychological flexibility mediates the effects of adaptive coping styles on emotional and psychological well-being (Kashdan, Barrios, Forsyth, \& Steger, 2006; Fledderus, Bohlmeijer, \& Pieterse, 2010).

Enhancing psychological flexibility is the focus of 2 treatment models: acceptance and commitment therapy (ACT) and mindfulness. ACT is a form of contextual behavioral therapy that aims to increase psychological flexibility (Hayes, Stosahl, Wilson, 1999). Clients learn that trying to change the content of their experiences is counterproductive. Instead, clients learn to detach from these experiences and to focus instead on behaviors that support their individual values. This is explained with the use of metaphors and encouraged by experiential exercises. Meta-analyses have shown medium to large effect sizes of ACT interventions on different symptoms of psychological distress (Hayes et al., 2006; Powers, Zum Vörde Sive Vörding, Emmelkamp, 2009).

Mindfulness interventions have a different background -e.g., Buddhist philosophybut share a goal similar to that of ACT interventions. Mindfulness refers to a state of being attentive to and aware of experiences occurring in the present moment in a nonjudgmental or accepting way (Kabat-Zinn, 1990; 1994). Mindfulness can be contrasted to a state of being caught up by memories, fantasies, or worries without paying attention to the present, as well as to automatic and habitual behavior that goes unnoticed. Mindfulness is usually taught by a variety of meditation and attention exercises and by psychoeducation. Wellknown evidence-based programs include mindfulness-based stress reduction (Teasdale et al., 2000) and mindfulness-based cognitive therapy (Baer, 2003). In a recent meta-analysis of 39 studies, mindfulness-based therapy yielded at least medium effect sizes on alleviating anxiety and depression (Hofmann, Sawyer, Witt, \& Oh, 2010).

A recent development has been to combine ACT with mindfulness training. This combination may be particularly effective because both interventions use strategies to increase the acceptance of negative thoughts and emotions and to promote behaving in a mindful and value-based way. For example, Roemer, Orsillo, \& Salters-Pedneault (2008) developed an individual protocol combining ACT and mindfulness-based cognitive therapy and found large effects on patients with generalized anxiety disorders.

Although ACT and mindfulness focus on the acceptance of psychological distress rather than on its avoidance and control, most studies have addressed effectiveness only in 
terms of a decrease in symptoms of mental illness. However, it can be expected that such interventions also promote mental health: experiential acceptance and value-based actions are supportive of a positive, engaged, and meaningful life. Only a few studies have addressed this expectation. Studies on ACT interventions have reported improvement of life satisfaction or quality of life (Forman, Herbert, Moitra, Yeomans, \& Geller, 2007; Lappalainen et al., 2007; Dalrymple \& Herbert, 2007; Dahl, Wilson, \& Nilsson, 2004) whereas studies of mindfulness interventions found effects on positive affects (Grossman, Tiefenthaler-Gilmer, Raysz, Kesper, 2007; Zautra et al., 2008). However, these studies mainly focused on emotional well-being, which constitutes only 1 aspect of positive mental health, besides psychological and social well-being. Furthermore, no studies have examined whether stimulating psychological flexibility is effective in promoting positive mental health.

We examined the effect of a preventive group intervention that builds on ACT and mindfulness. The intervention was implemented in a public health setting for persons with mild to moderate psychological distress. Our study assessed the effectiveness of the intervention on all 3 aspects of positive mental health and psychological flexibility in a randomized controlled trial with a waiting list control group. A secondary goal was to test the mediating effect of psychological flexibility on the promotion of mental health.

\section{Methods}

\section{Participants and procedure}

The group intervention was designed as a form of indicated prevention for adults aged 18 years and older with mild or moderate psychological distress. Study participants were recruited from March to May 2008 through press articles, leaflets, and posters, and through psychologists at 7 mental health institutions in the Netherlands. A total of 140 individuals responded and were assessed for eligibility by trained psychologists in clinical face-to-face interviews. Participants with severe psychological distress were excluded from this preventive trial and referred to a mental health institution for possible treatment. Other exclusion criteria were: (1) patients currently undergoing treatment at a mental health institution, (2) patients who started less than 3 months ago with psychopharmacological treatment, (3) persons reporting no psychological complaints or symptoms, or (4) participants missing 2 or more sessions of the intervention. A total of 47 individuals were excluded on the basis of those criteria.

After signing informed consent forms, the remaining 93 participants were randomly assigned to the ACT and mindfulness intervention $(n=49)$ or to a waiting list ( $n$ $=44$ ). An independent researcher carried out the block randomization for the 2 groups with stratification on gender and age $(<50$ years and $\geq 50$ years), by using a computer-generated random sequence of numbers. Participants completed measures on 3 occasions: at baseline (T0), post-treatment at 2 months (directly after the intervention; T1), and follow-up at 5 
months after baseline (T2). Figure 1 provides an overview of the flow of participants (see page 75). There were $75(80.6 \%)$ participants who filled out the questionnaires 3 times. The drop-out rate for the intervention group was $14.3 \%$ ( 7 out of 49). The mean age of the study participants was 49 years (range $=24-71)$. The majority were women $(81.7 \%$ ) and of Dutch origin (91.4\%). The participants varied in level of education: $26.9 \%$ had less than 13 years of education, $39.8 \%$ had more than 16 years, and $33.3 \%$ were in between. Furthermore, $46.2 \%$ of participants were married, and $52.7 \%$ of participants were gainfully employed.

\section{Intervention and control group}

ACT and mindfulness. The intervention "Living to the full" consisted of eight 2-hour sessions. It was a group-based intervention with an average of 7 participants per group. The intervention was based on 6 core processes of ACT that together promote psychological flexibility: (1) acceptance (active and aware embracement of aversive internal experiences), (2) cognitive defusion (creating a context where undesirable functions of thoughts disappear), (3) contact with the present moment, (4) self as context (experiencing that one is more than one's thoughts, feelings, and experiences), (5) choosing values in different life domains, and (6) commitment to choices based on these values (Hayes et al., 2006).

In session 1, the basic principles and visions of ACT were explained, and participants had to think about what they really wanted in life. This was a first exploration of their values. In sessions 2 and 3, the participants reflected on the avoidance and control strategies they were using and whether these strategies were effective in the long run. In sessions 4 through 6 , the participants learned how to come into contact with their present experiences, without trying to avoid or control them. Participants willingly practiced experiencing negative emotions, cognitive defusion, and self as context. In the last 2 sessions, the focus was on becoming aware of the most important personal values and making decisions on the basis of these values. In all sessions, participants learned mindfulness skills.

Waiting list control. Study participants assigned to the waiting list did not receive the ACT and mindfulness intervention. After the study ended, the waiting list participants were invited to take part in the intervention.

\section{Therapists}

Teams of 2 licensed psychologists provided therapy to 7 intervention groups at 7 different mental health organizations. All 14 psychologists received a 3-day training session that was given by 2 clinical psychologists with ample experience in ACT and mindfulness. All psychologists received a manual that clearly defined the structure and exercises of the 8 sessions of the group intervention. All exercises were role-played and discussed during the training. The therapists received feedback on their performances. 


\section{Measures}

The Acceptance and Action Questionnaire-II (AAQ-II) is a 10-item measure of psychological flexibility (Bond et al., 2011). The AAQ-II assesses the ability to accept aversive internal experiences and to pursue goals in the presence of these experiences on a 7-point scale ranging from never true (1) to always true (7). A total score, ranging from 10 to 70, was computed by summing the scores on the individual items. Higher scores on the AAQ-II indicate higher levels of psychological flexibility. The AAQ-II showed good construct and convergent and divergent validity. The psychometrical properties of the Dutch AAQ-II were comparable to those found among a general and clinical population in the Netherlands (Jacobs, Kleen, De Groot, A-Tjak, 2008). The AAQ-II showed good internal consistency in our study $(\alpha=0.86$; T0).

The Mental Health Continuum-Short Form (MHC-SF) is a 14-item questionnaire measuring emotional well-being ( 3 items), social well-being (5 items), and psychological well-being (6 items) (Keyes, 2002; 2005). Participants were asked to rate yow often they had experienced feelings of well-being in the past month. Items were scored on a 6-point scale ranging from never (1) to every day (6). A mean score across the individual items was computed for each component of well-being as well as for the total scale. Higher scores indicate better well-being and mental health. The Dutch MHC-SF showed good convergent and discriminant validity as well as high internal and moderate test-retest reliability in a representative study among Dutch adults (Lamers, Westerhof, Bohlmeijer, Ten Klooster, Keyes, 2010). The MHC-SF showed good internal consistency in this study (emotional well-being $\alpha=0.85$; social well-being $\alpha=0.74$; psychological well-being $\alpha=0.83$; MHCSF total $\alpha=0.91$; all at $\mathrm{T} 0$ ).

\section{Statistical analyses}

We performed the analyses with the observed data and intention-to-treat. We conducted intention-to-treat analyses after imputing all missing data on the continuous measures by using the expectation maximization method (SPSS version 17, missing value analysis; SPSS Inc, Chicago, IL). This method computes missing values based on maximum likelihood estimates by using observed data in an iterative process (Dempster, Laird, Rubin, 1977). The total percentage of imputed missing data was $11.3 \%$ ( $1.3 \%$ because of unanswered items and $10.0 \%$ because of incomplete assessments). Hence, all participants who were randomized were included in the statistical analyses.

The independent sample $t$ test and the $\chi^{2}$ test showed that there were no significant differences at baseline between the intervention group and the waiting list group for any of the demographic variables or outcome measures, indicating a successful randomization.

We conducted regression analyses to evaluate the intervention's impact on mental health and psychological flexibility at post-treatment and follow-up by using the baseline assessment of the outcome measure and the treatment dummy (intervention vs waiting list) as independent variables. We took into account that the observations were clustered as 
participants were nested in each of the 7 intervention groups at different regional mental health institutions. Therefore, we computed robust standard errors by using the first-order Taylor-series linearization method as implemented in Stata version 8.2 (StataCorp LP, College Station, TX). The 2-tailed test was considered significant at $p<.05$. Standardized mean differences (Cohen $d$ ) were calculated as the difference between the means of the treatment and control condition divided by the standard deviation of the control condition ( $d=0.2$ was considered as a small effect; $d=0.5$ as medium; and $d=0.8$ as large) (Cohen, 1992).

To examine whether improvement in psychological flexibility during and after the intervention would mediate the effects of the intervention on mental health, mediational analysis with bootstrapping procedures ( $n=5000$ bootstrap resamples) was used to assess the indirect effect of the mediational pattern outlined by Preacher and Hayes (2008). As prescribed, an indirect effect was considered significant in the case zero was not contained in the $95 \%$ confidence interval.

\section{Results}

Table 1 presents the imputed means and standard errors for the scores on psychological flexibility and mental health as well as the results of the regression analyses and the corresponding effect sizes. All results in the table apply to the imputed data set, taking clustering into account.

The ACT and mindfulness group had significantly more improvement in mental health at post-treatment and at follow-up than the waiting list group did. The Cohen $d$ showed medium to large effect sizes at post-treatment (0.56) and at follow-up (0.85). The intervention group reported greater emotional and psychological well-being at posttreatment and follow-up than did the control group, but not greater social well-being. We found medium effect sizes for emotional and psychological well-being. The ACT and mindfulness group showed greater improvement in psychological flexibility only at followup compared with the waiting list group, with a medium effect size of 0.74 .

\section{Mediating effects of psychological flexibility on mental health}

We first assessed whether improvement of psychological flexibility during the intervention (baseline to post-treatment) was a mediator for mental health at post-treatment. Step 1 in Table 2 shows that, with control for mental health and psychological flexibility at baseline, the ACT and mindfulness group showed a stronger increase in mental health at posttreatment than did the waiting list group. Step 2 in Table 2 shows that both psychological flexibility at baseline and the improvement of psychological flexibility during the intervention significantly predicted mental health at post-treatment. The treatment effect becomes nonsignificant. Mediation analysis showed that the mediating effect of improvement of psychological flexibility from baseline to post-treatment was significant ( $p$ $<.05$ ), with bootstrapping values between 0.078 and 0.399 (Preacher \& Hayes, 2008). 
We then analyzed whether improvement of psychological flexibility during the intervention (baseline to post-treatment) and after the intervention (post-treatment to follow-up) were mediators of mental health at follow-up. Step 1 in Table 3 shows that the ACT and mindfulness group reported better mental health at follow-up than did the waiting list group. Step 2 in Table 3 shows that baseline psychological flexibility and the improvement of psychological flexibility during and after the intervention predicted a better mental health at follow-up. The treatment effect was no longer significant. The mediation analysis showed that the mediating effect of the change of psychological flexibility during the intervention was significant $(p<.05$; bootstrapping values were between 0.077 and 0.457). However, the change in psychological flexibility after the intervention was not a significant mediator (bootstrapping values between -0.039 and 0.163) (Preacher \& Hayes, 2008).

Table 1. Means and Standard Errors in the Imputed Data Set for Mental Health (MHC-SF) and Psychological Flexibility (AAQ-II) (Baseline to Follow-up) and Results of Regression Analysis and Cohen's d for Treatment Effects, Taking Clustering Into Account

\begin{tabular}{|c|c|c|c|c|c|c|c|}
\hline \multirow[t]{2}{*}{ Measures } & \multicolumn{2}{|c|}{$\begin{array}{l}\text { Intervention } \\
(n=49)\end{array}$} & \multicolumn{2}{|c|}{$\begin{array}{l}\text { Waiting list } \\
(n=44)\end{array}$} & \multirow[b]{2}{*}{$B$} & \multirow[b]{2}{*}{$S E$} & \multirow[b]{2}{*}{$d$} \\
\hline & $M$ & SE & $M$ & SE & & & \\
\hline Mental health baseline & 3.24 & .11 & 3.06 & .11 & & & \\
\hline Mental health post-treatment & 3.75 & .14 & 3.23 & .14 & $.39 *$ & .15 & .56 \\
\hline Mental health follow-up & 3.83 & .16 & 3.20 & .11 & $.49 * *$ & .12 & .85 \\
\hline Emotional well-being baseline & 3.48 & .11 & 3.23 & .12 & & & \\
\hline Emotional well-being post-treatment & 4.11 & .08 & 3.52 & .18 & $.42 *$ & .17 & .49 \\
\hline Emotional well-being follow-up & 4.20 & .09 & 3.60 & .06 & $.45^{*}$ & .16 & .42 \\
\hline Social well-being baseline & 2.94 & .15 & 2.72 & .07 & & & \\
\hline Social well-being post-treatment & 3.26 & .17 & 2.82 & .14 & .28 & .16 & .49 \\
\hline Social well-being follow-up & 3.42 & .22 & 2.90 & .12 & .35 & .14 & .67 \\
\hline Psychological well-being baseline & 3.38 & .10 & 3.25 & .16 & & & \\
\hline Psychological well-being post-treatment & 3.98 & .17 & 3.42 & .16 & $.48^{*}$ & .16 & .53 \\
\hline Psychological well-being follow-up & 3.98 & .17 & 3.24 & .18 & $.65^{* *}$ & .13 & .64 \\
\hline Psychological flexibility baseline & 36.83 & 1.35 & 36.68 & .74 & & & \\
\hline Psychological flexibility post-treatment & 42.98 & 1.31 & 37.87 & 1.52 & 5.04 & 2.10 & .51 \\
\hline Psychological flexibility follow-up & 44.66 & 1.47 & 38.39 & 1.30 & $6.19 * *$ & 1.21 & .74 \\
\hline
\end{tabular}

Note. AAQ-II = Acceptance and Action Questionnaire-II, MHC-SF = Mental Health Continuum-Short Form Note. Regression analyses, taking clustering into account, were performed with the intervention versus control group and the baseline measurement as independent variables and the post-treatment or the follow-up as the dependent variables. B-values refer to the effect of group (intervention versus control); * $p<.05 ; * * p<.01$. 


\section{Analyses with observed data}

By way of sensitivity analysis, we examined whether the results using the intention-to-treat analysis were comparable to those using only the observed data. Figure 1 (at page 75) shows that we had complete data for 81 study participants at post-treatment and 77 at follow-up. The observed data analysis showed that the means and effect sizes for the different outcome measures were quite similar to those found with the imputed data set, which attests to the robustness of our findings. However, the new results were not always statistically significant, probably because of the reduced power associated with the smaller sample of participants with complete data.

Table 2. Hierarchical Regression Analysis in the Imputed Data Set of Mental Health at Post-treatment on Intervention, Baseline Mental Health, Baseline Psychological Flexibility, and Improvement of Psychological Flexibility between Baseline and Post-treatment

\begin{tabular}{|c|c|c|c|c|}
\hline Mental health (T1) & \multicolumn{2}{|c|}{ Step $1(B, S E)$} & \multicolumn{2}{|c|}{ Step $2(B, S E)$} \\
\hline $\begin{array}{l}\text { ACT \& mindfulness intervention } \\
\text { (Comp: waiting list group) }\end{array}$ & $.384 * *$ & .123 & .169 & .107 \\
\hline Baseline mental health (T0) & $.743 * * *$ & .066 & $.664 * * *$ & .060 \\
\hline Baseline psychological flexibility (T0) & -.002 & .007 & $.026 * * *$ & .007 \\
\hline Improvement in psychological flexibility (T1-T0) & & & $.046 * * *$ & .007 \\
\hline Explained variance (adjusted $\mathrm{R}^{2}$ ) & .607 & & $.733^{\mathrm{a}}$ & \\
\hline
\end{tabular}

Table 3. Hierarchical Regression Analysis in the Imputed Data Set of Mental Health at Follow-up on Intervention, Baseline Mental Health, Baseline Psychological Flexibility, and Improvement of Psychological Flexibility between Baseline and Post-treatment, and between Post-treatment and Follow-up

\begin{tabular}{lllll}
\hline Mental health (T2) & \multicolumn{2}{l}{ Step 1 (B, SE) } & \multicolumn{2}{l}{ Step 2 (B, SE) } \\
\hline ACT \& mindfulness intervention & $.489^{* *}$ & .127 & .213 & .110 \\
(Comp: waiting list group) & & & & \\
Baseline mental health (T0) & $.708^{* * *}$ & .073 & $.613^{* * *}$ & .060 \\
Baseline psychological flexibility (T0) & .008 & .007 & $.037^{* * *}$ & .007 \\
Improvement in psychological flexibility (T1-T0) & & & $.052^{* * *}$ & .008 \\
Improvement in psychological flexibility (T2-T1) & & & $.036^{* * *}$ & .009 \\
Explained variance (adjusted $\mathrm{R}^{2}$ ) & .608 & & $.746^{\mathrm{a}}$ & \\
\hline
\end{tabular}

Note. ACT $=$ Acceptance and Commitment Therapy; $* p<.05 ; * * p<.01 ; * * * p<.001 ;{ }^{\text {a }}$ Significant improvement in $\mathrm{R}^{2}$ Change $(p<.05)$. 


\section{Discussion}

In recent decades, the focus of public mental health has been on the prevention and treatment of mental illnesses. Fewer studies have focused on developing and testing interventions that primarily aim at enhancing positive mental health. In this study, we evaluated an intervention combining ACT with mindfulness. Both methods focus on enhancing a positive, meaningful, and engaged life rather than on the control and elimination of mental illness (Hayes et al., 2006; Baer, 2003; Sin \& Lyubomirsky, 2009). The intervention "Living to the full" was offered as a group intervention for people with mild to moderate psychological distress. The mental health at baseline was considerably lower than that in a study of the general Dutch population, indicating that there was room for improvement by the participants (Lamers et al., 2010). Indeed, the intervention had a significant effect on positive mental health that was sustained at follow-up. The medium effect size was similar to those found in a meta-analysis of the effect of positive psychology interventions on emotional or psychological well-being (Sin \& Lyubomirsky, 2009).

In line with the traditional perspective on mental health as the absence of mental illness, most previous studies have assessed the effects of ACT and mindfulness interventions on the reduction of psychological complaints. Our study extends previous research showing that interventions based on ACT or mindfulness also promote emotional well-being (Forman et al., 2007; Lappalainen et al., 2007; Dalrymple \& Herbert, 2007; Dahl et al., 2004). We found that both emotional and psychological well-being improved: after the intervention and at follow-up participants reported not only feeling greater happiness and satisfaction but also having a more fulfilling and meaningful life than did the control group. The finding of no effect on social well-being may be explained by the fact that societal functioning was not a major topic in the intervention. Such differential findings for emotional and psychological well-being compared with social well-being make clear that interventions promoting mental health will profit from explaining carefully which aspects of mental health are being targeted.

Mental health promotion involves the transformation of a risk model to a competence enhancement model (Barry \& Jenkins, 2007). The competence targeted in "Living to the full" is psychological flexibility. Our study corroborates previous studies that have shown that psychological flexibility can be substantially improved by ACT or mindfulness, or both (Roemer et al., 2008; Forman et al., 2007; Lappalainen et al., 2007; Dalrymple \& Herbert, 2007; Dahl et al., 2004). The effects were significant only at followup, suggesting that it takes time to develop such skills. Nevertheless, our study is the first to our knowledge to show that improvement in psychological flexibility during the treatment mediated the effects of the intervention on positive mental health after the intervention and at 3-months follow-up. Our study thereby provides the first evidence that mental health can be promoted by stimulating skills for acceptance and value-based action.

Several limitations of the present study need to be addressed. First, the number of participants, especially the number of male participants, was rather small. Nevertheless, our 
study size would rank among the top third of the 51 studies included in a recent metaanalysis on positive psychology interventions (Sin \& Lyubomirsky, 2009). Second, the use of a waiting list control group was suboptimal because there is no control for the possible influence of non-specific factors. Third, the follow-up period was relatively short, so it is not known whether the effects were maintained in the longer run. Last, we did not address the important question of whether the improvement in mental health was independent from a possible decline in mental illness.

Our findings provide support for the effectiveness of an ACT and mindfulness intervention in promoting emotional and psychological well-being by targeting the competence of psychological flexibility. At this moment the intervention is implemented in almost $50 \%$ of the mental health institutions in the Netherlands. This reveals not only the need for having an intervention that is aimed at increasing positive competences, but also the ease of its implementation. An important question from a public health perspective is how the scope of such interventions can be broadened. First, the intervention can be adapted to populations in other settings, such as at work, in schools, or in medical care facilities. Two studies have already shown that a short ACT intervention added to usual medical care had a positive effect on patients with chronic illnesses such as type 2 diabetes and epilepsy (Lundgren, Dahl, Melin, Kies, 2006; Gregg, Callaghan, Hayes, \& GlennLawson, 2007). Furthermore, the intervention could be offered on a larger scale as a selfhelp or online program. Guided self-help in a written format has been shown to be as effective as face-to-face therapy for mental illnesses (Hirai \& Clum, 2006; Gellatly et al., 2007). Internet-based interventions can probably reach other populations who cannot be reached by traditional treatments (Cuijpers \& Schuurman, 2007) and such interventions can be cost-effective (Smit et al., 2006). Most important, however, is that focusing on positive mental health appears to be attractive to the general public. 


\section{Acknowledgments}

The study was funded by the Innovation Fund Health Insurers (in Dutch, "Innovatiefonds Zorgverzekeraars"). The study has been registered in the Nederlands Trial Register, the Dutch primary register for clinical trials (NTR1296).

\section{Human participant protection}

Ethical principles in the country where the study was conducted (the Netherlands) were followed. The study was approved by the Medical-Ethical Review Board for Mental Health Care Institutes (METIGG; number 8203), which is recognized by the Central Committee for Research involving human participants. Its activities fall under the Dutch law (Wet Medisch-wetenschappelijk Onderzoek met Mensen). 


\section{References}

Barry, M., \& Jenkins, R. (2007). Implementing Mental Health Promotion. Oxford, England: Elsevier.

Baer, R.A. (2003). Mindfulness training as a clinical intervention: a conceptual and empirical review. Clinical Psychology: Science and Practice, 10, 125-143.

Biglan, A., Hayes, S.C., Pistorello, J. (2008). Acceptance and commitment: implications for prevention science. Prevention Science, 9, 139-152.

Bond, F. W., \& Bunce, D. (2003). The role of acceptance and job control in mental health, job atisfaction, and work performance. Journal Applied Psychology, 88, 1057-1067.

Bond, F. W., Hayes, S. C., Baer, R. A., Carpenter, K. C., Guenole, N., Orcutt, H. K., Waltz, T., \& Zettle, R. D. (2011). Preliminary psychometric properties of the Acceptance and Action Questionnaire-II: a revised measure of psychological flexibility and acceptance. Behavior Therapy, 42, 676- 688.

Butler, J., \& Ciarrochi, J. (2007). Psychological acceptance and quality of life in the elderly. Quality of Life Research, 16, 607-615.

Chawla, N., \& Ostafin, B. (2007). Experiential avoidance as a functional dimensional approach to psychopathology: an empirical review. Journal of Clinical Psychology, $63,871-890$

Chida, Y., \& Steptoe, A. (2008). Positive psychological well-being and mortality: a quantitative review of prospective observational studies. Psychosomatic Medicine, 70, 741-756.

Cowen, E. L. (2000). Prevention, wellness enhancement, Y2K and thereafter. The Journal of Primary Prevention, 21, 15-19.

Cohen, J.A.. (1992). Power primer. Psychological Bulletin, 112, 155-159.

Cuijpers, P., \& Schuurmans, J. (2007). Self-help interventions for anxiety disorders: an overview. Current Psychiatry Reports, 9, 284-290.

Diagnostic and Statistical Manual of Mental Disorders, Fourth Edition Text Revised. Washington, DC: American Psychiatric Association; 2000.

Dalrymple, K. L., \& Herbert, J. D. (2007). Acceptance and Commitment Therapy of generalized social anxiety disorder: a pilot study. Behavior Modification, 31, 543568.

Dahl, J., Wilson, K. G., \& Nilsson, A. (2004). Acceptance and commitment therapy and the treatment of persons at risk for long-term disability resulting from stress and pain symptoms: a preliminary randomized trial. Behavior Therapy, 35, 785-801.

Dempster, A. P., Laird, N. M., \& Rubin, D. B. (1977). Maximum likelihood from incomplete data via the EM algorithm. Journal of the Royal Statistical Society Series B Methodological, 39, 1-38.

Fledderus, M., Bohlmeijer, E. T., Smit, F., \& Westerhof, G. J. (2010). Mental health promotion as a new goal in public mental health care. A randomized controlled trial 
of an intervention enhancing psychological flexibility. American Journal of Public Health, 100, 2372-2378.

Forman, E. M., Herbert, J. D., Moitra, E., Yeomans, P. D., \& Geller, P. A. (2007). Randomized controlled effectiveness trial of acceptance and commitment therapy and cognitive therapy for anxiety and depression. Behavior Modification, 31, 772799.

Gellatly, J., Bower, P., Hennessy, S., Richards, D., Gilbody, S., \& Lovell, K. (2007). What makes self-help interventions effective in the management of depressive symptoms? Meta-analysis and meta-regression. Psychological Medicine, 37, 1217-1228.

Greenspoon, P. J, \& Saklofske, D. H. (2001). Toward an integration of subjective wellbeing and psychopathology. Social Indicator Research, 54, 81-108.

Gregg, J. A., Callaghan, G. M., Hayes, S. C., \& Glenn-Lawson, J. L. (2007). Improving diabetes self-management through acceptance, mindfulness, and values: a randomized controlled trial. Journal of Consulting and Clinical Psychology, 75, 336-343.

Grossman, P., Tiefenthaler-Gilmer, U., Raysz, A., \& Kesper, U. (2007). Mindfulness training as an intervention for fibromyalgia: evidence of postintervention and 3 -year follow-up benefits in well-being. Psychotherapy and Psychosomatics, 76, 226-233.

Herrman, H. S., Saxena, S., Moodie, R., eds. Promoting mental health: concepts, emerging evidence, practice. Geneva, Switzerland: World Health Organization; 2005. Available at: www.who.int/mental_health/evidence/ MH_Promotion_Book.pdf. Accessed January 22, 2010.

Hayes, S. C., Luoma, J. B., Bond, F. W., Masuda, A., Lillis, J. (2006). Acceptance and commitment therapy. Model, processes and outcomes. Behaviour Research and Therapy, 44, 1-25.

Hayes, S. C., Strosahl, K., \& Wilson, K. G. (1999). Acceptance and Commitment Therapy: An Experiential Approach to Behavior Change. New York, NY: Guilford.

Hirai, M., \& Clum, G .A. (2006). Meta-analytic study of self-help interventions for anxiety problems. Behavior Therapy, 37, 99-111.

Hofmann, S. G., Sawyer, A. T., Witt, A. A., \& Oh, D. (2010). The effect of mindfulnessbased therapy on anxiety and depression: a meta-analytic review. Journal of Consulting and Clinical Psychology, 78, 169-183.

Jané-Llopis, E., Barry, M. M. (2005). What makes mental health promotion effective? Promotion \& Education, 12, 47-54.

Jacobs, N., Kleen, M., de Groot, F., A-Tjak, J. (2008). Het meten van experiëntiéle vermijding. De Nederlandstalige versie van de Acceptance and Action Questionnaire-II (AAQ-II ) [Measuring experiential avoidance. Dutch translation of the Acceptance and Action questionnaire-II (AAQ-II)]. Gedragstherapie, 41, 349361 .

Kashdan, T. B., Barrios, V., Forsyth, J. P., \& Steger, M. F. (2006). Experiential avoidance as a generalized psychological vulnerability: Comparisons with coping and emotion 
regulation strategies. Behaviour Research and Therapy, 44, 1301-1320.

Kabat-Zinn, J. (1990). Full Catastrophe Living, Using the Wisdom of Your Body and Mind to Face Stress, Pain, and Illness. Delacorte: New York.

Kabat-Zinn, J. (1994). Wherever You Go, There You Are, Mindfulness Meditation in Everyday Life. Hyperion: New York.

Keyes, C. L. M. (2002). The mental health continuum: from languishing to flourishing in life. Journal of Health Social Behavior, 43, 207-222.

Keyes, C. L. M. (2004). The nexus of cardiovascular disease and depression revisited: the complete mental health perspective and the moderating role of age and gender. Aging and Mental Health, 8, 266-274.

Keyes, C. L. M. (2006). Mental health in adolescence: is America's youth flourishing? American Journal of Orthopsychiatry, 76, 395-402.

Keyes, C. L. M. (2005). Mental illness and/or mental health ? Investigating axioms of the complete state model of health. Journal of Consulting and Clinical Psychology, 73, 539-548.

Lamers, S. M. A., Westerhof, G. J., Bohlmeijer, E. T., ten Klooster, P. M., \& Keyes, C. L. M. (2010). Evaluating the psychometric properties of the Mental Health ContinuumShort Form (MHC-SF). Journal of Clinical Psychology, 67, 99-110.

Lundgren, T., Dahl, J., Melin, L., \& Kies, B. (2006). Evaluation of acceptance and commitment therapy for drug refractory epilepsy: a randomized controlled trial in South Africa - a pilot study. Epilepsia, 47, 173-179.

Lappalainen, R., Lehtonen, T., Skarp, E., Taubert, E., Ojanen, M., Hayes, S.C. (2007). Preliminary controlled effectiveness trial: the impact of CBT and ACT models using psychology trainee. Behavior Modification, 31, 488-511.

Maddux, J. E. (2009). Stopping the “madness'?: positive psychology and deconstructing the illness ideology and the DSM. In: Lopez SJ, Snyder CR, eds. Oxford Handbook of Positive Psychology. 2nd ed. New York, NY: Oxford University Press, 61-69.

Mrazek, P., Haggerty, R., eds. (1994). Reducing Risks for Mental Disorders: Frontiers for Preventive Intervention Research. Washington, DC: National Academy Press.

Preacher, K. J., \& Hayes, A. F. (2008). Asymptotic and resampling strategies for assessing and comparing indirect effects in multiple mediator models. Behavior Research Methods, 40, 879-891.

Roemer, L., Orsillo, S. M., \& Salters-Pedneault, K. (2008). Efficacy of an acceptance-based behavior therapy for generalized anxiety disorder: evaluation in a randomized controlled trial. Journal of Consulting and Clinical Psychology, 76, 1083-1089.

Sin, N. L., \& Lyubomirsky, S. (2009). Enhancing well-being and alleviating symptoms with positive psychology interventions: a practice-friendly meta-analysis. Journal of Clinical Psychology, 65, 467-487.

Sowden, A. J., Tilford, S., Delaney, F., Vogels, M., Gilbody, S., \& Sheldon, T. A. (1997). Mental health promotion in high risk groups. Quality in Health Care, 6, 219-225. 
Smit, F., Willemse, G., Koopmanschap, M., Onrust, S., Cuijpers, P., Beekman, A. (2006). Cost-effectiveness of preventing depression in primary care patients. Randomized trial. British Journal of Psychiatry, 188, 330-336.

Teasdale, J. D., Segal, Z. V., Williams, J. M. G., Ridgeway, V. A., Soulsby, J. M., \& Lau, M. A. (2000). Prevention of relapse/recurrence in major depression by mindfulnessbased cognitive therapy. Journal of Consulting and Clinical Psychology, 68, 615623.

Westerhof, G. J., \& Keyes, C. L. M. (2010). Mental illness and mental health: the two continua model across the lifespan. Journal of Adult Development, 17, 110-119.

Zautra, A. J., Davis, M. C., \& Reich, J. W., Nicassario, P., Tennen, H., Finan, P., ...Irwin, M.R. (2008). Comparison of cognitive behavioral and mindfulness meditation interventions on adaptation to rheumatoid arthritis for patients with and without history of recurrent depression. Journal of Consulting and Clinical Psychology, 76, 408-421. 
104 Chapter 5 


\section{Acceptance and Commitment Therapy as guided self-help for psychological distress and positive mental health: a randomized controlled trial}

Fledderus, M., Bohlmeijer, E. T., Pieterse, M. E., \& Schreurs, K. M. G. (2012). Acceptance and Commitment Therapy as Guided Self-help for Psychological Distress and Positive Mental Health: A Randomized Controlled Trial. Psychological Medicine, 42, 485-496. 


\section{Abstract}

Background. In order to reduce the high prevalence of depression, early interventions for people at risk of depression are warranted. This study evaluated the effectiveness of an early guided self-help programme based on acceptance and commitment therapy (ACT) for reducing depressive symptomatology.

Method. Participants with mild to moderate depressive symptomatology were recruited from the general population and randomized to the self-help programme with extensive email support $(n=125)$, the self-help programme with minimal email support $(n=125)$ or to a waiting list control group $(n=126)$. Participants completed measures before and after the intervention to assess depression, anxiety, fatigue, experiential avoidance, positive mental health and mindfulness. Participants in the experimental conditions also completed these measures at a 3-month follow-up.

Results. In the experimental conditions significant reductions in depression, anxiety, fatigue, experiential avoidance and improvements in positive mental health and mindfulness were found, compared with the waiting list condition (effect sizes Cohen's $d=$ 0.51-1.00). These effects were sustained at the 3-month follow-up. There were no significant differences between the experimental conditions on the outcome measures.

Conclusions. The ACT-based self-help programme with minimal email support is effective for people with mild to moderate depressive symptomatology. 


\section{Introduction}

In order to reduce the high prevalence of depression, early interventions for people at risk are warranted (Andrews et al., 2004; Cuijpers et al., 2008). Although such interventions are available and effective in reducing depressive symptoms and preventing the onset of depression, only a small proportion of people participate. Possible ways to increase the participation rate is to reduce the stigma associated with mental illnesses and to focus the intervention on depression as well as on other mental illnesses (Cuijpers et al., 2010). Early interventions should meet the following criteria: implementation within a positive framework to avoid the stigma associated with depression; targeting generic risk factors for multiple mental illnesses; and promoting positive mental health as well as reducing psychological distress, because a sound mental health prevents the onset of clinical disorders (Keyes et al., 2010; Wood \& Joseph, 2010). In this study an early intervention, based on acceptance and commitment therapy (ACT) and meeting these criteria, was offered to adults with mild to moderate depressive symptomatology as a guided self-help programme consisting of a manual "Living to the full" (a positive frame) and email support by a counsellor. The intervention targets both experiential avoidance (EA) that can be considered a generic risk factor for mental illnesses (Biglan et al., 2008) and positive mental health. A group format of this intervention has shown promising effects (Fledderus et al., 2010; Bohlmeijer et al., 2011a). In this study two different levels of email support by a counsellor were explored (minimal and extensive) to assess optimal treatment intensity. We hypothesized that both ACT interventions would show superior effects in reducing depressive symptoms and other mental distress (anxiety, fatigue) and in increasing positive mental health when compared with a waiting list. Furthermore, we expected positive effects in the process measures EA and mindfulness.

\section{Method}

\section{Participants}

In September 2009, participants were recruited through advertisements in Dutch newspapers. Inclusion criteria were an age of 18 years or older and mild to moderate depressive symptoms [ $>10$ and $<39$ on the Center of Epidemiological Studies-depression scale (CES-D); Radloff, 1977] and anxiety symptoms [> 3 and $<15$ on the Hospital Anxiety and Depression Scale-Anxiety subscale (HADS-A); Zigmond \& Snaith, 1983]. People with severe depressive symptomatology and/or anxiety (more than 1 standard deviation above the population mean on the CES-D (cut-off score $\geq 39$; Bouma et al., 1995) and/ or HADS-A (cut-off score $\geq 15$; Olssøn et al., 2005) were excluded, because severe distress would require more intensive individual diagnostics and treatment. For the remaining participants it was checked who were still responding positively to a screener for 
a depressive disorder [Web Screening Questionnaire (WSQ; Donker et al., 2009) Q1 = 6 and Q2 = 1]. As the WSQ yields a high number of false positives (Donker et al., 2009), those who were screened as having a depressive disorder underwent a telephone interview that employed the depressive episode module of the Mini International Neuropsychiatric Interview (MINI; Sheehan et al., 1998). People whom the MINI diagnosed as having a severe depressive episode were excluded. Other exclusion criteria were: (a) few depressive symptoms ( $\leq 10$ on the CES-D) and/or anxiety ( $\leq 3$ on the HADS-A); (b) receiving psychological or psychopharmacological treatment within the last 3 months; and (c) high suicide risk (Q15 = 3 on the WSQ).

\section{Procedure}

A total of 625 people responded to the advertisements and received an information sheet explaining the study and an informed consent form. This was signed by 507 people who then received a screening questionnaire comprising the CES-D, HADS-A and WSQ. First, 54 respondents were excluded because they had severe depression and/or anxiety according to their scores on CES-D and HADS-A. They were advised to contact their general practitioner. Second, 44 respondents were diagnosed by the WSQ as having a depressive disorder and subsequently underwent a telephone interview using the MINI. These interviews were conducted by Masters students of psychology who were being trained and supervised by a clinical psychologist (K.M.G.S.). Of the 43 respondents (one respondent could not be contacted), two were diagnosed with a severe depressive episode and were excluded and advised to contact their general practitioner. A further 75 respondents were excluded because they had few depression and/or anxiety symptoms $(n=58)$, did not complete the screening questionnaire $(n=15)$, could not be contacted for the interview $(n=$ $1)$ or currently received psychological treatment $(n=1)$. Hence a total of 376 participants were randomly assigned to the following three conditions: the ACT intervention with minimal email support (ACT-M; $n=125$ ), the same intervention with extensive email support (ACT-E; $n=125$ ) or to a waiting list (W-L; $n=126$ ). A block randomization was carried out for the three groups with stratification on gender and age $(<50$ and $\geq 50$ years), using computer-generated random sequences of numbers.

Table 1 shows an overview of the participants' characteristics. Their mean age was 42 years (range 18-73 years). The majority was female (70\%) and of Dutch origin (93\%). Most of the participants had a high level of education (86\%), a paid job (76\%) and were not married $(47 \%)$. 
Table 1. Characteristics of Participants

\begin{tabular}{|c|c|c|c|}
\hline Characteristic & $\begin{array}{l}\text { ACT-E } \\
(n=125)\end{array}$ & $\begin{array}{l}\text { ACT-M } \\
(n=125)\end{array}$ & $\begin{array}{l}\text { Waiting list } \\
(n=126)\end{array}$ \\
\hline \multicolumn{4}{|l|}{ Gender } \\
\hline Female & 87 & 87 & 88 \\
\hline Male & 38 & 38 & 38 \\
\hline Age (M, SD) & $42.64(10.96)$ & 42.35 (11.09) & 42.47 (11.29) \\
\hline \multicolumn{4}{|l|}{ Marital status } \\
\hline Married & 58 & 49 & 57 \\
\hline Divorced & 8 & 14 & 10 \\
\hline Widowed & 4 & 0 & 0 \\
\hline Unmarried & 54 & 62 & 59 \\
\hline \multicolumn{4}{|l|}{ Race } \\
\hline Dutch & 114 & 119 & 116 \\
\hline Other & 11 & 6 & 10 \\
\hline \multicolumn{4}{|l|}{ Education } \\
\hline High & 112 & 101 & 112 \\
\hline Middle & 12 & 20 & 13 \\
\hline Low & 1 & 4 & 1 \\
\hline \multicolumn{4}{|l|}{ Daily activities } \\
\hline Paid job & 91 & 94 & 100 \\
\hline No job & 33 & 31 & 26 \\
\hline
\end{tabular}

\section{Power analysis}

A sample size of 100 participants per condition at post-intervention was needed to detect an effect size of 0.40 (Cohen's $d$ ) for the primary outcome with a statistical power of $(1-\beta)=0.80$ in a two-tailed test $(p<0.05)$. Taking into account a drop-out rate of $20 \%$, we needed to recruit 375 people.

\section{Measures}

All participants completed measures on two occasions: at baseline (T0) and at postintervention at 9 weeks (T1; directly after the intervention). Those assigned to the experimental conditions completed a third measure at the 3-month follow-up (T2; 5 months after baseline). The $\mathrm{W}-\mathrm{L}$ group received the intervention after the waiting list period of 9 weeks. All questionnaires were administered online. The primary outcome measure was the level of depressive symptomatology as measured with the CES-D (20 items, score 0-60). Higher scores mean more depressive symptoms (Radloff, 1997; Haringsma et al., 2004).

Secondary outcome measures were anxiety, fatigue and a positive mental health. Anxiety was measured with the HADS-A (seven items, score 0-21) for assessing the presence and severity of anxious symptoms. Higher scores mean more anxiety symptoms (Spinhoven et al., 1997; Zigmond \& Snaith, 2003). The subjective fatigue subscale of the Checklist Individual Strength was used to assess the severity of fatigue (eight items, score 8-56). A high score indicates severe fatigue (Vercoulen et al., 1999). Positive mental health was assessed with the Mental Health Continuum short form that measures emotional well- 
being (three items), social well-being (five items) and psychological well-being (six items). Participants were asked to rate how often they had experienced feelings of well-being in the past month on a scale ranging from 1 (never) to 6 (daily). A mean score across the individual items was computed for each component of well-being. Higher scores indicate greater emotional, social and psychological well-being (Keyes, 2005; Lamers et al., 2010).

Process measures included assessments of EA and mindfulness. The Acceptance and Action Questionnaire-II was used to measure the ability to accept aversive internal experiences and to pursue values in the presence of these experiences (10 items, score 1070). Higher scores indicated lower levels of EA (Jacobs et al., 2008; Bond et al., 2011). The Five Facet Mindfulness Questionnaire (FFMQ) was used to measure five facets of mindfulness: observing (eight items), describing (eight items), acting with awareness (eight items), non-judging (eight items) and non-reactivity (seven items) (all scores range from 840, except non-reactivity facet range from 7 to 35). Higher scores indicate more mindfulness (Baer et al., 2006; Bohlmeijer et al., 2011b). All outcome measures showed good psychometric properties.

To evaluate the satisfaction of the participants after the intervention, the Client Satisfaction Questionnaire (CSQ-8) was used which consists of eight items on a scale from 1 (very negative) to 4 (very positive). A mean score across individual items was computed (Attkisson \& Zwick, 1982; De Brey, 1983). Also a question was included on how the participants evaluated the programme on a scale from 1 to 10 .

\section{Counsellors}

The email support was provided by five psychology Masters students of the University of Twente. They received a 2-day workshop from a clinical psychologist with ample experience in ACT. The student counsellors studied the self-help manual and performed all the exercises included in the manual. In the workshop they learned the processes of ACT and practised writing emails in the role of both client and counsellor. Each student provided 25 participants with minimal email support and 25 participants with extensive email support during a period of 9 weeks. The emails were supervised by a clinical psychologist. On average the counsellor spent 9 min on the extensive email support and 3 min on the minimal email support.

\section{Intervention and email support}

Participants of the experimental conditions received the self-help book 'Living to the full' (Bohlmeijer \& Hulsbergen, 2008) by regular mail. The book comprises nine modules, divided into three parts. The participants were instructed to complete one module per week. The modules are based on six core processes of ACT that together promote psychological flexibility: acceptance (active and aware embracement of aversive internal experiences), cognitive defusion (creating a context in which undesirable functions of thoughts disappear), contact with the present moment, self as context (experiencing that one is more 
than one's thoughts, feelings and experiences), choosing values in different life domains, and commitment to choices on the basis of these values (Hayes et al., 2006).

In the first part of the book, participants reflect on their avoidance and control strategies and whether these are effective in the long run. In the second part, participants learn how to come into contact with their present experiences without trying to avoid or control them. Cognitive defusion and experiencing self as context are practised. In the third part, the focus is on becoming aware of the most important personal values and making decisions based on these values. Each module uses experiential exercises and metaphors for illustrating the processes of ACT. Furthermore, the participants were asked to do daily mindfulness exercises, based on mindfulness-based stress reduction (Kabat-Zinn, 1990, 1994). The mindfulness exercises lasted on average 1-15 $\mathrm{min}$ and were on an audio compact disc which was provided with the book.

Both experimental conditions received the same frequency of email support. The participants received a standardized email from the counsellors every week on the same day concerning the module that they had carried out in the previous week. Participants were expected to respond within 2 days, after which they received a feedback email from the counsellor. In the minimal email support the standardized email comprised questions on their progress (e.g. did you perform all the exercises?), which was met with positive and encouraging feedback from the counsellor. In the extensive email support the standardized email also comprised questions on what they had discovered or experienced in the previous week (e.g. what did you experience when you performed the exercises?). Furthermore, participants were allowed to ask a question on the text or exercises. The counsellor responded both to the question and to the experiences of the participants and offered advice and instruction with regard to the text and exercises.

Participants assigned to the W-L group received the self-help book by regular mail after the post-intervention assessment. Email counselling was not provided.

\section{Statistical analyses}

The statistical analyses were done using PASW 18 (Predictive Analytics Software; IBM, USA). One-way analysis of variance (ANOVA) and $\chi^{2}$ tests showed that there were no significant differences at baseline between the experimental conditions and the W-L group for any of the demographic variables or outcome measures, indicating successful randomization. Intention-to-treat analyses were conducted with the use of PASW Missing Value Analysis (SPSS Inc., USA) to impute all missing data on the continuous measures with the expectation-maximization method. This method computes missing values based on maximum likelihood estimates using observed data in an iterative process (Dempster et al., 1977). The total percentage of missing data was $7.9 \%$ due to unanswered items $(0.7 \%)$ or incomplete assessments (7.2\%). These missing values at baseline, post-intervention and follow-up were imputed. A comparison of results based on the imputed intention-to-treat sample versus the observed data revealed similar outcomes. Therefore, only the results 
from the intention-to-treat analyses are reported. Comparisons were two-tailed and interpreted with a significance of $p<.05$.

To examine differences between the conditions on all the outcome measures, a 3 (group) $x$ (time) ANOVA was used. In the case of significant timer group interactions, the post hoc test Tukey's honestly significant difference (HSD) test was used. To examine the change from post-intervention to follow-up in the experimental conditions, paired tests and a 2 (group) x 2 (time) ANOVA were used.

To identify whether gender, educational level (high v. low), the level of depression, anxiety and EA at baseline moderated the effect of the intervention on the change of depressive symptomatology from baseline to post-intervention, regression analyses were used. The medians on the scores on depression, anxiety and EA at baseline were used as cut-off scores for recoding them as dichotomous variables. In a linear regression model the intervention dummy variable (experimental conditions $=1 \mathrm{v}$. W-L= 0 ), interaction term with the potential moderator as a dichotomous variable and their main effects were entered.

Effect sizes at post-intervention were calculated with Cohen's d using the means and the pooled standard deviations of the measurements of the conditions (effect size of 0.56-1.2 was considered large, 0.33-0.55 as moderate, and less than 0.33 as small) (Lipsey et al., 1993).

With the Jacobson and Truax methodology, the proportion of participants was determined who made a clinically significant change on the CES-D from baseline to posttreatment (Jacobson \& Traux, 1991). First, the reliable change was calculated with the reliable change index (a reduction of $\geq 12$ points). Second, because we studied a population with mild to moderate depressive symptomatology and people with mild to moderate depressive disorders, the scores below one standard deviation of the mean pre-test scores on the CES-D were considered the recovery criterion (a score $\leq 16$ ). The score of 16 also has been found in previous research as the cut-off score to indicate the presence of clinically relevant depressive symptoms (Beekman et al., 1997; Smit et al., 2006). A clinically significant change on the CES-D is thus defined as having a reliable change (a reduction of at least 12 points) between the measurements and thereby crossing the cut-off of 16 . Participants that had a clinically relevant change were either coded 1 (implying favourable treatment response, 'success') or 0 ('failure'). The binary outcome was used to calculate the odds ratio (OR) using logistic regression. Based on the clinically significant change proportions, the number needed to treat (NNT) was calculated (Cook \& Sackett, 1995). 


\section{Results}

\section{Drop-out}

In Figure 1 the flow of participants is given. At post-intervention, data were available for 340 participants (drop-out rate 9.6\%) and at follow-up for 204 participants (drop-out rate $18.4 \%$ ). There were no significant differences at baseline on all the measures between participants who completed the assessments and those who did not.

\section{Intervention adherence and participants' satisfaction}

There were 22 participants $(17.6 \%)$ in the ACT-M group and $28(22.4 \%)$ in the ACT-E group that did not fully adhere to the intervention. The main reasons given for noncompletion were that the intervention was too time-consuming or too demanding. There were no significant differences between participants that adhered to the ACT-M and ACT-E intervention in the average number of weeks completed, number of emails sent, time spent weekly (in hours) on the self-help programme or the participant's satisfaction. They completed on average 7.1 weeks ( $n=188$, range 4-8 weeks) and sent on average 7.4 emails ( $n=200$, range 1-9 emails). The participants spent on average $4 \mathrm{~h}$ per week on the self-help programme. On the CSQ-8 participants evaluated the intervention with 3.2 (scale from 1 to 4) (S.D. $=0.44, n=188)$. On a scale from 1 to 10 the intervention was evaluated with a 7.7 (S.D. $=1.01, n=194)$.

\section{Outcome of the interventions}

Means and standard deviations for all the outcome measures as well as the results from the repeated-measures ANOVA are presented in Table 2. For all the outcome measures significant interactions were found $[\mathrm{F}(2,373)=18.96-38.92$, all $p<0.001]$. Post-hoc testing with the Tukey HSD test revealed that both the ACT-M and ACT-E participants were significantly improved from baseline to post-intervention compared with the W-L condition.

The two intervention conditions did not significantly differ on improvement from baseline to post-intervention on any of the outcome measures. In Table 3 the results of the effect sizes between the conditions at post-intervention are presented. On all the outcome measures, moderate to high effect sizes were found for the ACT-M and ACT-E groups compared with the W-L condition. 
Figure 1. Participant Flow

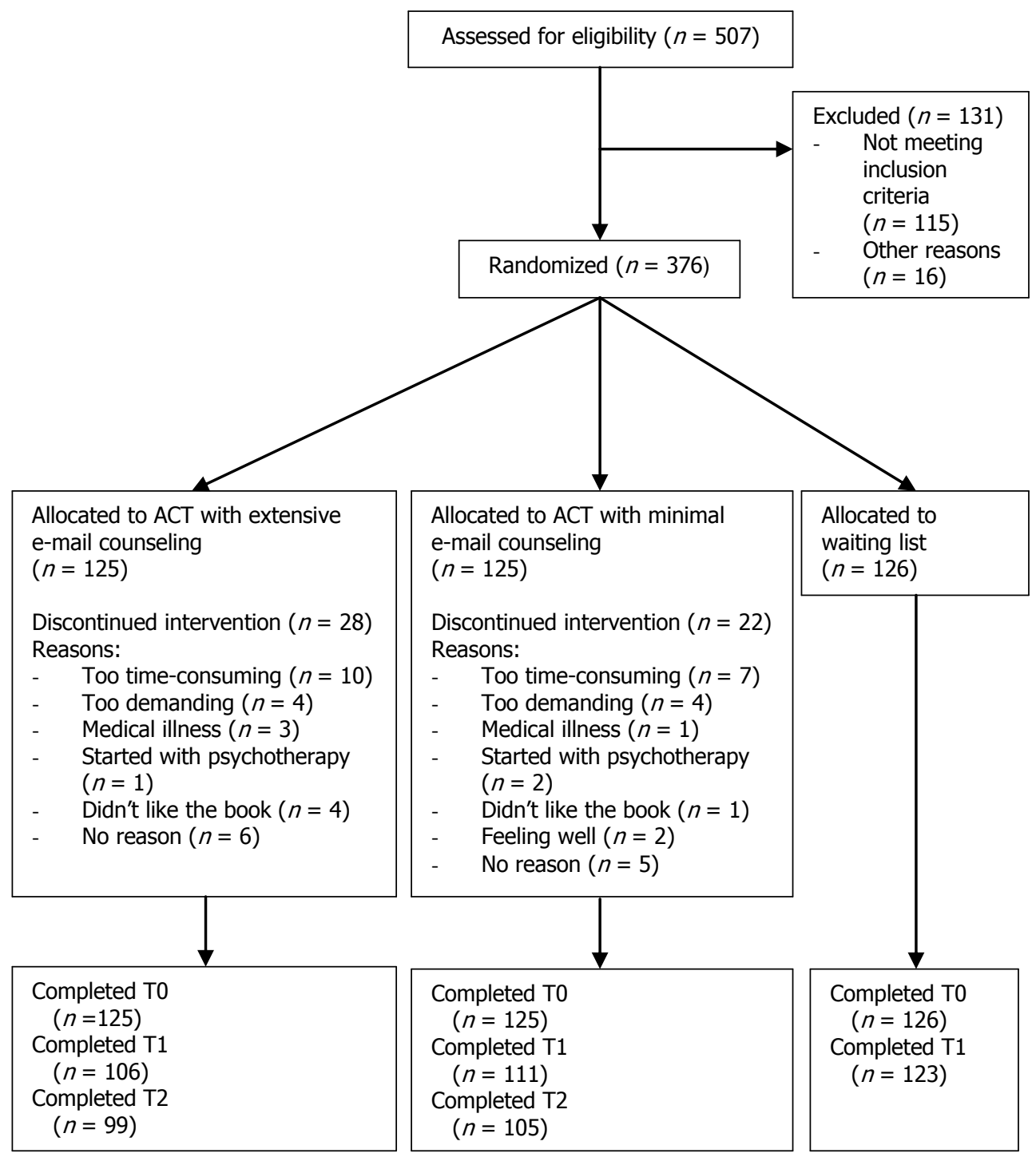




\section{Change from post-intervention to follow-up}

Both experimental groups showed maintenance of the effects on the primary and secondary measures from post-intervention to follow-up. Significant reductions in EA were found from post-intervention to follow-up in the ACT-E group $[t(124)=-2.64, p=.009]$ and in the ACT-M group $[t(124)=-4.14, p<.000]$. With regard to mindfulness, improvements were observed for the FFMQ-observe in the ACT-E group $[t(124)=-2.16, p=.033]$ and deteriorations in the FFMQ-describe in the ACT-M group $[t(124)=2.27, p=.025]$. Overall these findings suggest that on all measures the effects were maintained or improved at the 3-month follow-up, except for the mindfulness facet 'describe'. Repeated-measures ANOVA revealed no significant differences between ACT-E and ACT-M on the change in outcome measures from post-intervention to follow-up.

\section{Moderator analyses}

A significant interaction was found for the condition by the baseline level of depressive symptoms $(<23=0$ and $\geq 23=1)$ on the primary outcome $(\beta=-.175, p=.007)$. Participants with a higher level of depressive symptoms at baseline showed greater reduction in depression after completion of the intervention compared with the W-L group. Between-group effect size at post-intervention was higher for people with higher levels of depression at baseline (Cohen's $d$ CES-D $<23=0.71$, Cohen's $d$ CES-D $\geq 23=1.08$ ). No significant interactions were found for the condition by gender, level of education (high or low), the level of anxiety symptoms at baseline $(<10=0$ and $\geq 10=1)$ and the level of EA at baseline $(<40=0$ and $\geq 40=1)$.

\section{Clinically relevant change}

The proportion of participants that reached a clinically significant change on the CES-D in the ACT-E group was 42/125 (34\%) versus 7/126 (6\%) in the W-L group [OR 8.60, 95\% confidence interval (CI) 3.69-20.08, $p<.001$, NNT = 3.57]. In the ACT-M group, 49/125 (39\%) reached a clinically significant change, which also resulted in a significant difference compared with the W-L group (OR 10.96, 95\% CI 4.72-25.46, $p<.001$, NNT = 2.98). There were no significant differences between the experimental conditions on the proportions of clinically relevant change. 
Table 2. Mean Scores (SD) for all Outcome Measures and the Results from the Repeated Measures ANOVA

\begin{tabular}{|c|c|c|c|c|c|c|c|c|c|c|}
\hline \multirow[t]{2}{*}{ Outcome } & \multirow[t]{2}{*}{ Group } & \multicolumn{2}{|l|}{ Pre } & \multicolumn{2}{|l|}{ Post } & \multicolumn{2}{|c|}{ Follow-up } & \multirow[t]{2}{*}{ Time } & \multirow[t]{2}{*}{ Group } & \multirow{2}{*}{$\begin{array}{l}\text { Time } x \\
\text { Group }\end{array}$} \\
\hline & & $M$ & SD & $M$ & SD & $M$ & SD & & & \\
\hline \multicolumn{11}{|c|}{ Primary outcome } \\
\hline CES-D & ACT-E & 23.14 & 6.48 & 13.84 & 7.55 & 14.04 & 8.62 & $311.09 * * *$ & $11.50 * * *$ & $30.62 * * *$ \\
\hline & $\begin{array}{l}\text { ACT-M } \\
\text { WL }\end{array}$ & $\begin{array}{l}22.43 \\
22.45\end{array}$ & $\begin{array}{l}6.65 \\
6.68\end{array}$ & $\begin{array}{l}12.82 \\
19.76\end{array}$ & $\begin{array}{l}6.99 \\
8.48\end{array}$ & 13.38 & 7.78 & & & \\
\hline \multicolumn{11}{|c|}{ Secondary outcomes } \\
\hline HADS-A & $\begin{array}{l}\text { ACT-E } \\
\text { ACT-M } \\
\text { WL }\end{array}$ & $\begin{array}{l}9.36 \\
9.67 \\
9.33\end{array}$ & $\begin{array}{l}2.62 \\
2.53 \\
2.34\end{array}$ & $\begin{array}{l}6.22 \\
6.02 \\
8.69\end{array}$ & $\begin{array}{l}2.98 \\
2.96 \\
3.19\end{array}$ & $\begin{array}{l}5.92 \\
5.91\end{array}$ & $\begin{array}{l}3.22 \\
3.03\end{array}$ & $273.00 * * *$ & $10.60 * * *$ & $38.53 * * *$ \\
\hline CIS & $\begin{array}{l}\text { ACT-E } \\
A C T-M \\
W L\end{array}$ & $\begin{array}{l}36.90 \\
39.16 \\
38.24\end{array}$ & $\begin{array}{l}11.05 \\
9.80 \\
10.58\end{array}$ & $\begin{array}{l}28.58 \\
31.20 \\
37.36\end{array}$ & $\begin{array}{l}11.40 \\
11.85 \\
11.51\end{array}$ & $\begin{array}{l}28.84 \\
31.12\end{array}$ & $\begin{array}{l}12.77 \\
12.03\end{array}$ & $136.44 * * *$ & $8.06 * * *$ & $24.45 * * *$ \\
\hline $\begin{array}{l}\text { MHC-SF- } \\
\text { EM }\end{array}$ & $\begin{array}{l}\text { ACT-E } \\
\text { ACT-M }\end{array}$ & $\begin{array}{l}3.27 \\
3.42\end{array}$ & $\begin{array}{l}.92 \\
.89\end{array}$ & $\begin{array}{l}4.10 \\
4.26\end{array}$ & $\begin{array}{l}.87 \\
.82\end{array}$ & $\begin{array}{l}4.17 \\
4.21\end{array}$ & $\begin{array}{l}.84 \\
.92\end{array}$ & $193.27 * * *$ & $6.10 * *$ & $30.04 * *$ \\
\hline & WL & 3.43 & .90 & 3.56 & .94 & & & & & \\
\hline $\begin{array}{l}\text { MHC-SF- } \\
\text { SOC }\end{array}$ & $\begin{array}{l}\text { ACT-E } \\
\text { ACT-M } \\
\text { WL }\end{array}$ & $\begin{array}{l}2.79 \\
2.81 \\
2.78\end{array}$ & $\begin{array}{l}.84 \\
.88 \\
.81\end{array}$ & $\begin{array}{l}3.48 \\
3.46 \\
2.92\end{array}$ & $\begin{array}{l}.96 \\
.97 \\
.97\end{array}$ & $\begin{array}{l}3.51 \\
3.51\end{array}$ & $\begin{array}{l}.86 \\
1.00\end{array}$ & $151.52 * * *$ & $5.15^{* *}$ & $19.77 * * *$ \\
\hline $\begin{array}{l}\text { MHC-SF- } \\
\text { PSY }\end{array}$ & $\begin{array}{l}\text { ACT-E } \\
A C T-M \\
W L\end{array}$ & $\begin{array}{l}3.20 \\
3.27 \\
3.44\end{array}$ & $\begin{array}{l}.88 \\
.94 \\
.77\end{array}$ & $\begin{array}{l}4.04 \\
4.12 \\
3.56\end{array}$ & $\begin{array}{l}.89 \\
.93 \\
.99\end{array}$ & $\begin{array}{l}4.01 \\
4.09\end{array}$ & $\begin{array}{l}.92 \\
.94\end{array}$ & $207.03^{* * *}$ & 1.78 & $32.91 * * *$ \\
\hline $\begin{array}{l}\text { Process n } \\
\text { FFMQ- } \\
\text { Observe }\end{array}$ & $\begin{array}{l}\text { asures } \\
\text { ACT-E } \\
\text { ACT-M } \\
\text { WL }\end{array}$ & $\begin{array}{l}25.01 \\
25.25 \\
25.00\end{array}$ & $\begin{array}{l}5.24 \\
5.11 \\
5.16\end{array}$ & $\begin{array}{l}27.53 \\
27.76 \\
24.55\end{array}$ & $\begin{array}{l}4.72 \\
4.56 \\
5.99\end{array}$ & $\begin{array}{l}28.17 \\
27.64\end{array}$ & $\begin{array}{l}4.29 \\
4.92\end{array}$ & $59.15^{* * *}$ & $4.85^{* *}$ & $24.92^{* * *}$ \\
\hline $\begin{array}{l}\text { FFMQ- } \\
\text { Des- } \\
\text { cribe }\end{array}$ & $\begin{array}{l}\text { ACT-E } \\
\text { ACT-M } \\
W L\end{array}$ & $\begin{array}{l}25.74 \\
25.97 \\
25.37\end{array}$ & $\begin{array}{l}6.42 \\
6.00 \\
6.22\end{array}$ & $\begin{array}{l}28.77 \\
29.11 \\
25.71\end{array}$ & $\begin{array}{l}5.41 \\
5.72 \\
6.37\end{array}$ & $\begin{array}{l}29.02 \\
28.52\end{array}$ & $\begin{array}{l}5.21 \\
5.82\end{array}$ & $106.53^{* * *}$ & $4.57 * *$ & $18.96 * * *$ \\
\hline $\begin{array}{l}\text { FFMQ- } \\
\text { Act } \\
\text { Aware }\end{array}$ & $\begin{array}{l}\text { ACT-E } \\
A C T-M \\
W L\end{array}$ & $\begin{array}{l}21.40 \\
20.31 \\
21.02\end{array}$ & $\begin{array}{l}4.84 \\
5.24 \\
4.80\end{array}$ & $\begin{array}{l}25.30 \\
24.89 \\
21.30\end{array}$ & $\begin{array}{l}4.67 \\
5.08 \\
5.23\end{array}$ & $\begin{array}{l}25.70 \\
25.15\end{array}$ & $\begin{array}{l}5.25 \\
5.36\end{array}$ & $136.90 * * *$ & $8.20 * * *$ & $28.57 * * *$ \\
\hline $\begin{array}{l}\text { FFMQ- } \\
\text { Non } \\
\text { Judge }\end{array}$ & $\begin{array}{l}\text { ACT-E } \\
\text { ACT-M } \\
W L\end{array}$ & $\begin{array}{l}23.17 \\
22.76 \\
23.02\end{array}$ & $\begin{array}{l}5.27 \\
5.49 \\
5.38\end{array}$ & $\begin{array}{l}29.77 \\
29.40 \\
24.34\end{array}$ & $\begin{array}{l}5.47 \\
5.77 \\
6.48\end{array}$ & $\begin{array}{l}29.85 \\
29.58\end{array}$ & $\begin{array}{l}5.96 \\
5.83\end{array}$ & $292.40 * * *$ & $11.71^{* * *}$ & $38.92 * * *$ \\
\hline $\begin{array}{l}\text { FFMQ- } \\
\text { Non } \\
\text { React }\end{array}$ & $\begin{array}{l}\text { ACT-E } \\
\text { ACT-M } \\
W L\end{array}$ & $\begin{array}{l}19.39 \\
19.03 \\
19.17\end{array}$ & $\begin{array}{l}3.55 \\
3.88 \\
3.89\end{array}$ & $\begin{array}{l}23.36 \\
23.91 \\
19.80\end{array}$ & $\begin{array}{l}3.66 \\
3.70 \\
4.49\end{array}$ & $\begin{array}{l}23.64 \\
23.71\end{array}$ & $\begin{array}{l}3.90 \\
4.01\end{array}$ & $230.59 * * *$ & $14.34 * * *$ & $38.74 * * *$ \\
\hline AAQ-II & $\begin{array}{l}\text { ACT-E } \\
\text { ACT-M } \\
\text { WL }\end{array}$ & $\begin{array}{l}40.08 \\
41.34 \\
40.86\end{array}$ & $\begin{array}{l}7.93 \\
8.96 \\
8.83\end{array}$ & $\begin{array}{l}48.95 \\
49.64 \\
43.00\end{array}$ & $\begin{array}{l}8.55 \\
9.59 \\
10.27\end{array}$ & $\begin{array}{l}50.32 \\
51.42\end{array}$ & $\begin{array}{l}9.75 \\
9.71\end{array}$ & $234.13^{* * *}$ & $6.51^{* *}$ & $26.29 * * *$ \\
\hline
\end{tabular}


Note. ACT-E = Acceptance and Commitment Therapy with extensive e-mail support; ACT-M = Acceptance and Commitment Therapy with minimal e-mail support; CES-D = Center for Epidemiologic Studies Depression Scale; HADS-A = Hospital Anxiety and Depression Scale-Anxiety subscale; CIS = Checklist Individual Strength; MHC$\mathrm{SF}=$ Mental Health Continuum-Short Form; EM = emotional; SOC = social; PSY = psychological; FFMQ = Five Facet Mindfulness Questionnaire; AAQ-II = Acceptance and Action Questionnaire-II; $* * p<.01 ; * * * p<.00$.

Table 3. Effect Sizes (Cohen's $d$ ) between Conditions at Post-intervention

\begin{tabular}{lll}
\hline & ACT-E vs Waiting list & ACT-M vs Waiting list \\
\cline { 2 - 3 } $\begin{array}{l}\text { Primary outcome } \\
\text { CES-D }\end{array}$ & 0.74 & 0.89 \\
Secondary outcomes & & \\
HADS-A & 0.80 & 0.87 \\
CIS & 0.77 & 0.53 \\
MHC-SF-EM & 0.60 & 0.79 \\
MHC-SF-SOC & 0.62 & 0.56 \\
MHC-SF-PSY & 0.51 & 0.58 \\
Process measures & & \\
FFMQ-Observe & 0.55 & 0.60 \\
FFMQ-Describe & 0.52 & 0.56 \\
FFMQ-ActAware & 0.81 & 0.70 \\
FFMQ-NonJudge & 0.91 & 0.82 \\
FFMQ-NonReact & 0.87 & 1.00 \\
AAQ-II & 0.63 & 0.70 \\
\hline
\end{tabular}

Note. ACT-E = Acceptance and Commitment Therapy with extensive e-mail support; ACT-M = Acceptance and Commitment Therapy with minimal e-mail support; CES-D = Center for Epidemiologic Studies Depression Scale; HADS-A = Hospital Anxiety and Depression Scale-Anxiety subscale; CIS = Checklist Individual Strength; MHC$\mathrm{SF}=$ Mental Health Continuum-Short Form; EM = emotional; SOC = social; PSY = psychological; FFMQ = Five Facet Mindfulness Questionnaire; AAQ-II = Acceptance and Action Questionnaire-II.

\section{Medication use}

Of the participants, 10 in the intervention groups (ACT-E $=4$, ACT-M $=6$ ) and three in the control group reported at baseline to have started more than 3 months previously with a psychopharmacological treatment (and were thus not excluded from the study). During the intervention seven participants started with medication ( ACT-E $=2, \mathrm{ACT}-\mathrm{M}=2, \mathrm{~W}-\mathrm{L}=3$ ) and seven participants stopped (ACT-E $=1$, ACT-M $=5, \mathrm{~W}-\mathrm{L}=1$ ). Due to these small numbers and the equal distribution over the conditions, it is unlikely that the present findings can be explained by changes in medication use preceding or during the trial.

\section{Discussion}

\section{Effects on psychological distress and positive mental health}

Participants who received the guided ACT self-help intervention had significantly more reduction in depressive symptoms directly after the intervention compared with participants in the W-L group, and this reduction was sustained at the 3-month follow-up.The large effect sizes (Cohen's $d=0.74-0.89$ ) found in this study are largely consistent with meta- 
analyses with guided self-help treatment for depression (Gregory et al., 2004; Gellathy et al., 2007). As such, the results confirm earlier studies that showed that interventions for people with subthreshold depression are effective in reducing depressive symptomatology (Cuijpers et al., 2007). Our study further showed that the intervention resulted in a particularly large effect size among participants with relatively high baseline levels of depressive symptomatology (Cohen's $d=1.08$ ). As the presence of clinically relevant depressive symptoms is known to be an important risk factor for clinical depression (Cuijpers \&Smit, 2004), this outcome suggests that guided ACT self-help early intervention decreases the risk of developing a (future) full clinical depression. Moreover, the ACT intervention resulted in significant large reductions in anxiety and fatigue after the intervention and at the 3-month follow-up. This finding corroborates earlier studies that showed that ACT is effective in reducing anxiety and fatigue (Forman et al., 2007; Lappalainen et al., 2007; Bohlmeijer et al., 2011a). The ACT intervention also significantly improved positive mental health, confirming previous research showing that ACT interventions promote emotional well-being (e.g. life satisfaction or quality of life) in patients with anxiety or depression (e.g. Forman et al., 2007; Lappalainen et al., 2007). Also psychological and social well-being were improved, suggesting that an intervention that is aimed at increasing acceptance and value-based actions is supportive for a positive, engaged and meaningful life.

\section{Effects on EA and mindfulness}

Large effect sizes were found on EA at post-intervention and at follow-up further reductions were found in the experimental conditions. This finding corroborates previous studies that showed that EA can be substantially reduced by ACT. It indicates that the participants are more inclined to accept their undesirable feelings, thoughts or body sensations without trying to avoid the form or frequency (Hayes et al., 2006). This is also confirmed by the large effect sizes FFMQ-acting with awareness that were found on the FFMQ subscales 'non-judging' and 'non-reactivity'. This means that the participants and have a more non-evaluative stance toward thoughts and feelings and allow them to come and go (Baer et al., 2006). On the other subscales of the FFMQ also large effects sizes were found in the experimental conditions after the intervention. Future research could examine the possibly mediating role of EA or mindfulness.

\section{Level of support}

No significant differences in the level of email support provided by counsellors were detected. This appears to be in line with earlier studies that have found that minimal contact with a counsellor is enough for a self-help programme to be as effective as face-to-face therapy (Cuijpers et al., 2010). Although our study was not powered to detect smaller effect size differences between two effective interventions (Cohen's $d<0.40$ ) and thus more subtle differences could have been missed, the similarities in the effects were highly 
consistent. In both the minimal and extensive email support, moderate to large effect sizes were found on all outcome measures and the participants in both conditions were highly satisfied with the intervention. This implies that for this intervention minimal email support suffices and more extensive email counselling does not further improve outcomes. It should be noted that the intensity of email contact differed, not the frequency, as this was held constant in both conditions. Further research could examine whether even less frequent contact could be effective, such as merely providing a clear scheduled deadline for finishing the programme (e.g. Nordin et al., 2010) or as an online intervention with automatic feedback.

\section{Limitations}

This study has several limitations. The use of a W-L control group is suboptimal, because of a lack of control for non-specific factors. Also, it would have strengthened the design if a longer follow-up period and a follow-up assessment for the control group had been included. With the present study it cannot be demonstrated that the effects at the 3-month follow-up were attributable to the ACT intervention and not, for example, to spontaneous remission. Our participants were mainly highly educated females, so generalization of the results has to be made with prudence. However, reaching this group is not uncommon for self-help (e-health) interventions (e.g. Carlbring et al., 2007). Furthermore, moderator analyses showed that there were no significant intervention effects for gender or education, indicating that the intervention is potentially broadly applicable. Another limitation is that only partial and limited use was made of a diagnostic instrument. The MINI was used for diagnosing severe depressive episodes with people who scored positively on the WSQ but who did not meet the exclusion criterion of a severe depressive disorder. Hence the sample in this study consisted of both people with clinically relevant depressive symptomatology and people with mild to moderate depressive disorders. However, this limitation can also be seen as a strength. Apparently, the inclusion of a heterogeneous population with regard to their range of depressive symptomatology did not negatively affect treatment effectiveness. This underscores the generalizability of the findings.

\section{Implications and future directions}

This study is the first to show that ACT is effective as an early intervention offered as a guided self-help programme to participants with mild to moderate depressive symptomatology. Offering an early intervention in a positive frame and as a self-help programme might be less stigmatizing for participants than the traditional mental health services. Our study has shown that the ACT intervention not only affected depressive symptomatology but also symptoms of anxiety and fatigue. Apparently, by targeting a general risk factor (EA), a broad spectrum of psychological distress can be reduced. This implies that a generic preventive intervention could extend to other mental disorders as well. In our study positive mental health was a secondary outcome. There is a growing 
body of knowledge that underscores positive mental health as a major public health goal. Recent studies have shown that having positive mental health protects against the risk of mental illnesses (Keyes et al., 2010; Wood \& Joseph, 2010). Furthermore, Fava et al. (2001) found that even when clinical symptoms are absent, low positive mental health can be seen as a risk factor for future relapse among recovering patients. There is also growing evidence of interventions aiming at enhancing positive mental health both in clinical practice (e.g. Fava et al., 2005) and in public mental health (e.g. Fledderus et al., 2010). In future studies positive mental health could therefore be considered as a primary outcome of interventions aiming at people with low positive mental health.

Future research could examine whether a guided self-help ACT intervention is effective in reducing the onset of a major depressive disorder. Though a dropout rate of $18 \%$ is acceptable and similar to other self-help studies (e.g. Seekles et al., 2011), it is an important issue to prevent drop-out from self-help interventions. Future studies could examine how lower drop-out rates can be achieved, for example, to tailor a self-help treatment according to the patient profile (e.g. Andersson et al., 2011). Furthermore, it could be examined whether the intervention could be tailored to people with a low social economic status, as this status is clearly associated with depression (Lorant et al., 2007). One important modification could be the use of comics to illustrate the main concepts and metaphors of the intervention. 


\section{Acknowledgements}

The study was funded by the Netherlands Foundation for Mental Health (Fonds Psychische Gezondheid). It was approved by an independent medical ethics committee (METIGG; no. 9212) and recorded in the Dutch primary trial register for clinical trials (NTR1985). 


\section{References}

Andersson, G., Estling, F., Jakobsson, E., Cuijpers, P., \& Carlbring, P. (2011). Can the patient decide which modules to endorse ? An open trial of tailored Internet treatment of anxiety disorders. Cognitive Behaviour Therapy, 40, 57-64.

Andrews, G., Issakidis, C., Sanderson, K., Corry, L., \& Lapsley, H. (2004). Utilizing survey data to inform public policy, comparison of the cost-effectiveness of treatment of ten mental disorders. British Journal of Psychiatry, 84, 526-533.

Attkisson, C.C., \& Zwick, R. (1982). The client satisfaction questionnaire. Psychometric properties and correlations with service utilization and psychotherapy outcome. Evaluation and Program Planning, 5, 233-237.

Baer, R.A., Smith, G.T., Hopkins, J., Krietemeyer, J., \& Toney, L. (2006). Using self-report assessment methods to explore facts of mindfulness. Assessment, 13, 27-45. 10

Beekman, A.T., Deeg, D. J., Van Limbeek, J., Braam, A. W., De Vries, M. Z., \& van Tilburg, W. (1997). Criterion validity of the Center for Epidemiologic Studies Depression scale (CESD), results from a community-based sample of older subjects in the Netherlands. Psychological Medicine, 27, 231-235.

Biglan, A., Hayes, S .C., \& Pistorello, .J (2008). Acceptance and commitment, implications for prevention science. Prevention Science, 9, 139-152.

Bohlmeijer, E. T., Fledderus, M., Rokx, T. A. J. J., \& Pieterse, M. E. (2011a). Efficacy of an early intervention based on acceptance and commitment therapy for adults with depressive symptomatology: evaluation in a randomized controlled trial. Behaviour Research and Therapy, 9, 62-67.

Bohlmeijer, E.T., \& Hulsbergen, M. (2008). Voluit leven. Mindfulness of de kunst van het aanvaarden, nu als praktisch hulpboek [Living to the Full. Mindfulness or the Art of Acceptance, now as a Practical Help Book]. Boom: Amsterdam.

Bohlmeijer, E.T., ten Klooster, P. M., Fledderus, M., Veehof, M. M., \& Baer, R. (2011b). Psychometric properties of the Five Facet Mindfulness Questionnaire in depressed adults and development of a short form. Assessment, 18, 308-320.

Bond, F. W., Hayes, S. C., Baer, R. A., Carpenter, K. C., Guenole, N., Orcutt, H. K., Waltz, T., \& Zettle, R. D. (2011). Preliminary psychometric properties of the Acceptance and Action Questionnaire-II: a revised measure of psychological flexibility and acceptance. Behavior Therapy, 42, 676-688.

Bouma, J., Ranchor, A. V., Sanderman, R., \& van Sonderen, E. (1995). Het meten van symptomen van depressie met de CES-D, een handleiding. [Measuring Symptoms of Depression with the CES-D, A Guide]. Noordelijk Centrum voor Gezondheidsvraagstukken: Groningen.

Carlbring, P., Gunnarsdottir, M., Hedensjo, .L, Andersson, G., Ekselius, L., \& Furmark, T. (2007). Treatment of social phobia, randomized trial of Internet-delivered 
cognitive behavioural therapy with telephone support. British Journal of Psychiatry 90, 123-128.

Cook, R. J., \& Sackett, D.L. (1995). The number needed to treat, a clinically useful measure of treatment effect. British Medical Journal, 310, 452-454.

Cuijpers, P., Donker, T., van Straten, A., Li, J., \& Andersson, G. (2010). Is guided self-help as effective as face-to-face psychotherapy for depression and anxiety disorders? A systematic review and meta-analysis of comparative outcome studies. Psychological Medicine, 40, 1943-1957.

Cuijpers, P., \& Smit, F. (2004). Subthreshold depression as a risk indicator for major depressive disorder, a systematic review of prospective studies. Acta Psychiatrica Scandinavica, 109, 325-331.

Cuijpers, P., Smit, F., \& van Straten, A. (2007). Psychological treatments of subthreshold depression, a meta-analytic review. Acta Psychiatrica Scandinavica, 115, 434-441.

Cuijpers, P., van Straten, A., Smit, F., Mihalopoulos, C., \& Beekman, A. (2008). Preventing the onset of depressive disorders, a meta-analytic review of psychological interventions. American Journal of Psychiatry, 65, 1272-1280.

Cuijpers, P., van Straten, A., Warmerdam, L., \& van Rooy, M. J. (2010). Recruiting participants for interventions to prevent the onset of depressive disorders. Possible ways to increase participation rates. BMC Health Services Research, 10, 181.

De Brey, H. A. (1983). Cross-national validation of the client satisfaction questionnaire, the Dutch experience. Evaluation and Program Planning, 6, 395-400.

Dempster, A.P., Laird, N.M., \& Rubin, D.B. (1977). Maximum likelihood from incomplete data via the EM algorithm. Journal of the Royal Statistical Society Series B Methodological, 39, 1-38.

Donker, T., van Straten, A., Marks, I., \& Cuijpers, P. (2009). A brief web-based screening questionnaire for common mental disorders, development and validation. Journal of Medical Internet Research, 11, 19.

Fava, G. A., Rafanelli, C., Ottolini, F., Ruini, C., Cazzaro, M., \& Grandi, S. (2001). Psychological well-being and residual symptoms in remitted patients with panic disorder and agoraphobia. Professional Psychology, Research and Practice, 31, 899905.

Fava, G. A., Ruini, C., Rafanelli, C., Finos, L., Salmaso, L., Mangelli, L., \& Sirigatti, S. (2005). Well-being therapy of generalized anxiety disorder. Psychotherapy Psychosomatic, 74, 26-30.

Fledderus, M., Bohlmeijer, E.T., Smit, F., \& Westerhof, G. J. (2010). Mental health promotion as a new goal in public mental health care. A randomized controlled trial of an intervention enhancing psychological flexibility. American Journal of Public Health, 100, 2372-2378.

Forman, E. M., Herbert, J. D., Moitra, E., Yeomans, P. D., \& Geller, P. A. (2007). Randomized controlled effectiveness trial of acceptance and commitment therapy 
and cognitive therapy for anxiety and depression. Behavior Modification, 31, 772799.

Gellathy, J., Bower, P., Hennessy, S., Richards, D., Gilbody, S., \& Lovell, K. (2007). What makes self-help interventions effective in the management of depressive symptoms? Meta-analysis and meta-regression. Psychological Medicine, 37, 1217-1228.

Gregory, R., Canning, S., Lee, T., \& Wise, J. (2004). Cognitive bibliotherapy for depression,a meta-analysis. Professional Psychology, Research and Practice 35, 275-280.

Haringsma, R., Engels, G.I., Beekman, A. T. F., \& Spinhoven, P. (2004). The criterion validity of the Center for Epidemiological Studies Depression Scale (CES-D) in a sample of self-referred elders with depressive symptomatology. International Journal of Geriatric Psychiatry, 19, 558-563.

Hayes, S. C., Luoma, J. B., Bond, F. W., Masuda, A., \&Lillis, J. (2006). Acceptance and commitment therapy. Model, processes and outcomes. Behaviour Research and Therapy, 44, 1-25.

Jacobs, N., Kleen, M., de Groot, F., \& A-Tjak, J. (2008). Het meten van experiëntiéle vermijding. De Nederlandstalige versie van de Acceptance and Action Questionnaire-II (AAQ-II ) [Measuring experiential avoidance. Dutch translation of the Acceptance and Action questionnaire-II (AAQ-II)], Gedragstherapie, 41, 349361.

Jacobson, N. S., \& Truax, P. (1991). Clinical significance, a statistical approach to defining meaningful change in psychotherapy research. Journal of Consulting and Clinical Psychology, 59, 12-19.

Kabat-Zinn, J. (1990). Full Catastrophe Living, Using the Wisdom of Your Body and Mind to Face Stress, Pain, and Illness. Delacorte: New York.

Kabat-Zinn, J. (1994). Wherever You Go, There You Are, Mindfulness Meditation in Everyday Life. Hyperion: New York.

Keyes, C.L.M. (2005). Mental illness and/or mental health ? Investigating axioms of the complete state model of health. Journal of Consulting and Clinical Psychology, 73, 539-548.

Keyes, C. L. M., Dhingra, S. S., Simoes, E. J. (2010). Change in level of positive mental health as a predictor of future risk of mental illness. American Journal of Public Health, 100, 2366-2371.

Lamers, S. M. A., Westerhof, G. J., Bohlmeijer, E. T., ten Klooster, P.M., \& Keyes, C. L. M. (2010). Evaluating the psychometric properties of the Mental Health ContinuumShort Form (MHC-SF). Journal of Clinical Psychology, 67, 99-110.

Lappalainen, R., Lehtonen, T., Skarp, E., Taubert, E., Ojanen, M., \& Hayes, S.C. (2007). Preliminary controlled effectiveness trial: the impact of CBT and ACT models using psychology trainee. Behavior Modification, 31, 488-511. 
Lipsey, M. W., \& Wilson, D. B. (1993). The efficacy of psychological, educational and behavioral treatment. Confirmation from meta-analysis. American Psychologist, 48, 1181-1209.

Lorant, V., Croux, C., Weich, S., Deliège, D., Mackenbach, J., \& Ansseau, M. (2007). Depression and socio-economic risk factors: 7-year longitudinal population study. British Journal of Psychiatry, 190, 293-298.

Nordin, S., Carlbring, P., Cuijpers, P., \& Andersson, G. (2010). Expanding the limits of bibliotherapy for panic disorder: randomized trial of self-help without support but with a clear deadline. Behavior Therapy, 41, 267-276.

Olssøn, I., Mykletun, A., \& Dahl, A. A. (2005). The Hospital Anxiety and Depression rating scale, a cross-sectional study of psychometrics and case findings abilities in general practice. BMC Psychiatry, 5, 46.

Radloff, L.S. (1977). The CES-D scale, a self-report depression scale for research in the general population. Applied Psychological Measurement, 1, 385-401.

Seekles, W., van Straten, A., Beekman, A., van Marwijk, H., \& Cuijpers, P. (2011). Effectiveness of guided self-help for depression and anxiety disorders in primary care:a pragmatic randomized controlled trial. Psychiatry Research, 187, 113-120.

Sheehan, D. V., Lecrubier, Y., Sheehan, K. H., Amorim, P., Janav, J., Weiller, E., Hergueta T., Baker R, \& Dunbar G. C. (1998). The Mini-International Neuropsychiatric Interview (MINI). The development and validation of a structured diagnostic psychiatric interview for DSM-IV and ICD-10. Journal of Clinical Psychiatry, 59, 22-33.

Smit, F., Ederveen, A., Cuijpers, P., Deeg, D., Beekman, A. (2006). Opportunities for costeffective prevention of late-life depression. An epidemiological approach. Archives of General Psychiatry, 63, 290-296.

Spinhoven, P. H., Ormel, J., Sloekers, P. P. A., Kempen, G. I. J. M., \& Speckens, A. E. M., van Hemert, A. M. (1997). A validation study of the Hospital Anxiety and Depression Scale (HADS) in different groups of Dutch subjects. Psychological Medicine, 27, 363-370.

Vercoulen, J. H. M. M., Alberts, M., \& Bleijenberg, G. (1999). The Checklist Individual Strength (CIS). Gedragstherapie, 32, 131-136.

Wood, A. M., Joseph, S. (2010). The absence of positive psychological (eudemonic) wellbeing as a risk factor for depression, a ten year cohort study. Journal of Affective Disorders, 122, 213-217.

Zigmond, A.S., \& Snaith, R.P. (1983). The Hospital Anxiety and Depression Scale. Acta Psychiatrica Scandinavica, 67, 361-370. 


\section{The impact of changes in psychological flexibility on psychological distress in a randomized controlled trial on Acceptance and Commitment Therapy}

Fledderus, M., Bohlmeijer, E. T., Fox, J. P., Schreurs, K. M. G., \& Spinhoven, P. The Impact of Changes in Psychological Flexibility on Psychological Distress in a Randomized Controlled Trial on Acceptance and Commitment Therapy. Submitted for publication to Behaviour Research and Therapy. 


\section{Abstract}

Objective: This study examined the impact of changes in psychological flexibility on depression and anxiety in an early guided self-help Acceptance and Commitment Therapy (ACT) intervention for people with psychological distress.

Method: Adults with mild to moderate psychological distress were randomized to the selfhelp programme with e-mail support ( $n=250)$, or to a waiting list control group $(n=126)$. Participants completed measures before and after the intervention to assess depression, anxiety and psychological flexibility. Participants in the experimental condition also completed these measures during the intervention (after three and six weeks) and at a threemonth follow-up.

Results: The effects of the ACT intervention on anxiety and depression were mediated by improvements in psychological flexibility during the intervention. Right from the start of the intervention it appeared that psychological flexibility had positive effects on the levels of depression and anxiety over time. Higher levels of psychological flexibility had a larger impact on depression and anxiety over time. Furthermore, it was shown that changes in psychological flexibility at the end of the ACT intervention are important for further reductions in anxiety.

Conclusion: This study confirms the importance of targeting psychological flexibility in an ACT intervention for achieving a substantial long-term impact on psychological distress. 


\section{Introduction}

There is growing empirical support for Acceptance and Commitment Therapy (ACT) for the treatment of a variety of mental illnesses (Powers, Zum Vörde Sive Vörding, \& Emmelkamp, 2009). ACT is a behaviour therapy that is mainly focused on increasing psychological flexibility. Psychological flexibility is a competence that includes two mutually dependent processes: acceptance of experiences and value-based behaviour (Hayes, Luoma, Bond, Masuda, \& Lillis 2006). A psychologically flexible person is willing to remain in contact with unwanted private experiences, rather than trying to avoid, alter or control them. When this struggle and attempt to control or avoid these unwanted private experiences is relinquished, an individual can shift his/her energy to long-term desired qualities or values in life, even in the presence of unwanted private events (Ciarrochi, Billich, \& Godsell, 2010). A person can then be in contact with present experiences and choose or persist in behaviour that is in line with important values and goals. Several studies have shown that high psychological flexibility is related to life satisfaction and quality of life, whereas low psychological flexibility is related to psychological distress, such as anxiety and depression (Hayes et al., 2006).

In the ACT-treatment model, psychological flexibility is an important mechanism of change during the treatment for mental health (Ciarrochi, Billich, \& Godsell, 2010). Many studies have already shown that an ACT treatment can improve psychological flexibility and reduce mental illnesses, such as depression, social anxiety and post-traumatic stress-disorder (e.g. Roemer, Orsillo, \& Salters-Pednault, 2008; Bohlmeijer, Fledderus, Rokx, \& Pieterse, 2011; Gratz, \& Gunderson, 2006). A recent study has shown that ACT is also effective as an early self-help intervention with minimal e-mail counselling for mild to moderate psychological distress (Fledderus, Bohlmeijer, Pieterse, \& Schreurs, 2011). Compared with a waiting list, high effect sizes were found after the intervention on depression (Cohens' $d=.89$ ), anxiety (Cohen's $d=.86$ ) and psychological flexibility (Cohen's $d=.70$ ).

Although these studies suggest that psychological flexibility is indeed important for mental health, less is known about how and when psychological flexibility changes during and after an ACT treatment for mental illnesses. Understanding the role of psychological flexibility in ACT and its impact on mental illness can potentially optimize the treatments (Laurenceau, Hayes, \& Feldman, 2007). Various studies already showed that changes in psychological flexibility mediated the effects of an ACT treatment for social anxiety (Dalrymple \& Herbert, 2007; Kocovski, Fleming, Rector, 2009), borderline personality disorder (Gratz \& Gunderson, 2006) and depression (Forman, Herbert, Moitra, Yeomans, \& Geller, 2007; Lappalainen, Lehtonen, Skarp, Taubert, Ojanen, \& Hayes, 2007; Bohlmeijer et al, 2011) on the observed outcomes. Furthermore, it was found in a sample of 43 patients that during an acceptance-based behaviour treatment for generalized anxiety, changes in acceptance and value-based actions during treatment predicted changes in 
anxiety after the treatment (Hayes, Orsillo, \& Roemer, 2010). Two other studies with samples of 42 and 19 patients showed that during an ACT treatment for social anxiety, changes in social anxiety symptoms from mid-to post-treatment were preceded by changes in psychological flexibility from baseline to mid-treatment, even after controlling for earlier changes in social anxiety from baseline to mid-treatment (Dalrymple \& Herbert, 2007; Kocovski et al., 2009).

These studies imply that improvements in psychological flexibility can have a large impact on the reduction of clinical symptoms. However, more studies with larger and different samples and more time measurements are needed to study the precise role of psychological flexibility on levels of psychological distress in ACT and whether changes in psychological flexibility lead to a decline in clinical symptoms, rather than vice versa (Ciarrochi et al., 2010).

In this study we examined if and how changes in psychological flexibility can have a large impact on levels of psychological distress during and after an early guided self-help ACT intervention. This intervention was offered to a large sample of adults with mild to moderate psychological distress $(n=250)$. Both psychological flexibility and the outcome variables (anxiety and depression) were measured at baseline, two times during the intervention, post-intervention and at a three-month follow-up. First, mediational analyses were performed according to the procedures outlined by Preacher and Hayes (2008). It was assessed whether changes in psychological flexibility during the intervention period mediated the effects of the intervention on anxiety and depression at post-intervention. Second, the impact of psychological flexibility on depression and anxiety over time was assessed with multilevel growth models. With these analyses, it was examined how psychological flexibility is related to anxiety and depression during and after the ACT intervention. Third, it was examined if changes of psychological flexibility occurred during the intervention and whether these changes predicted later outcomes of depression and anxiety. This was done with a cross-lagged panel design. With this design, the possible causal pathways were examined between psychological flexibility and the outcomes.

With this study, we wanted to conduct in-depth analyses of changes in psychological flexibility and its relation with and effects on the levels of depression and anxiety in ACT intervention for adults with mild to moderate psychological distress.

\section{Method}

\section{Participants and procedure}

The data from this study are derived from a randomized controlled trial on the effects of a guided self-help ACT intervention on psychological distress and positive mental health. More detailed information about the study design and procedures can be found in Fledderus et al. (2011). In short, in September 2009 participants were recruited through advertisements in Dutch newspapers for a study on the effects of guided self-help based on 
ACT. Inclusion criteria were an age of 18 years or older and mild to moderate depressive and/or anxiety symptoms. People with severe depressive symptomatology were excluded. Other exclusion criteria were (a) few depressive symptoms and/or anxiety; (b) receiving psychological or psychopharmacological treatment within the last three months; and (c) high suicide risk. Figure 1 shows the participant's flow. A total of 376 participants were randomly assigned to the following three conditions: the ACT intervention with minimal email support ( $n=125$ ) (ACT-M), the same intervention with extensive e-mail support ( $n=$ 125) (ACT-E) or a waiting list $(n=126)$. The effects of the two experimental conditions on depression, anxiety and psychological flexibility were similar. Therefore, in this study the two experimental conditions were analyzed together as one group with all participants receiving the guided self-help ACT intervention $(n=250)$.

Table 1 shows an overview of the participants' characteristics. Their mean age was 42 years (range $=18-73$ ). The majority was female $(70 \%)$ and of Dutch origin $(93 \%)$. Most of the participants had a high level of education (86\%), a paid job (76\%) and were not married (47\%). Data were available for 340 participants at post-intervention (dropout rate 9.6\%). At follow-up, data was available for 204 participants (dropout rate 18.4\%). The study was approved by an independent medical ethics committee (METIGG; number 9212) and recorded in the Dutch primary trial register for clinical trials (NTR1985).

Table 1. Characteristics of Participants

\begin{tabular}{lll}
\hline Characteristic (in \%) & $\begin{array}{l}\text { ACT } \\
(n=250)\end{array}$ & $\begin{array}{l}\text { Waiting list } \\
(n=126)\end{array}$ \\
\hline Gender & & \\
Female & 69.6 & 69.8 \\
Male & 30.4 & 30.2 \\
Age (M, SD) & $42.50(11.00)$ & $42.47(11.29)$ \\
$\quad$ Marital status & & \\
Married & 43.0 & 75.2 \\
Divorced & 8.8 & 7.9 \\
Widowed & 1.6 & 46.9 \\
Unmarried & 46.5 & 92.1 \\
Race & & 7.9 \\
Dutch & 93.2 & 88.9 \\
Other & 6.8 & 13.3 \\
Education & & .8 \\
$\quad$ High & 85.2 & 79.4 \\
Middle & 12.8 & 20.6 \\
Low & 2.0 & \\
Daily activities & 74.3 & \\
Paid job & 25.7 & \\
No job & Note. ACT = Acceptance and Commitment Therapy. &
\end{tabular}


Figure 1. Participant Flow

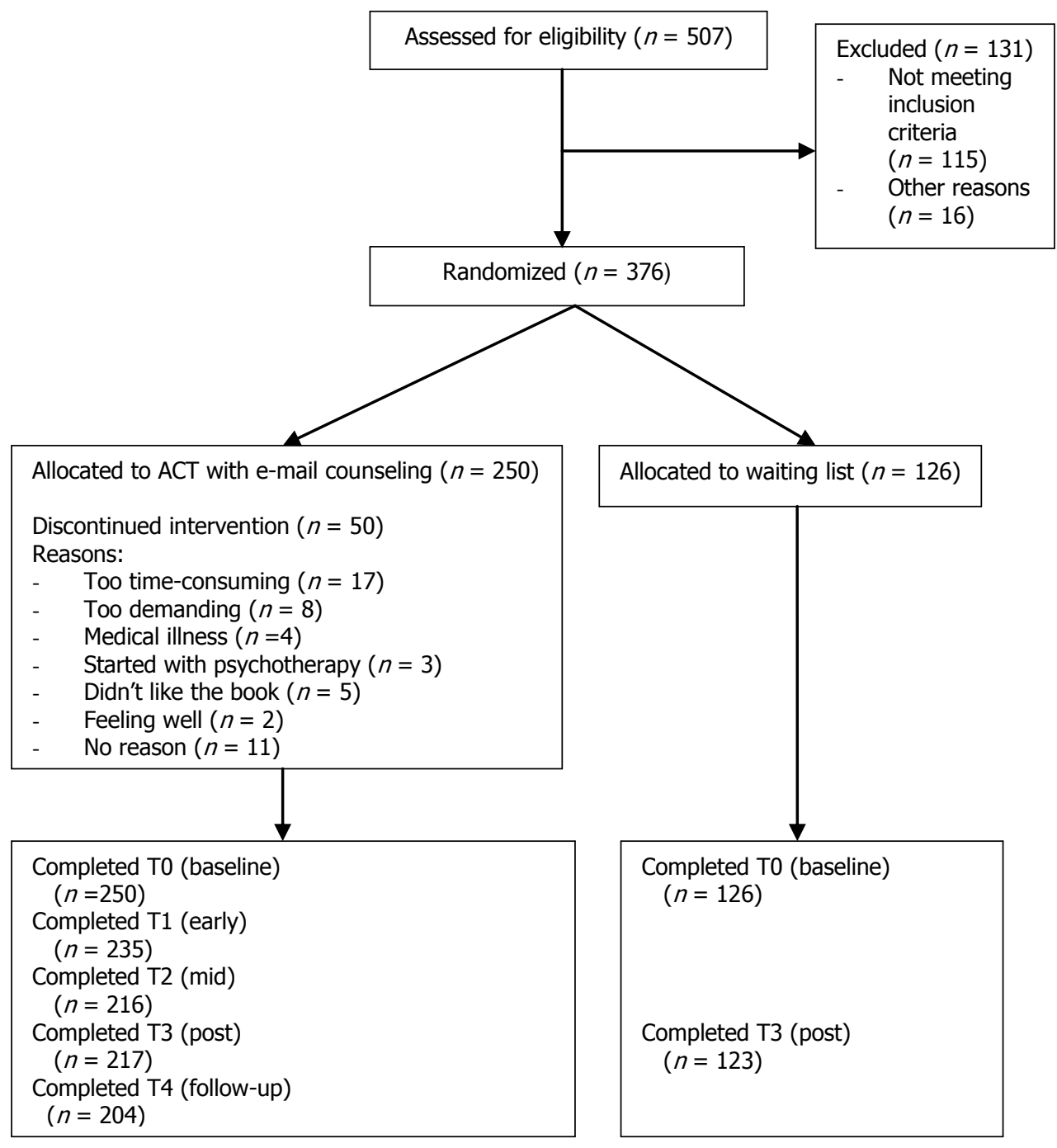




\section{Measures}

All participants completed measures on two occasions: at baseline (T0; pre-intervention) and at post-intervention at 9 weeks (T3; directly after the intervention). The experimental conditions also completed measures at early-intervention (T1; three weeks after baseline), mid-intervention (T2; 6 weeks after baseline) and at the three-month follow-up (T3; 5 months after baseline). The waiting list group received the intervention after the waiting list period of 9 weeks. All questionnaires were administered online.

Center of Epidemiological Studies-Depression Scale (CES-D). The CES-D (Radloff, 1977) is a 20-item questionnaire that measures depressive symptoms in the general population. Respondents rate on a 4-point scale ranging from hardly ever (less than 1 day) (0) to predominantly (5-7 days) (3) to what extent they had experienced depressive symptoms in the previous week. Summation of the scores results in a total score ranging from 0 to 60. The Dutch translation showed good psychometric properties in a group of elderly people (Haringsma, Engels, Beekman, \& Spinhoven, 2004). The scale showed high internal consistency in this study $(\alpha=.78, \mathrm{~T} 0)$.

Hospital Anxiety and Depression Scale-Anxiety subscale (HADS-A). The HADSA (Zigmond \& Snaith, 1983) is a 7-item questionnaire that assesses the presence and severity of anxious symptoms. Respondents rate on a 4-point scale ranging from not at all (0) to often (3) to what extent they had experienced anxiety symptoms in the previous week. The total HADS-A scores range from 0 to 21. The Dutch translation showed good psychometric properties (Spinhoven et al., 1997). The scale showed low internal consistency in this study at T0 $(\alpha=.56)$. However, the internal consistency at the other measurements at $\mathrm{T} 1$ to $\mathrm{T} 3$ were satisfactory with alphas between $.72-.81$.

Acceptance and Action Questionnaire-II (AAQ-II) The AAQ-II (Bond et al., 2011) is a 10-item measure of psychological flexibility. The AAQ-II assesses on a 7-point scale ranging from never true (1) to always true (7) the subject's willingness to be in contact with negative private events, the acceptance of these events, and whether they can live according to their values. Summation of the scores results in a total score ranging from 10 to 70 , whereby a higher score indicates more psychological flexibility. The Dutch AAQ-II showed good psychometric properties (Jacobs, Kleen, de Groot, \& A-Tjak, 2008) and good internal consistency in the current study $(\alpha=.85$, T0 $)$

\section{Intervention and email support}

Participants of the experimental conditions received the self-help book 'Living to the full' (Bohlmeijer \& Hulsbergen, 2008) by regular mail. The book comprises 9 modules, divided into three parts. The participants were instructed to complete one module per week. The modules are based on six core processes of ACT that together promote psychological flexibility: acceptance (active and aware embracement of aversive internal experiences), cognitive defusion (creating a context in which undesirable functions of thoughts disappear), contact with the present moment, self as context (experiencing that one is more 
than one's thoughts, feelings and experiences), choosing values in different life domains, and commitment to choices on the basis of these values (Hayes et al., 2006).

The first and second part of the book are based on acceptance and mindfulness processes. In the first part, participants reflect on their avoidance and control strategies and whether these are effective in the long run. In the second part, participants learn how to come into contact with their present experiences without trying to avoid or control them. Cognitive defusion and experiencing self as context are practised. This last part of the book is based on commitment and behaviour processes, with the focus on becoming aware of the most important personal values on various life domains and making decisions based on these values. Each module uses experiential exercises and metaphors for illustrating the processes of ACT. Furthermore, the participants were asked to do daily mindfulness exercises, based on mindfulness-based stress reduction (Kabat-Zinn, 1990; Kabat-Zinn, 1994). The mindfulness exercises lasted on average 10-15 minutes and were on an audioCD which was provided with the book.

The intervention was supported with email counselling provided by five psychology Master students of the University of Twente who were supervised by a clinical psychologist. The participants received a standardized email from the counsellors every week on the same day concerning the module that they had carried out in the previous week. Participants were expected to respond within two days, after which they received a feedback email from the counsellor. Participants assigned to the waiting list received the self-help book by regular mail after the post-intervention assessment. Email counselling was not provided.

\section{Statistical analyses}

The mediational analyses and the cross-lagged regressions were done using PASW 18 and using intention-to-treat analyses. Therefore, missing data on the measurements (from T0T3) were imputed with the use of SPSS Missing Value Analysis with the expectationmaximization method. This method computes missing values based on maximum likelihood estimates using observed data in an iterative process (Dempster et al., 1977). The total percentage of missing data was $9.36 \%$ due to unanswered items ( $.64 \%$ ) or incomplete assessments (8.7\%). A comparison of results based on the imputed intention-to-treat sample versus the observed data revealed similar outcomes. Therefore, only the results from the intention-to-treat analyses are reported. Comparisons were two-tailed and interpreted with a significance of $p<0.05$.

First, to analyze whether psychological flexibility mediated the effects in the intervention on anxiety and depression, mediational analyses were performed using the baseline and post-intervention measurements of depression, anxiety, and psychological flexibility of the intervention group and waiting list group. In order to examine whether change of psychological flexibility during the intervention (from T0 to T3) would mediate the effects of the intervention on scores of depression and anxiety at post-intervention, mediational analysis with bootstrapping procedures ( $n=5000$ bootstrap resamples) were 
used to assess the indirect effect of the mediational pattern using the SPSS macro designed by Preacher and Hayes (2004). An indirect effect was considered significant in the case zero was not contained in the $95 \%$ bias-corrected confidence interval.

Second, it was investigated how changes in psychological flexibility are related to changes in depression and anxiety over time using the hierarchical linear modelling framework. It is to be expected that measurements over time from the same participants are more alike than measurements from different participants. The repeated measurements are said to be nested within participants, which supports the use of multilevel models. The multilevel modelling approach makes it possible to treat the participant as a random factor and the repeated measurements are assumed to be independently distributed given the level of the random factor or random effect. This way, within-subject variation over time and between-subject variation in depression and anxiety can be modelled. The time-specific repeated measurements of psychological flexibility can be related to depression and anxiety at the (lower) observation level (level 1) of the model, controlling for the within-subject dependency over time through a random subject effect. The between-subject differences are modelled at a higher level (level 2), where between-subject variances and time-invariant participant characteristics can be defined. In longitudinal data and repeated measurements studies, the lower-level unexplained residuals are often still correlated given the random subject effect. The estimated effects of psychological flexibility on depression and anxiety can be biased when the level-1 residuals are not properly modelled. Therefore, the multilevel analyses of repeated measurements of depression and anxiety on psychological flexibility require careful specification of the covariance structure of the unexplained level1 residuals.

In PASW 18, the mixed models routine was used to fit various (linear) multilevel models with continuous repeated measures for depression and anxiety. In a first multilevel analysis, the variance components at the level of observations and the level of participants were estimated for each outcome variable. The time in weeks was used as an explanatory variable such that a linear growth model for the outcome measure was defined at level 1 . Furthermore, different covariance structures at level 1 were evaluated to capture the correlation structure given the linear trend including a random subject effect.

In a second multilevel analysis, the effect of psychological flexibility on depression and anxiety was estimated given the linear trend through the time variable and the random intercept across subjects. Psychological flexibility was incorporated as a time-dependent measure such that the relationship with depression and anxiety was analyzed over time.

Furthermore, the interaction effect of time with psychological flexibility was incorporated to test whether the effect of psychological flexibility on depression and anxiety varied across time. In a subsequent analysis the effect of psychological flexibility and the interaction effect with time were modelled as random to test whether their effects varied across participants. Therefore, the subject-specific effects of psychological flexibility on depression and anxiety were estimated and it was tested whether the corresponding between-subject variance was significantly different from zero. Furthermore, the between- 
subject variance of the random interaction effect was tested to be significantly different from zero. Restricted maximum likelihood estimates were computed and Student's t-test was used to test the significance of fixed effects parameters. The Wald test was used to test the significance of variance components.

Third, to examine whether changes in psychological flexibility during treatment predicted post-to follow-up intervention, changes in anxiety and depression cross-lagged regressions were performed (e.g. Spinhoven, Dyck, Giesen-Bloo, Kooiman, \& Arntz, 2007; Burns, Kubilus, Bruehl, \& Harden, 2003; Evon \& Burns, 2004). Residual changes scores for three changes in time during treatment for all variables were calculated by regression: the early-intervention score on the pre-intervention score (T0-T1), the mid-intervention score on the early-intervention score (T1-T2), post-intervention on the mid-intervention (T2-T3), and follow-up on the post-intervention scores (T3-T4). Cross-lagged correlations among these residual change scores were computed. When a correlation from the pre-to post-intervention changes in psychological flexibility (the scores between T0-T3) were statistically significant with post-to follow-up scores on the outcome variables, cross-lagged regressions were performed. In these regressions it is assessed whether early changes in psychological still predict later changes in the outcome variables after controlling for autocorrelation (i.e. the correlations between changes during treatment and late changes from post-to follow-up in psychological flexibility) and for synchronous correlation (i.e. the correlations between changes during treatment in psychological flexibility and the changes during treatment in the outcome variables). With regression analyses the inverse association was also examined.

\section{Results}

\section{Mediation of psychological flexibility during the intervention}

The results of the mediational analysis are presented in Table 3. The first step of the regression analyses showed that the ACT intervention significantly predicted the change scores of depression and anxiety. In the second step, the change scores of psychological flexibility were also entered in the regression analyses. This step showed that the change scores of psychological flexibility significantly reduced depression and anxiety. Moreover, the intervention effect is reduced by $32 \%$ for both depression and anxiety. The biascorrected bootstrapping values were between -2.93 and -1.46 for depression and -1.17 and .56 for anxiety, indicating a mediating effect of psychological flexibility. 
Table 2. Means and Standard Deviations of Depression (CES-D), Anxiety (HADS-A), and Psychological Flexibility (AAQ-II)

\begin{tabular}{llllllllllll}
\hline Outcome & Group & \multicolumn{2}{l}{ Pre (T0) } & \multicolumn{3}{c}{ Early (T1) } & \multicolumn{2}{c}{ Mid (T2) } & \multicolumn{2}{c}{ Post (T3) } & \multicolumn{3}{c}{ Follow-up (T4) } \\
\hline \multirow{3}{*}{ CES-D } & & $M$ & $S D$ & $M$ & $S D$ & $M$ & $S D$ & $M$ & $S D$ & $M$ & $S D$ \\
\cline { 2 - 12 } & ACT & 22.79 & 6.57 & 17.71 & 7.77 & 15.64 & 8.30 & 13.33 & 7.28 & 13.71 & 8.20 \\
& WL & 22.45 & 6.68 & & & & & 19.76 & 8.48 & & \\
HADS-A & ACT & 9.52 & 2.58 & 7.80 & 3.02 & 6.85 & 3.17 & 6.12 & 2.96 & 5.91 & 3.12 \\
& WL & 9.33 & 2.34 & & & & & 8.69 & 3.19 & & \\
AAQ-II & ACT & 40.71 & 8.47 & 44.04 & 8.84 & 48.88 & 8.95 & 49.29 & 9.08 & 50.87 & 9.72 \\
& WL & 40.86 & 8.83 & & & & & 43.00 & 10.27 & & \\
\hline
\end{tabular}

Note. $\mathrm{ACT}=$ Acceptance and Commitment Therapy, $\mathrm{WL}=$ waiting list control group, $\mathrm{CES}-\mathrm{D}=$ Center for

Epidemiologic Studies-Depression Scale, HADS-A = Hospital Anxiety and Depression Scale-Anxiety subscale, $\mathrm{AAQ}-\mathrm{II}=$ Acceptance and Action Questionnaire-II.

Table 3. Regression Analysis of Depression (CES-D) and Anxiety (HADS-A) at Follow-up on Intervention, and Improvement of psychological flexibility AAQ-II between Baseline and Post-treatment

\begin{tabular}{|c|c|c|c|c|}
\hline \multirow{3}{*}{ Depression } & & \multirow{2}{*}{$\begin{array}{l}\text { Step 1 } \\
\text { Beta } \\
\end{array}$} & \multicolumn{2}{|l|}{ Step 2} \\
\hline & & & Beta & Adjusted $\mathrm{R}^{2}$ \\
\hline & ACT intervention (Comp: Control group) & $-.367 * * *$ & $\begin{array}{l}-.248 * * * \\
-341 * * *\end{array}$ & .133 \\
\hline Anxiety & $\begin{array}{l}\text { ACT intervention (Comp: Control group) } \\
\text { Improvement in psychological flexibility }\end{array}$ & $-.372 * * *$ & $\begin{array}{l}-.253 * * * \\
-.340 * * *\end{array}$ & $\begin{array}{l}.136 \\
.368^{\mathrm{a}}\end{array}$ \\
\hline
\end{tabular}

\section{Relationship between psychological flexibility and depression over time}

With the repeated measures for depression as the outcome variable, a multilevel model was estimated, where time was a fixed level-1 predictor and the intercept varied randomly across participants. A first-order antedependent covariance structure was chosen to model the level-1 residuals (Zimmerman \& Núñez-Antón, 2009). This covariance structure consists of time-dependent heterogeneous variances and covariances between adjacent level-1 residuals. Each time-dependent covariance element is constructed from a timedependent covariance parameter and time-dependent variances. Information criteria (REML and AIC) were used to fit the most appropriate covariance structure for the unexplained level-1 residuals.

In Table 4 (model 1), it can be seen that the average depression (CES-D) level at the baseline (T0) is around 21.09 for participants with a random subject effect of zero. The average effect of time is -.38 and significantly different from zero, which means that in the population the depression level decreases about .38 points in one week. The variance of the random (subject) intercept is significant and around 12.01 such that there is much variation in depression levels between participants at the baseline. The estimates of the timedependent variance parameters show that the residual variation increases till the mid- 
intervention from 34.78 to 72.86 , and decreases after the mid-intervention from 72.86 to 60.57 , conditional on the negative linear trend. The linear decreasing trend cannot explain all variation in the time-dependent depression levels and the residual variation is relatively high after the mid-intervention. The correlation between level-1 residuals, conditional on measurements from the same subject over time, also increases from .14 to .68 and then decreases to .48. This means that given the linear decreasing trend of depression the subsequent unexplained residuals within a participant become more correlated over time and reduce slightly at the three month follow-up. It can be concluded with the increasing residual variance that, besides the linear trend, there is an unexplained common individual pattern in depression levels. This pattern is characterized by an increasing within-subject variance and increasing correlated within-subject measurements.

In the second multilevel analysis, the linear trend was replaced by a curvilinear trend by including the squared time variable as a level-1 predictor. Furthermore, the timedependent measurement for psychological flexibility (AAQ-II) and its interaction with time were included in the model. The average level of psychological flexibility equals zero due to the fact that the measurement was grand-mean centered. From Table 4 (model 2), it follows that the average level of depression equals 19.80 for the participants with an average level of psychological flexibility at the baseline. The decline in depression is about .99 points per week conditional on the acceptance level but the significant positive quadratic time component leads to a decelerating negative trend of depression over time. This means that the individual depression changes negatively and almost linearly after the baseline but decelerates after a few weeks. The decreasing trend in depression flattens out and the depression level of participants with an average psychological flexibility level over time will increase after 12.4 weeks. The effect of psychological flexibility is negative and around -.35 but its squared term is significantly positive and around .04 . This means that effect of psychological flexibility on depression also follows a decelerating trend, where the negative slope flattens out due to the quadratic component. The average linear effect of psychological flexibility is around -.35 but the effect of psychological flexibility on depression varies across participants, where the between-subject variance is .023 and significantly different from zero. Besides the decelerating negative relationship over time of psychological flexibility on depression, a significant negative interaction effect of psychological flexibility with time was estimated. This time-specific interaction effect is around -.018 and indicates that the subjects with above average psychological flexibility levels will have depression levels below the established decelerating negative relationship.

The estimates of the first-order antedependent parameters show that conditional on the mean structure including a random intercept and a random slope effect for psychological flexibility the residual variation is more constant over time. This means that the decelerating negative trend and the decelerating negative relationship between psychological flexibility and depression explain most of the changes in depression across time. Note that the unexplained variance in the depression at the baseline is for both multilevel models almost the same. It can also be seen that the unexplained correlation 
between time-dependent residuals is much lower. The correlation between the withinsubject depression measurements is much better explained due to the psychological flexibility and time variables. Furthermore, the information criteria supported the conclusions about the model improvement.

\section{Relationship between psychological flexibility and anxiety over time}

A multilevel model was estimated using the repeated measures for anxiety (HADS-A) as an outcome variable and time as a fixed level-1 predictor. The intercept varied randomly across participants to allow between-subject variation in anxiety. The average anxiety level at the baseline (T0) is around 8.57 for subjects with a random subject effect of zero. The average effect of time is -.18 , which means that in the population the anxiety level decreases about .18 points in one week. The participants' average anxiety levels differ, since the between-subject variance in anxiety levels is around 4.48. The fitted residual covariance matrix consisted of time-specific variances. The residual variance estimates at the baseline and at the three-month follow-up are higher than the between-subject variation. At these points in time there is more variation in anxiety between individuals than expected from the between-subject differences. There was no significant correlation between measurements from the same participant given the negative linear trend.

In a second multilevel analysis, the linear trend of time was extended with the squared time variable to define a curvilinear trend over time of anxiety. The time-dependent measurement for psychological flexibility (grand-mean centered) was included and its interaction effect with time to explore their effects on anxiety. It follows from Table 4 that the negative linear trend of -.35 is decelerated by a positive effect of the squared time variable. For participants with a random effect of zero and an average psychological flexibility level, after more than 25 weeks the anxiety level will be above the baseline level. Psychological flexibility has a significant negative effect on anxiety but this effect varies slightly across participants. The between-subject variation in psychological flexibility is around .004. There is a significant interaction effect of psychological flexibility with time. A high psychological flexibility level at the end of the study leads to a lower anxiety level than at the beginning of the study. Therefore, it can be concluded that the relationship between psychological flexibility and anxiety can be characterized by an accelerating negative slope.

The between-subject variation, given the curvilinear trend of time and the psychological flexibility level, decreased from 4.48 to 2.58 . Although the unexplained residual variation is smaller, there is still above-average residual variation at the baseline and at the three-month follow-up. Furthermore, a common significant within-subject autoregressive correlation was found over time. It can be seen that the within-subject residuals are positively correlated. 
Table 4. Multilevel Analysis with Depression (CES-D), Anxiety (HADS-A) and Psychological Flexibility (AAQ-II)

\begin{tabular}{|c|c|c|c|c|c|c|c|c|}
\hline \multirow[b]{3}{*}{ Parameter } & \multicolumn{4}{|c|}{ Depression } & \multicolumn{4}{|l|}{ Anxiety } \\
\hline & \multicolumn{2}{|l|}{ Model 1} & \multicolumn{2}{|l|}{ Model 2} & \multicolumn{2}{|l|}{ Model 1} & \multicolumn{2}{|l|}{ Model 2} \\
\hline & Est. & SE & Est. & SE & Est. & SE & Est. & SE \\
\hline \multicolumn{9}{|l|}{ Fixed effects } \\
\hline Intercept & 21.09 & .39 & 19.80 & .43 & 8.57 & .17 & 8.67 & .18 \\
\hline Time & -.38 & .03 & -.99 & .10 & -.19 & .01 & -.35 & .04 \\
\hline Time squared & & & .04 & .00 & & & .01 & .00 \\
\hline Psychological flexibility & & & -.35 & .03 & & & -.13 & .01 \\
\hline $\begin{array}{l}\text { Psychological flexibility } \\
\text { squared }\end{array}$ & & & .01 & .00 & & & & \\
\hline $\begin{array}{l}\text { Time* Psychological } \\
\text { flexibility }\end{array}$ & & & -.02 & .02 & & & -.01 & .00 \\
\hline \multicolumn{9}{|l|}{ Random Effects } \\
\hline Intercept (Subject) & 12.01 & 4.45 & 7.04 & 2.05 & 4.48 & .53 & 2.58 & .39 \\
\hline \multicolumn{9}{|l|}{ Residual Variance } \\
\hline \multicolumn{9}{|l|}{ Repeated Measures } \\
\hline Baseline $=1$ & 34.79 & 5.73 & 30.19 & 3.59 & 5.56 & .68 & 4.25 & .51 \\
\hline Time $=2$ & 52.06 & 7.19 & 32.15 & 4.11 & 4.38 & .52 & 4.00 & .51 \\
\hline Time $=3$ & 72.87 & 9.04 & 35.64 & 4.66 & 4.72 & .61 & 3.59 & .49 \\
\hline Time $=4$ & 69.11 & 9.00 & 23.59 & 3.38 & 4.81 & .62 & 2.84 & .42 \\
\hline Time $=5$ & 60.57 & 7.63 & 21.63 & 3.14 & 7.61 & .99 & 4.25 & .54 \\
\hline First-order AD 1 & 14 & .11 & .06 & .09 & & & .13 & .06 \\
\hline First-order AD 2 & .48 & .07 & .26 & .09 & & & & \\
\hline First-order AD 3 & .68 & .05 & .40 & .09 & & & & \\
\hline First-order AD. 4 & .48 & .08 & .33 & .09 & & & & \\
\hline \multicolumn{9}{|l|}{ Information Criteria } \\
\hline -2LogLikelihood (REML) & 7133.24 & & 6689.16 & & 5234.85 & & 4862.95 & \\
\hline AIC & 7153.24 & & 6711.62 & & 5246.85 & & 4878.95 & \\
\hline
\end{tabular}

Note. CES-D = Center for Epidemiologic Studies Depression Scale; HADS-A = Hospital Anxiety and Depression Scale-Anxiety subscale; AAQ-II = Acceptance and Action Questionnaire-II.

\section{Cross-lagged correlations between psychological flexibility, depression and anxiety}

Pearson's correlations were calculated between all the residual change scores (T0-T1, T1T2, T2-T3, T3-T4) of psychological flexibility, depression and anxiety. Synchronous correlation showed that the changes in psychological flexibility during and after the intervention were significantly related to the changes in depression and anxiety during and after the intervention. Autocorrelations showed that pre-early and mid-post psychological flexibility were significantly related to post-follow-up psychological flexibility. Furthermore, pre-early depression was significantly associated with post-follow-up depression and mid-post anxiety was significantly related to post-follow-up anxiety. Crosslagged correlations showed that mid-post psychological flexibility was significantly correlated with post-follow-up depression, whereas mid-post depression was not significantly related to post-follow-up psychological flexibility. Furthermore, mid-post psychological flexibility was significantly correlated with post-follow-up anxiety, and the 
converse correlation was also significant. Pre-early depression was significantly associated with post-follow-up psychological flexibility. The converse correlation was not significant.

Table 5. Cross-lagged Regressions for Psychological Flexibility

\begin{tabular}{|c|c|c|c|c|c|c|c|}
\hline Variable & $B$ & $S E B$ & $\begin{array}{l}\text { Adjusted } \\
\mathrm{R}^{2}\end{array}$ & & $B$ & SE B & $\begin{array}{l}\text { Adjusted } \\
\mathrm{R}^{2}\end{array}$ \\
\hline T3-T4 CES-D & & & & T3-T4 AAQ-II & & & \\
\hline Step 1 & & & & Step 1 & & & \\
\hline T2-T3 CES-D & -.085 & .053 & & T2-T3 AAQ-II & -.301 & .051 & \\
\hline T3-T4 AAQ-II & -.538 & .053 & $.288 * * *$ & T3-T4 CES-D & -.592 & .051 & $.369 * * *$ \\
\hline Step 2 & & & & Step 2 & & & \\
\hline T2-T3 AAQ-II & -.454 & .056 & $.437 * * *$ & T2-T3 CES-D & -.286 & .056 & $.428 * * *$ \\
\hline T3-T4 HADS-A & & & & T3-T4 AAQ-II & & & \\
\hline Step 1 & & & & Step 1 & & & \\
\hline T2-T3 HADS-A & -.085 & .056 & & T2-T3 AAQ-II & -.273 & .074 & \\
\hline T3-T4 AAQ-II & -.486 & .056 & $.230 * * *$ & T3-T4 HADS-A & -.560 & .069 & $.296 * * *$ \\
\hline Step 2 & & & & Step 2 & & & \\
\hline T2-T3 AAQ-II & -.364 & .059 & $.332 * * *$ & T2-T3 HADS-A & -.090 & .061 & .299 \\
\hline T3-T4 CES-D & & & & T3-T4 AAQ-II & & & \\
\hline Step 1 & & & & Step 1 & & & \\
\hline T0-T1 CES-D & -.060 & .054 & & T0-T1 AAQ-II & .134 & .053 & \\
\hline T3-T4 AAQ-II & -.528 & .054 & $.284 * * *$ & T3-T4 CES-D & -.529 & .053 & $.299 * * *$ \\
\hline Step 2 & & & & Step 2 & & & \\
\hline T0-T1 AAQ-II & -.072 & .059 & .286 & T0-T1 CES-D & -.007 & .058 & .296 \\
\hline
\end{tabular}

\section{Testing cross-lagged correlations with multiple regressions}

With the significant cross-lagged correlations, multiple regressions were performed to check whether psychological flexibility remained a predictor for the outcome variables when controlling for autocorrelations and synchronous correlations. To illustrate, in the first step with post-follow-up depression as dependent variable, mid-post depression and postfollow-up psychological flexibility were entered in the regression analyses. In step two, mid-post psychological flexibility was added. To test the converse cross-lagged correlation, mid-post psychological flexibility and post-follow-up depression were entered in the regression analyses with post-follow-up psychological flexibility as dependent variable. Mid-post depression was entered in the second step. Results in Table 5 shows that mid-post psychological flexibility significantly predicted post-follow-up depression. When testing the converse, results showed that mid-post depression significantly predicted post-followup psychological flexibility. Pre-early depression no longer significantly predicted postfollow-up psychological flexibility in the regression analyses. The converse association was also not significant. Furthermore, regression analyses showed that mid-post psychological flexibility significantly predicted post-follow-up anxiety. The converse association was not significant. 


\section{Discussion}

In this study we examined the impact of changes in psychological flexibility on the reduction of psychological distress in an early guided self-help ACT intervention. The evaluation of the intervention in a previous study showed that the intervention significantly improved psychological flexibility and reduced depression and anxiety after the intervention. At the three-month follow-up these results were maintained (see Fledderus et al., 2011). This study had three different aims. The first was to examine the mediating role of psychological flexibility. It was found that improved psychological flexibility during the intervention mediated the effects of the self-help ACT intervention on reduced depression and anxiety after the intervention. Previous studies support this finding (e.g. Forman et al., 2007; Lappalainen et al., 2007).

The second aim of study was to examine how changes in psychological flexibility over time are related to depression and anxiety. Therefore, a multilevel growth model was defined with the mediator and outcome variables using the five time measurements of the participants who received the guided self-help programme $(n=250)$. Results showed that, with an average level of psychological flexibility, the individual levels of depression and anxiety showed a negative curvilinear trend over time and then a few weeks after the intervention the levels of depression and anxiety will increase over time, indicating a parabolic curve. This means that when participants do not improve on psychological flexibility over time, they will experience increasing levels of psychological distress. This result underscores the importance of targeting psychological flexibility during an ACT intervention. These findings are in line with the theory on which ACT is built that low levels of psychological flexibility is a precursor for psychological distress and leads to high levels of psychological distress (Carriochi et al., 2011). Earlier studies already showed that low levels of psychological flexibility make people more vulnerable for developing psychopathology in reaction to various stressors (Biglan, Hayes, \& Pistorello, 2008; Kashdan, Barrios, Forsyth, \& Steger, 2006).

Our study showed that right from the beginning of the intervention, psychological flexibility had positive effects on the levels of depression and anxiety and that higher levels of psychological flexibility even had a larger positive impact on the depression and anxiety levels over time. The core aim of the self-help ACT intervention was to enhance psychological flexibility in order to reduce psychological distress. The results demonstrate that the intervention effectively achieved that aim. This study corroborates the findings of earlier studies that showed that ACT is effective in substantially reducing psychological distress in community dwelling people (Forman et al., 2007; Lappalainen et al., 2007) and that improvements in psychological flexibility are associated with reductions in psychological distress (e.g. Dalrymple \& Herbert, 2007; Kocovski et al., 2009). Only the effects of psychological flexibility on depression flatten out over time, indicating that the long-term effects on depression remain stable. This corresponds with earlier studies that 
showed that the effects on depression were sustained after an ACT intervention (e.g. Roemer et al, 2008; Fledderus et al., 2010).

The third aim of the study was to examine whether changes in depression and anxiety after the intervention were preceded by changes in psychological flexibility during the intervention. All the synchronous correlations were significant and no significant crosslagged associations between pre-early and early-post intervention changes in psychological flexibility and post-follow-up changes in psychological distress were found. Furthermore, regression analyses showed that mid-post changes in psychological flexibility predicted later changes in depression, but the reverse was also true. These findings suggest that the changes in psychological flexibility are circular; changes in psychological flexibility may account for changes in psychological distress and vice versa in the same time lags. Only the results for anxiety showed that changes in psychological flexibility at the end of the intervention predicted later changes in anxiety and not vice versa.

Taken together, the results showed that high levels of psychological flexibility can have a large long-term impact on the levels of psychological distress. It seems that especially enhancement of psychological flexibility at the end of the intervention is important for further reductions in anxiety. In the last three sessions of the intervention participants were encouraged to choose important values and act upon them even in the face of unpleasant thoughts or emotions. This requires a more regular application of the various skills the participants learn in the ACT intervention, such as acceptance, cognitive defusion and mindfulness. Our study suggests that when persons are able to incorporate these skills in daily life, they will experience less anxiety. Earlier research has shown that improved value-based actions at the end of an ACT treatment for chronic pain patients were associated with less pain and depression after the treatment (Vowles \& McCracken, 2008).

For a further validation of the ACT treatment model, it is important to determine whether psychological flexibility is a mechanism of change in an ACT intervention. Although our study largely confirms that psychological flexibility is indeed an important mechanism of change, some indicators were also found that suggest that changes in psychological flexibility and distress are more circular and that these changes occur simultaneously in the same time lags. Furthermore, since the levels of psychological distress decreased immediately from the start of the ACT intervention, our study suggests that no large improvements in psychological flexibility were needed in order to observe improvements in psychological distress. More research is needed to study whether psychological flexibility is a mechanism of change by using more time measurements, for example after each ACT session, and using other advanced analysis (Laurenceau et al., 2007). Furthermore, future studies could include other possible mechanisms of change, such as value-based behaviour or mindfulness skills.

In order to have a large impact on the public mental health, it is important that early intervention should focus on diverse mental illnesses to reach larger groups for preventive services (Cuijpers, Van Straten, Warmerdam, \& Van Rooy, 2010). The early guided ACT intervention targeted psychological inflexibility related to various mental 
illnesses. Earlier studies have shown that psychological inflexibility can be seen as an important risk factor for psychopathology (Biglan et al., 2008; Kashdan et al., 2006). By targeting this generic risk factor, the ACT intervention may thus have a broad transdiagnostic impact. Our study confirms this. More research is needed to examine whether targeting psychological inflexibility prevents the incidence of developing a mental disorder.

There are several limitations in this study. First, there was no control group in the hierarchical linear modelling analyses and cross-lagged analyses, so it is not clear whether the changes in the mediator and outcomes were attributable to the ACT intervention. However, this limitation can be mitigated. At baseline the participants showed clinically relevant symptoms of anxiety and depression. The post-intervention measurement included a control group and showed high between-effects sizes between the experimental groups and the control condition and the effects at the follow-up were sustained. Moreover, large improvements were also found in other domains such as positive mental health, mindfulness and fatigue (see Fledderus et al., 2011). Therefore, it can be presumed that these results were unlikely to occur without an intervention. A second limitation is that a relatively short follow-up period was used in this study. Future studies could include a longer follow-up period. Third, the cross-lagged panel design only uses correlations, so conclusions about causality cannot be strictly drawn from this design.

To conclude, this study is the first that examined in a large sample of people, beside the mediating role of psychological flexibility, also with in-depth analysis if and how changes in psychological flexibility occurred during and after an ACT intervention. Our study showed that changes in psychological flexibility during and after an early guided ACT intervention had a substantial long-term impact on the reduction of psychological distress. It seems that especially at the end of the ACT intervention changes in psychological flexibility are important for further reductions in anxiety. 


\section{References}

Biglan, A., Hayes, S. C., \& Pistorello, J. (2008). Acceptance and commitment: Implications for prevention science. Prevention Science, 9, 139-152.

Bohlmeijer, E. T., \& Hulsbergen, M. (2008). Voluit leven. Mindfulness of de kunst van het aanvaarden, nu als praktisch hulpboek. [Living to the Full. Mindfulness or the art of Acceptance, now as a practical help book]. Boom: Amsterdam.

Bohlmeijer, E. T., Fledderus, M., Rokx, T. A. J. J., \& Pieterse, M. E. (2011). Efficacy of an early intervention based on Acceptance and Commitment Therapy for adults with depressive symptomatology: Evaluation in a randomized controlled trial. Behaviour Research and Therapy, 49, 62-67.

Bond, F. W., Hayes, S. C., Baer, R. A., Carpenter, K. C., Guenole, N., Orcutt, H. K., Waltz, T., \& Zettle, R. D. (2011). Preliminary psychometric properties of the Acceptance and Action Questionnaire-II: A revised measure of psychological flexibility and acceptance. Behavior Therapy, 42, 676-688.

Bouma, J., Ranchor, A. V., Sanderman, R., \& van Sonderen, E. (1995). Het meten van symptomen van depressie met de CES-D, een handleiding [Measuring symptoms of depression with the CES-D, a guide]. Noordelijk Centrum voor Gezondheidsvraagstukken: Groningen.

Burns, J.W., Kubilus, A., Bruehl, S., \& Harden, R.N. (2003). Do changes in cognitivefactors influence outcome following multidisciplinary treatment for chronic pain? A cross-lagged panel analysis. Journal of Consulting and Clinical Psychology, 71, 81-91.

Ciarrochi, J., Billich, L., \& Godsell, C. (2010). Psychological flexibility as a mechanism of change in acceptance and commitment therapy. In R. Baer (Ed.), Assessing mindfulness and acceptance processes in clients: Illuminating the theory andpractice of change (pp. 51-75). Oakland, CA: Context Press/New Harbinger Publications.

Dalrymple, K. L., \& Herbert, J. D. (2007). Acceptance and Commitment Therapy for generalized social anxiety disorder: A pilot study. Behavior Modification, 31, 543568.

Dempster, A. P., Laird, N. M., \& Rubin D. B. (1977). Maximum likelihood from incomplete data via the EM algorithm. Journal of the Royal Statistical Society. Series B Methodological, 39, 1-38.

Evon, D. \& Burns, J. W. (2004). Process and outcome in cardiac rehabilitation: An examination of cross-lagged effects. Journal of Consulting and Clinical Psychology, 72, 605-616.

Fledderus, M., Bohlmeijer, E. T., Smit, F., \& Westerhof, G. J. (2010). Mental health promotion as a new goal in public mental health care: A randomized controlled trial of an intervention enhancing psychological flexibility. American Journal of Public Health, 100, 2372-2378. 
Fledderus, M., Bohlmeijer, E. T., Pieterse, M. E., \& Schreurs, K. M. G. (2012). Acceptance and commitment therapy as guided self-help for psychological distress and positive mental health:randomized controlled trial. Psychological Medicine, 42, 485-496.

Forman, E. M., Herbert, J. D., Moitra, E., Yeomans, P. D., \& Geller, P. A. (2007). A randomized controlled effectiveness trial of acceptance and commitment therapy and cognitive therapy for anxiety and depression. Behavior Modification, 31, 772-99.

Gratz, K. L., \& Gunderson, J. G. (2006). Preliminary data on an acceptance-based emotion regulation group intervention for deliberate self-harm among women with Borderline Personality Disorder. Behavior Therapy, 37, 25-35.

Haringsma, R., Engels, G. I., Beekman, A. T. F., \& Spinhoven, P. (2004). The criterion validity of the Center for Epidemiological Studies Depression Scale (CES-D) in a sample of self-referred elders with depressive symptomatology. International Journal of Geriatric Psychiatry, 19, 558-563.

Hayes, S. C., Luoma, J. B., Bond, F. W., Masuda, A., \& Lillis, J. (2006). Acceptance and commitment therapy: Model, processes and outcomes. Behaviour Research and Therapy, 44, 1-25.

Hayes, S. A., Orsillo, S. M., \& Roemer, L. (2010). Changes in proposed mechanisms of action in an acceptance-based behavior therapy for generalized anxiety disorder. Behaviour Research and Therapy, 48, 238-245.

Jacobs, N., Kleen, M., Groot, de F., \& A-Tjak, J. (2008). Het meten van experiëntiële vermijding. De Nederlandstalige versie van de Acceptance and Action Questionnaire-II (AAQ-II ). [Measuring experiential avoidance. Dutch translation of the Acceptance and Action questionnaire-II (AAQ-II) ]. Gedragstherapie, 41, 349361 .

Kabat-Zinn, J. (1990). Full catastrophe living: Using the wisdom of your body and mind to face stress, pain, and illness. New York: Delacorte.

Kabat-Zinn, J. (1994). Wherever you go, there you are: Mindfulness meditation in everyday life. New York: Hyperion.

Kadzdin, A.E. (2007). Mediators and mechanisms of change in psychotherapy researchAnnual reviewof clinical psychology, 3, 1-27.

Kashdan, T. B., Barrios, V., Forsyth, J. P., \& Steger, M. F. (2006). Experiential avoidance as a generalized psychological vulnerability: Comparisons with coping and emotion regulation strategies. Behaviour Research and Therapy, 44, 1301-1320.

Kocovski, N. L., Fleming, J., \& Rector, N.A. (2009). Mindfulness and acceptance-based group therapy for social anxiety disorder: An open trial. Cognitive and Behavioral Practice, 16, 276-289.

Lappalainen, R., Lehtonen, T., Skarp, E., Taubert, E., Ojanen, M., \& Hayes, S. C.(2007). A Preliminary controlled effectiveness trial the impact of CBT and ACT models using psychology trainee. Behavior Modification, 31, 488-511. 
Laurenceau, J., Hayes, A. M., \& Feldman, G. C. (2007). Some methodological and statistical issues in the study of change processes in psychotherapy. Clinical Psychology Review, 27, 682-695.

Olssøn, I., Mykletun, A., \& Dahl, A. A. (2005). The Hospital Anxiety and Depression rating scale: A cross-sectional study of psychometrics and case findings abilities in general practice. BMC Psychiatry, 5, 46.

Powers, M. B., Zum Vörde Sive Vörding , M. B., \& Emmelkamp, P. M. G. (2009) Acceptance and Commitment Therapy: A meta-analytic review. Psychotherapy and Psychosomatics, 78, 73-80.

Preacher, K. J., \& Hayes, A. F. (2008). Asymptotic and resampling strategies for assessing and comparing indirect effects in multiple mediator models. Behavior Research Methods, 40, 879-891.

Preacher, K. J., Hayes, A. F. (2004). SPSS and SAS procedures for estimating indirect effects in simple mediation models. Behavior Research Methods, Instruments, \& Computers, 36, 717-731.

Radloff, L.S. (1977). The CES-D scale: A self-report depression scale for research in theGeneral population. Applied Psychological Measurement, 1, 385-401.

Roemer, L., Orsillo, S. M., \& Salters-Pedneault (2008). Efficacy of an acceptance-based behavior therapy for generalized anxiety disorder: evaluation in a randomized controlled trial. Journal of Consulting and Clinical Psychology, 76, 1083-1089.

Spinhoven, P. H., Ormel, J., Sloekers, P. P. A, Kempen, G. I. J. M., Speckens, A. E. M., \& van Hemert, A. M. (1997). A validation study of the Hospital Anxiety and Depression Scale (HADS) in different groups of Dutch subjects. Psychological Medicine, 27, 363-370.

Spinhoven, P., Giesen-Bloo, J., van Dyck, R., Kooiman, K., \& Arntz, A. (2007). The therapeutic alliance in schema-focused therapy and transference-focused psychotherapy for borderline personality disorder. Journal of Consulting and Clinical Psychology, 75, 104-115.

Vowles, K. E., \& McCracken, L. M. (2008). Acceptance and values-based action in chronic pain: A study of treatment effectiveness and process. Journal of Consulting and Clinical Psychology, 76, 397-407.

Zigmond, A. S. \& Snaith, R. P. (1983). The hospital anxiety and depression scale. Acta psychiatrica Scandinavica, 67, 361-370.

Zimmerman, D. L, \& Núñez-Antón, V. A. (2009). Antedependence Models for Longitudinal Data. Chapman \& Hall. 
$148 \quad$ Chapter 7 
General discussion 


\section{Discussion}

Depression is a major public mental health challenge associated with a considerable burden of disease and economic costs. As many people suffer from clinically relevant symptoms and consequently are at a high risk of actually developing a major depression, prevention interventions are crucial for reducing the onset thereof. In this thesis a new prevention intervention for adults with mild to moderate depression was introduced. The main aims of this intervention, based on Acceptance and Commitment Therapy (ACT) and called "Living to the full", are to reduce psychological distress and promote positive mental health by enhancing psychological flexibility and mindfulness. The "Living to the full" programme has been developed as both a group and self-help course. This chapter will first address the psychometric properties of a measurement that assesses psychological flexibility. Following this is the discussion of the main results of the randomized controlled trials on the effectiveness of the "Living to the full" programme and several implications for the implementation of the programme. Finally, the strengths and limitations of this thesis will be broached as well implications for future studies.

\section{Measuring psychological flexibility}

The Acceptance and Action Questionnaire-II (AAQ-II) is a self-report instrument that measures the ability to accept aversive internal experiences and to pursue goals and values in the presence of these experiences - a construct referred to as psychological flexibility (Bond et al., 2011). Bond et al. (2011) prefer to use psychological flexibility or its reverse inflexibility as the overarching terms of the ACT-model that is measured with the AAQ-II instead of using the terms acceptance or its reverse experiential avoidance (EA). The processes acceptance and EA can be understood as examples of psychological flexibility and inflexibility, respectively. For example, the main focus of an ACT treatment is not necessarily the avoidance of unwanted private experiences, rather it may be on the identification of values. However, when ACT was originally conceived the overarching term of the ACT-model was mainly the reduction of experiential avoidance (or increasing acceptance). Therefore, in many studies they refer to experiential avoidance (or acceptance) when using the AAQ-II (e.g., Costa \& Pinto-Gouveia, 2011; Wheaton, Berman, \& Abramowith, 2010). According to Bond et al. (2011) it is still appropriate to use these terms for describing the AAQ-II.

The AAQ-II is developed because the earlier version (AAQ) has several limitations concerning the internal and incremental validity (Chawla \& Ostafin, 2007). Due to the broad item content of the different related constructs of EA, such as the need for emotional and cognitive control, avoidance of negative private events and inability to take needed action in the face of private events, it is unclear whether the AAQ measures one overarching construct or a multidimensional construct (Chawla \& Ostafin, 2007). Furthermore, it is unclear what the AAQ adds to other theoretically related constructs that also represent motivation to accept or avoid aversive private experiences, such as 
mindfulness and thought-suppression scales (Chawla \& Ostafin, 2007). To overcome these limitations the AAQ-II was developed (Bond et al., 2011).

To date, few studies have assessed the psychometric properties of the AAQ-II with classical tests (such as confirmative factor analyses) (Bond et al., 2011; Jacobs, Kleen, De Groot, \& A-Tjak, 2008; McCracken \& Zhao-O'Brien, 2010). Chapter 2 expands on the previous evaluation of the psychometric properties of the AAQ-II by using more advanced and robust methods based on Item Response Theory (IRT). With these methods, we provided further empirical support that the AAQ-II is a valid and reliable measure to assess psychological flexibility in adults with depressive symptomatology.

It is important to demonstrate that the AAQ-II contributes to information beyond that which is attained by other theoretically linked constructs that also involve the ability to accept personal events, such as mindfulness, or actions to change aversive personal experiences, such as maladaptive coping styles (passive, avoidance and palliative coping). In Chapter 3, it was shown that the AAQ-II was not associated with avoidant and palliative coping and moderately with passive coping. Furthermore, the AAQ-II mediated the effects of passive coping on psychological distress and emotional and psychological well-being. This finding corroborates the concept of AAQ-II as an important construct that differs from the way people cope with their problems or unpleasant situations. We also found that the AAQ-II accounted for a higher proportion of variance in predicting depression and positive mental health when added to five mindfulness facets as measured with the Five Facet Mindfulness Questionnaire (FFMQ; Baer, Smith, Hopkins, Krietemeyer, \& Toney, 2006). This implies that AAQ-II has a unique role in predicting these outcomes above and beyond these mindfulness facets hence justifying its use in studies.

To study the effectiveness of the "Living to the full" programme, the AAQ-II was used as a measure of experiential avoidance (Chapter 4) or as psychological flexibility (Chapters 5-7). These studies showed that moderate to large changes in the AAQ-II were observed before, during and after the "Living to the full" programme. Furthermore, we found that the improvements in psychological flexibility mediated the effects of the intervention on depression, anxiety and positive mental health. In addition, in Chapter 7 it was shown that changes in psychological flexibility during and after an early guided ACT intervention had a substantial long-term impact on the reduction of depression and anxiety. These findings show that the AAQ-II is moderately to highly sensitive to change within a public mental health context. This means that the AAQ-II can measure changes in psychological (in)flexibility as a result of an ACT intervention.

In sum, the results showed that the AAQ-II is a useful measure with good psychometric properties for assessing the process of change in psychological flexibility during and after an ACT intervention. However, several limitations must be addressed. Although the AAQ-II was developed as a overall measure of all six interrelated processes that were described in the first chapter for assessing psychological flexibility, it seems that the AAQ-II is mainly focused on the unwillingness of experience unwanted private experiences and less on the identification of values and living according to these values. 
There are three out of ten items in the AAQ-II that are related to value-based behavior, but these items share largely the same content (e.g., "My painful memories prevent me from having a fulfilling life" and "My painful experiences and memories make it difficult for me to live a life that I would value"). It is unclear whether these items suffice to measure commitment to value-based behavior and the process of value clarification is not well covered. In Chapter 7, it was shown that when participants were able to identify their values and live according their values by the end of the ACT intervention, a greater reduction in anxiety was later observed. Also earlier research has shown that improved value-based actions at the end of an ACT treatment for chronic pain patients were associated with less pain and depression after the treatment (Vowles \& McCracken, 2008). Therefore, it seems that assessing the discovery of values and value-based behaviour as a processes of change in an ACT intervention in a more comprehensive way is recommended. At the moment, the University of Twente is developing a questionnaire, called the Twente Values Scale, that is focused on measuring the process of valuing and living according to these values. Preliminary analyses showed good psychometric properties (Trompetter et al., in preparation).

Another limitation of the AAQ-II is that some difficulties were detected with the seven response options used. Our study showed that the participants were unable to consistently distinguish between the seven response options nor did they elect the lowest and highest response options. As the AAQ-II is used as a sum score, it is worthwhile to further investigate the utility of the current response format in different settings.

\section{Broad impact of the "Living to the full" programme}

In Chapters 4-6 the effectiveness of the indicated prevention "Living to the full" programme based on ACT was investigated in two randomized controlled trials with a waiting list as a control group. Medium to high effect sizes were found on depression and anxiety after the group and self-help course and at the three-month follow-up. These findings are highly relevant because people with clinically relevant symptoms of depression and anxiety have a higher risk of developing a mental health disorder (Cuijpers \& Smit, 2004). We found that improvements in psychological flexibility during the intervention mediated the effects of either course on depression and anxiety after the intervention and at the three-months follow-up. This is supported further by the finding of the multi-level modelling (Chapter 7), namely that if participants in the self-help course showed no improvement over time in their levels of psychological flexibility, their levels of depression and anxiety were increased after the intervention. Together these findings are in line with the theory on which ACT is built, namely that psychological inflexibility is a precursor of psychological distress and leads to high levels of psychological distress (Ciarrochi, Billich, \& Godsell, 2010).

By targeting this generic risk factor for mental health illness (Biglan, Hayes, \& Pistorello, 2008), it seems that the programme is suitable for people with both depression and/or anxiety symptoms. This would mean that even a larger group for prevention services 
could be reached (Cuijpers, Van Straten, Warmerdam, Van Rooy, 2010). This seems especially relevant, because there is high comorbidity between depression and anxiety (Preisig, Merikangas, Angst, 2001). Besides the reductions in anxiety and depression, the group and the self-help course were shown to be effective in reducing fatigue. Reducing fatigue is important because it is related to both poorer psychological and physical health (Cardol, Bensing, Verhaak, \& De Bakker, 2005). These results support previous studies that demonstrated that ACT is effective in the treatment of depression and anxiety (Dalrymple \& Herbert, 2007; Forman, Herbert, Moitra, Yeomans, Geller, 2007; Kocovski, Fleming, \& Rector, 2009; Lappalainen et al., 2007; Muto, Hayes, \& Jeffcoat, 2011). Furthermore, the results corroborate the findings from previous studies that indicated prevention interventions based on cognitive behavioral techniques implemented as a course can substantially reduce psychological distress (Cuijpers, Smit \& Van Straten, 2007). To the best of our knowledge, we have conducted the first study that explored the effects of a similar course based on ACT and that showed the suitability of ACT for indicated prevention intervention.

The "Living to the full" programme differs from the current indicated prevention by aiming the intervention on the promotion of positive mental health rather than primarily focusing on the reduction or prevention of mental illness. The main focus of most prevention interventions is on what is going wrong with people which make the disease even more central in the intervention (Maddux, 2009). For example, the widely available "Coping with depression" course is a psycho-educational intervention based on cognitive behavioral techniques. In the intervention clients learn different skills, such as restructuring negative cognitions and behavioural activation to increase pleasant events, that help them in coping with their depression. The main focus of outcome is the reduction of depression symptoms (Cuijpers, Muñoz, Clarke, \& Lewinsohn, 2009). ACT broadens this focus to the development of generally applicable skills aimed at the promotion of positive mental health (Orsillo, Roemer, \& Holowka, 2005). With these skills clients learn to engage in activities that are line with their personal values and goals in various important life domains (Orsillo et al., 2005). ACT emphasizes explicitly on changes that will lead to a more fulfilling, vital and meaningful life, instead of only focusing on those behaviors that are avoided or feared in order to reduce depression or anxiety (which is more common for cognitive behavioural approaches) (Orsillo et al., 2005). This indicates that ACT is more health-oriented than illness-oriented.

This focus is in line with the recent reorientation on mental health care. There is a need to shift the focus more toward the promotion of positive mental health, rather than solely the treatment of mental illness (Slade, 2010; Power, 2010). This complies to the recent approach to mental health, namely, that positive mental health is more than the absence of mental illness (Keyes, 2005; Keyes, Dhingra, \& Simoes, 2010). The World Health Organization (2005) also underscores the importance of mental health promotion as a new goal for public health. Positive mental health does have important individual, societal, and economic consequences, as already discussed in the introduction of this thesis. 
Positive mental health promotion is therefore an important and complementary activity with mental illness prevention (Power, 2010). An important challenge for the coming years is, therefore, to study whether and how positive mental health can be effectively promoted. In the "Living to the full" programme the competences psychological flexibility and mindfulness were targeted for the promotion of positive mental health.

The "Living to the full" programme proved to effectively promote positive mental health confirming previous research showing that ACT interventions promote emotional well-being (e.g. life satisfaction or quality of life) in patients with anxiety or depression (e.g. Forman et al., 2007; Lappalainen et al., 2007). We found that both emotional and psychological well-being were improved. Participants who followed the guided self-help programme also reported increased social well-being. In Chapter 5 we provide the first evidence that positive mental health can be promoted by stimulating skills for acceptance and value-based action. In the "Living to the full" programme clients are encouraged to discover their values on various life domains and to take action even in the presence of unwanted personal experiences. They learn to have a willingness stance towards all private experiences, not only depression symptoms but towards all possible emotions that might occur towards a value-based living. By learning to consistently choose to act effectively in any given situation, behaviour repertoires will be developed that are broad, flexibly, effective and values driven (Ciarrochi et al., 2010; Orsillo et al., 2005). Because the competence psychological flexibility is so broadly applicable, it might have long-term beneficial effects on emotional, social and psychological well-being. Furthermore, a person with higher levels of positive well-being is less vulnerable for developing a mental illness (Wood \& Joseph, 2010). A recent study of Vowles, McCracken, and O’Brien (2011) showed that even after three years after an ACT treatment psychological flexibility had positive effects on the daily function of people with chronic pain.

Another competence that is targeted in the ACT programme is mindfulness. In the ACT programme mindfulness exercises were augmented with short meditational exercises. Large effect sizes were found after the guided self-help course on the mindfulness skills acting with awareness, nonjudging and nonreactivity as measured with the FFMQ (Baer et al., 2006; Bohlmeijer, Ten Klooster, Fledderus, Veehof, \& Baer, 2011). The effects of the "Living to the full" programme corroborates earlier studies that showed that the combination of ACT and mindfulness is effective for generalized anxiety (Roemer, Orsillo, \& Salters-Pedneault 2008) and social anxiety disorder (Kokovski, Fleming, \& Rector, 2009). Also the combination of mindfulness with Cognitive Behavioural Therapy has been found to be effective for recurrent depression (Ma \& Teasdale, 2004; Godfrin \& Van Heeringen, 2010; Kuyken et al., 2008). A recent study showed that the effects of Mindfulness-based Cognitive Therapy for patients with recurrent depression were mediated by mindfulness skills on the reduction of depression symptoms at a 15-month follow-up (Kuyken et al., 2010). This suggests that the development of mindfulness skills have a longterm impact on relapse prevention of depression. In the "Living to the full" programme mindfulness is not merely learned as a skill for reducing distress, but rather as a skill that 
supports psychological flexibility and positive mental health. By this broader application, the development of mindfulness skills might have a long-term impact on both mental illness prevention and mental health promotion. However, future studies need to further address this. Brown and Ryan (2003) showed in their study that mindfulness enhances well-being and indicated that when individuals are acting more mindfully they live more according to their values and interest.

To conclude, it appeared that ACT is effective in promoting positive mental health and reducing psychological distress by targeting psychological flexibility and enhancing mindfulness. By targeting these positive skills, the "Living to the full" programme showed to have a substantial impact on public mental health.

Several implications for future studies can be given. First, future studies on the effectiveness of ACT could consider positive mental health as a primary outcome of the intervention. Whereas all present ACT effectiveness studies mainly assess psychological distress as the primary outcome, the main goal of ACT is, as already described above, not to eliminate distress. Also therapists who work with ACT could shift their focus to both the promotion of mental health and the reduction of psychological distress, particularly because, and as already described in the introduction, curing mental illness does not necessarily - nor automatically - lead to positive mental health (Slade, 2010; Keyes, 2005).

Second, future studies could also examine whether an ACT intervention is effective for people with low positive mental health, because this is a group that has a higher risk of developing a mental health disorder (Wood \& Joseph, 2010, Keyes, Dhingra, \& Simoes, 2010). By including both people with clinically relevant symptoms of psychological distress and/or with low positive mental health, a larger group of people can possibly be reached for prevention services. The reason for this might be because people with low positive mental health do not necessarily have clinically relevant symptoms of mental illnesses (Keyes, 2005).

\section{Implementation of the "Living to the full" programme}

With the intervention appearing to be effective, nationwide implementation of the "Living to the full programme" is an important next step. The group course is currently being implemented at at least thirteen mental health institutions in the Netherlands, indicating that the course has been adopted in regular practice (Dijkstra \& Ruiter, 2011). Chapter 5 showed that the self-help course with minimal e-mail counselling achieved similar effect sizes as the extensive e-mail counselling. This implies that the self-help programme with email counselling can be easily implemented at mental health care institutions, because it demands little therapy time and it is probably more cost-effective than face-to-face therapy (Smit et al., 2006). Furthermore, it offers several advantages to the clients, because participating in a self-help course reduces travel time, allows them to participate from home and avoids the stigma of going to a therapist (Cuijpers \& Schuurmans, 2007). In our studies, we found that the self-help course attracted a different group of participants than those in the group course. The group course was a heterogeneous group, with great 
diversity in education and daily activities. The self-help course, on the other hand, mainly attracted highly educated employed women, which is not uncommon for self-help (online) interventions (Carlbring et al., 2007). Hence self-help intervention might reach other people who are not willing to participate in a face-to-face intervention. Offering self-help as well as group courses may increase the reach of prevention services at the mental health institutions.

It appeared that the participants were satisfied with the "Living to the full" programme. The participants evaluated both the group course and the self-help course with on average an 8 (on a scale from 1 to 10). Most participants evaluated the programme as good and useful. The compliance with the "Living to the full" programme was satisfactory. Furthermore, it appeared that the threshold for enrolling in the "Living to the full" programme is low. In 2010, it was calculated that the 13 mental health services conducted the group course 53 times and that in total 500 people participated (Dijkstra \& Ruiter, 2011). This suggests that group course is accessible to people with mild to moderate psychological distress. As the programme is aimed at promoting positive competences, it allows the programme to have a more positive connotation instead of including the name of the distress (i.e. that of which people want to rid themselves, such as depression or anxiety). The positive-sounding "Living to the full" might be more appealing and reduce the stigma associated with mental illness for people with psychological distress. This is also supported by the fact that more than 600 people responded to the advertisements that included a positive slogan ("I want to get more out of my life") and $60 \%$ of whom were included in the study. After five days of advertising, the registration period had to be closed because we were not able to include more participants in the study. On account of the difficulty of reaching people with clinically relevant symptoms, it is a beneficial finding that both the group and the self-help course are apparently regarded as accessible by adults with mild to moderate depression and/or anxiety. However, more research is needed to investigate whether a more positive name or positive slogan in a recruitment strategy is indeed more attractive for people with clinically relevant symptoms of depression or anxiety. This might afford greater insight into which recruitment strategy is the most optimal for reaching the target group.

In order to reach more people, it should be determined how the programme can be targeted to a patient's profile. First, it should be examined how the "Living to the full" programme can be adapted to ethnic minority groups, i.e. Turkish and Moroccan clients. These groups often have to wait longer to receive help and have less contact with professionals at mental health institutions (Fassaert et al., 2010). Most of these clients lack adequate proficiency of the Dutch language - a problem that might be solved by offering the (self-help) "Living to the full" programme in other languages. Second, it might warrant investigation into whether the intervention could be targeted to people with a low social economic status, as this is clearly associated with depression (Lorant et al., 2007). One important modification could be the use of comics to illustrate the intervention's main concepts and metaphors. A project about these modifications is in preparation. 
In order to have a large impact on public mental health it is important that the "Living to the full" programme is available on a large scale. This can be achieved by implementing the programme as an online programme. The "Living to the full" programme has already been developed as an online programme and several studies are currently being conducted to examine whether the online programme with automatic or personal feedback is effective for people with mild to moderate distress. The advantage of an online programme is that it can easily be implemented at mental health care institutions and is probably more cost-effective than face-to-face therapy (Warmerdam, Smit, Van Straten, Riper, \& Cuijpers, 2010). Furthermore, the online programme can be specified to the patients' different needs, i.e. that a client can choose his/her own modules. Choosing online modules based on personal interests and needs seems to be very effective for patients with anxiety (e.g. Andersson, Estling, Jakobsson, Cuijpers, \& Carlbring, 2010).

Another way of implementing the "Living to the full" programme on a larger scale is to implement it in primary care. Apparently many patients generally prefer to consult their general practitioner for treatment for mild to moderate depression or anxiety. The general practitioner might have the advantage of being more accessible, affordable and less stigmatizing than mental health services. Earlier research already has shown that cliniciansupported online cognitive behavioural therapy in primary care is effective for mild to moderate depression and anxiety (Sørensen Høifødt, Strøm, Kolstrup, Eisemann, \& Waterloo, 2011).

\section{Strengths and limitations}

Several strengths and limitations of this thesis must be mentioned. One strength is that the group course was evaluated in its natural setting, hence supporting its external validity. The recruitment strategy used in the study is comparable to that used in daily practice by mental health services. Also, the mental health services that participated in the study are comparable to other mental health services in the Netherlands, which underscores the generalizability of the findings. Another strength is the high number of participants who were included in the study of the effectiveness of the self-help intervention. It is the first study that examined the effects of an ACT intervention in such a large sample.

A limitation is that no instruments for diagnosing mental disorders were used in the effectiveness study of the group course of the "Living to the full" programme, so it was unclear how many participants suffered from a mental disorder before and after the intervention. This limitation can be mitigated, because in the study all the participants were assessed for eligibility by trained psychologists during clinical face-to-face interviews. Based on their expertise and experience, people with severe distress were excluded from the study. In the study of the effectiveness of the self-help course only partial and limited use was made of a diagnostic instrument. The MINI was used for diagnosing severe depressive episodes with people who scored positively on the WSQ but who did not meet the exclusion criterion of a severe depressive disorder. Hence, the samples in the studies of the effectiveness of the "Living to the full" programme therefore probably consisted of both 
people with clinically relevant depressive symptoms and people with mild to moderate depressive disorders. However, this limitation can also be seen as strength. Apparently, the inclusion of a heterogeneous population with regard to their range of depressive symptomatology did not negatively affect treatment effectiveness. For example, we found that for both high levels of depression and lower levels of depression at baseline the selfhelp intervention was effective. Both trials were not conducted in ideal circumstances but pragmatically followed daily practices.

It would have strengthened the designs of the effectiveness studies of the "Living to the full" programme if longer follow-up periods had been included. Although we found that the effects were sustained at the three-month follow-up, a longer follow-up period could detect whether these effects were also sustained for a longer period, for example at 6 months and after 1 year. Furthermore, it would have strengthened the designs if the "Living to the full" programme had not only been compared to a waiting list control group but also to an active control group. In our studies we could not control for non-specific factors, such as social interaction and therapeutic alliance.

\section{Implications for future research}

Several implications for future research can be given. There is a need to investigate the whether the intervention is effective in reducing the incidence of mental health disorders. The use of diagnostic instruments and a longer follow-up is hence called for, as is the comparison of the intervention with an active control group. With more data on whether the intervention can reduce the incidence of depression and anxiety and on the costs (e.g., material, health care costs), a cost-effectiveness analysis of the programme could be performed. Cost-effectiveness analyses generate important information for the mental health institutions and other stakeholders, such as health insurance companies.

Further studies on possible moderators might optimize the ACT intervention because more information will be collated on for whom the intervention is the most effective. Moderator analyses on the guided self-help intervention showed that there were no significant intervention effects for gender or education, indicating that the intervention is potentially broadly applicable.

In Chapter 7, we evaluated in a large sample with multiple measurements how psychological flexibility was related over time to depression and anxiety. To date, this is the first study that assessed with advanced analyses (i.e. multilevel modelling and crosslagged analyses) in a large group of participants the impact of the changes in psychological flexibility during and after an ACT intervention. We found some indicators that psychological flexibility and psychological distress were more circular; psychological flexibility may account for changes in psychological distress and vice versa. More research is needed to examine this finding further with, for example, measurements after each ACT session. Also, future studies could include other possible mechanisms of change, such as value-based behaviour or mindfulness skills. With more knowledge of the mechanism of change, these components might be intensified in an ACT treatment to make the 
intervention more effective. The use of qualitative research methods could provide more information about which processes of the programme were the most effective for the participants and why.

It needs to be addressed further how the "Living to the full" programme can be adapted to a client's profile, such as someone's ethnic background or low social economic status. Also other applications of the programme can be examined further, such as offering the programme as an online application. Earlier studies have shown that ACT is also applicable to other target groups, such as people with chronic pain (Veehof, Van Oskam, Schreurs, \& Bohlmeijer, 2011). The self-help programme is already adopted to people with chronic pain, called "Living with pain" (Veehof, Schreurs, Bohlmeijer, Hulsbergen, 2010). Currently the programme is investigated.

\section{Conclusion}

Overall, we conclude that a new preventive programme has become available that is based on a health model and not on a disease model. Both reduction of psychological distress and promotion of positive mental health are important outcomes. This thesis found that the effectiveness of this programme is promising. The programme is already widely implemented in mental health care. Evaluation of long term effects is now warranted. 


\section{References}

Andersson, G., Estling, F., Jakobsson, E., Cuijpers, P., \& Carlbring, P. (2011). Can the patient decide which modules to endorse? An open trial of tailored Internet treatment of anxiety disorders. Cognitive Behaviour Therapy, 40, 57-64.

Baer, R. A., Smith, G.T., Hopkins, J., Krietemeyer, J., \& Toney, L. (2006). Using selfreport assessment methods to explore facts of mindfulness. Assessment, 13, 27-45.

Biglan, A., Hayes, S. C., \& Pistorello, J. (2008). Acceptance and commitment: implications for prevention science. Prevention Science, 9, 139-152.

Bohlmeijer, E.T, ten Klooster, P. M., Fledderus, M., Veehof, M., \& Baer, R. (2011). Psychometric properties of the Five Facet Mindfulness Questionnaire in depressed adults and development of a short form. Assessment, 18, 308-320.

Bond, F. W., Hayes, S. C., Baer, R. A., Carpenter, K. C., Guenole, N., Orcutt, H. K., Waltz, T., \& Zettle, R.D. (2011). Preliminary psychometric properties of the Acceptance and Action Questionnaire-II: a revised measure of psychological flexibility and acceptance. Behavior Therapy, 42, 676-688.

Brown. K. W., \& Ryan, R. M. (2003). The Benefits of Being Present: Mindfulness and Its Role in Psychological Well-Being. Journal of Personality and Social Psychology, 84, 822-848.

Cardol, M., Bensing, J., Verhaak, P., \& de Bakker, D. (2005). Moeheid: determinanten, beloop en zorg. [Fatigue: Determinants, development and care]. Utrecht: NIVEL.

Carlbring, P., Gunnarsdottir, M., Hedensjo, L., Andersson, G., Ekselius, L., \& Furmark, T. (2007). Treatment of social phobia, randomized trial of Internet-delivered cognitive behavioural therapy with telephone support. British Journal of Psychiatry, 90, 123 128.

Chawla, N., \& Ostafin, B. (2007). Experiential avoidance as a functional dimensional approach to psychopathology: An empirical review. Journal of Clinical Psychology, 63, 871-890.

Ciarrochi, J., Billich, L., \& Godsell, C. (2010). Psychological flexibility as a mechanism of change in acceptance and commitment therapy. In R. Baer (Ed.), Assessing mindfulness and acceptance processes in clients: Illuminating the theory and practice of change (pp. 51-75). Oakland, CA: Context Press/New Harbinger Publications.

Costa, J., \& Pinto-Gouveia, J. (2011). The mediation effect of experiential avoidance between coping and psychopathology in chronic pain. Clinical Psychology \& Psychotherapy, 18, 34-47.

Cuijpers, P., van Straten, A., Warmerdam, L., \& van Rooy, M. J. (2010). Recruiting participants for interventions to prevent the onset of depressive disorders. Possible ways to increase participation rates. BMC Health Services Research, 10, 181. 
Cuijpers, P., \& Schuurmans, J. (2007). Self-help interventions for anxiety disorders: an overview. Current Psychiatry Reports, 9, 284-290.

Cuijpers, P., \& Smit, F. (2004). Subthreshold depression as a risk indicator for major depressive disorder, a systematic review of prospective studies. Acta Psychiatrica Scandinavica, 109, 325-331.

Cuijpers, P., Smit, F., \& Straten, A. van. (2007). Psychological treatments of subthreshold depression, a meta-analytic review. Acta Psychiatrica Scandinavica, 115, 434-441.

Cuijpers, P., Straten, A. van, Smit, F., Mihalopoulos, C., \& Beekman, A. (2008). Preventing the onset of depressive disorders, a meta-analytic review of psychological interventions. American Journal of Psychiatry, 65, 1272-1280.

Cuijpers, P., Muñoz, R.F., Clarke, G.N., Lewinsohn, P.M. (2009). Psychoeducational treatment and prevention of depression: the "Coping with Depression" course thirty years later. Clinical Psychology Review, 29, 449-458.

Dahl, J., Wilson, K. G., \& Nilsson, A. (2004). Acceptance and commitment therapy and the treatment of persons at risk for long-term disability resulting from stress and pain symptoms: a preliminary randomized trial. Behavior Therapy, 35, 785-801.

Dalrymple, K. L., \& Herbert, J. D. (2007). Acceptance and Commitment Therapy of generalized social anxiety disorder: a pilot study. Behavior Modification, 31, 543568 .

Dijkstra, M., \& Ruiter, M. (2011). Aard en Omvang GGZ-en Verslavingspreventie 2010: Ontwikkelingen in de inhoud, organisatie en omvang van de GGZ- en Verslavingspreventie. Trimbos Institute.

Fassaert, T., Peen, J., van Straten, A., de Wit, M., Schrier, A., Heijnen, H., Cuijpers, P., Verhoeff, A., Beekman, A., \& Dekker, J. (2010). Ethnic Differences and Similarities in Outpatient Treatment for Depression in the Netherlands. Psychiatric Services, 61, 690-697.

Forman, E. M., Herbert, J. D., Moitra, E., Yeomans, P. D., \& Geller, P. A. (2007). Randomized controlled effectiveness trial of acceptance and commitment therapy and cognitive therapy for anxiety and depression. Behavior Modification, 31, 772799.

Godfrin, K. A., \& van Heeringen, C. (2010). The effects of mindfulness based cognitive therapy on recurrence of depressive episodes, mental health and quality of life: A randomized controlled study. Behaviour Research and Therap , 48, 738-746.

Jacobs, N., Kleen, M., de Groot, F., \& A-Tjak, J. (2008). Het meten van experiëntiële vermijding. De Nederlandstalige versie van de Acceptance and Action Questionnaire-II (AAQ-II ) [Measuring experiential avoidance. Dutch translation of the Acceptance and Action questionnaire-II (AAQ-II)]. Gedragstherapie, 41, 349361.

Kashdan, T. B., Barrios, V., Forsyth, J. P., \& Steger, M. F. (2006). Experiential avoidance as a generalized psychological vulnerability: Comparisons with coping and emotion regulation strategies. Behaviour Research and Therapy, 44, 1301-1320. 
Keyes, C. L. M. (2005). Mental illness and/or mental health? Investigating axioms of the complete state model of health. Journal of Consulting and Clinical Psychology, 73, 539-548.

Keyes, C. L. M., Dhingra, S. S., Simoes, E. J. (2010). Change in level of positive mental health as a predictor of future risk of mental illness. American Journal of Public Health, 10, 2366-2371.

Kocovski, N. L., Fleming, J., \& Rector, N. A. (2009). Mindfulness and acceptance-based group therapy for social anxiety disorder: An open trial. Cognitive and Behavioral Practice, 16, 276-289.

Kuyken, W., Byford, S., Taylor, R. S., Watkins, E., Holen, E., ... Teasdale J. D. (2008). Mindfulness-based cognitive therapy to prevent relapse in recurrent depression. Journal of Consulting and Clinical Psychology, 76, 966-978.

Kuyken, W., Watkins, E., Holden, E., White, K., Taylor, R. S., ... Dalgleish T. (2010). How does mindfulness-based cognitive therapy work? Behaviour Research and Therapy, 48, 1105-1112.

Lappalainen, R, Lehtonen, T., Skarp, E., Taubert, E., Ojanen, M., \& Hayes, S.C. (2007). Preliminary controlled effectiveness trial: the impact of CBT and ACT models using psychology trainee. Behavior Modification, 31, 488-511.

Lorant, V., Croux, C., Weich, S., Deliege, D., Mackenbach, J., Ansseau, M. (2007). Depression and socio-economic risk factors: 7-year longitudinal population study. British Journal of Psychiatry, 190, 293-298.

Ma, S. H., \& Teasdale, J. D. (2004). Mindfulness-based cognitive therapy for depression: Replication and exploration of differential relapse prevention effects. Journal of Consulting and Clinical Psychology, 72, 31-40.

Maddux, J. E. (2009). Stopping the "madness": positive psychology and deconstructing the illness ideology and the DSM. In: Lopez, S.J., Snyder, C.R., eds. (2009). Oxford Handbook of Positive Psychology. New York; Oxford University Press, 61-69.

McCracken, L. M., \& Zhao-O'Brien, J. (2010). General psychological acceptance and chronic pain: there is more to accept than the pain itself. European Journal of Pain, 14, 170-175.

Muto, T., Hayes, S. C., \& Jeffcoat, T. (2011). The effectiveness of Acceptance and Commitment Therapy bibliotherapy for enhancing the psychological health of Japanese college students living abroad. Behavior Therapy, 42, 323-35.

Orsillo, S. M., Roemer, L., \& Holowka, D. (2005). Acceptance-based behavioral therapies for anxiety: Using acceptance and mindfulness to enhance traditional cognitivebehavioral approaches. In S. M. Orsillo \& L. Roemer (Eds.), Acceptance- and mindfulness-based approaches to anxiety: Conceptualization and treatment. New York: Springer.

Power, A. K. (2010) Transforming the nation's health: Next steps in mental health promotion. American Journal of Public Health, 100, 2343-2346. 
Preisig, M., Merikangas, K. R., \& Angst, J. (2001). Clinical significance and comorbidity of subthreshold depression and anxiety in the community. Acta Psychiatrica Scandinavica, 104, 96-103.

Slade, M. (2010). Mental illness and well-being: the central importance of positive psychology and recovery approaches. BMC Health Services research, 10, 26.

Smit, F., Willemse, G., Koopmanschap, M., Onrust, S., Cuijpers, P., \& Beekman, A. (2006). Cost-effectiveness of preventing depression in primary care patients. Randomised Trial. British Journal of Psychiatry, 188, 330-336.

Sørensen Høifødt, R., Strøm, C., Kolstrup, N., Eisemann, M., \& Waterloo, K. (2011). Effectiveness of cognitive behavioural therapy in primary health care: a review. Family Practice, 0, 1-16.

Trompetter, H. R, Schreurs, K. M. G., ten Klooster, P. M., Fledderus, M., \& Bohlmeijer, E. T. (in preparation). Evaluation of the psychometric properties of the Twente Values Scale.

Veehof, M. M., van Oskam, J., Schreurs, K. G. M., \& Bohlmeijer, E. T. (2011). Acceptance-based interventions for the treatment of chronic pain: A systematic review and meta-analysis. Pain, 152, 533-542.

Veehof, M., Schreurs, K. M. G., Hulsbergen, M., \& Bohlmeijer. E. T. (2010). Leven met pijn. De kunst van het aanvaarden. Amsterdam: Uitgeverij Boom.

Vowles, K. E., \& McCracken, L .M. (2008). Acceptance and values-based action in chronic pain: A study of treatment effectiveness and process. Journal of Consulting and Clinical Psychology, 76, 397-407.

Vowles, K. E., McCracken, L. M., O'Brien, J. Z. (2011). Acceptance and values-based action in chronic pain: A three-year follow-up analysis of treatment effectiveness and process. Behaviour Research and Therapy, 49, 748-55.

Warmerdam, L., Smit, F., van Straten, A., Riper, H., \& Cuijpers, P. (2010). Cost-utility and cost-effectiveness of internet-based treatment for adults with depressive symptoms: randomized trial. Journal of Medical Internet Research, 12, 53.

Wheaton, M. G., Berman, N. C, \& Abramowitz, J. S. (2010). The contribution of experiential avoidance and anxiety sensitivity in the prediction of health anxiety. Journal of Cognitive Psychotherapy, 24, 229-239.

Wood, A. M., \& Joseph, S. (2010). The absence of positive psychological (eudemonic) well-being as a risk factor for depression, a ten-year cohort study. Journal of Affective Disorders, 122, 213-217.

World Health Organization. (2005). Promoting mental health; concepts, emerging evidence,practice. Geneva; WHO. 
164 Chapter 8 


\section{Summary in Dutch}




\section{Summary in Dutch}

In het eerste hoofdstuk werd beschreven dat preventieve interventies die zich richten op mensen met lichte tot matige depressieklachten nodig zijn om te verkomen dat deze mensen een depressieve stoornis ontwikkelen. Depressie heeft een hoge ziektelast en veroorzaakt hoge zorgkosten en economische kosten. Ondanks het feit dat er in Nederland effectieve preventieve interventies bestaan die gericht zijn op het verminderen van depressieklachten, bereiken deze interventies vaak niet de doelgroep. Het huidige aanbod in preventieve interventies gaat voornamelijk uit van een ziektemodel, terwijl uit onderzoek blijkt dat geestelijke gezondheid meer is dan alleen de afwezigheid van geestelijke ziekte. In dit hoofdstuk werd daarom beargumenteerd dat een interventie die zich niet alleen richt op het verminderen van psychische klachten, maar ook op het versterken van positieve geestelijke gezondheid een mogelijke oplossing is voor het verhogen van deelname aan deze interventies. Een therapie die hierbij goed aansluit is Acceptance and Commitment Therapy (ACT) gecombineerd met mindfulness. Verder werd in dit hoofdstuk een introductie gegeven van de theoretische achtergrond van ACT. ACT is gericht op het verlagen van de experiëntiële vermijding door het verhogen van de psychologische flexibiliteit. Psychologische flexibiliteit is het vermogen om negatieve gevoelens en gedachten te accepteren, in contact te blijven met het huidige moment en om in elke situatie vanuit de eigen waarden te blijven handelen. Mindfulness is het vermogen om zonder oordeel op te merken wat zich van moment tot moment aan iemand voordoet. De preventieve cursus "Voluit leven" is gebaseerd op ACT en mindfulness en is bedoeld voor mensen met milde tot matige depressieklachten. De interventie is gericht op het bevorderen van de positieve geestelijke gezondheid en op reductie van psychisch leed. Positieve geestelijke gezondheid wordt bevorderd door het versterken van de vaardigheden psychologische flexibiliteit en mindfulness. De reductie van verschillende psychische klachten (onder andere depressie en angst) wordt aangepakt door het verminderen van de experiëntiële vermijding. Het programma "Voluit leven" is ontwikkeld als groepscursus en als zelfhulpcursus.

In het tweede hoofdstuk werden de psychometrische kwaliteiten van de Acceptance and Action Questionnaire-II (AAQ-II) onderzocht in een sample van 376 volwassenen met lichte tot matige depressie en angst. Deze vragenlijst meet psychologische flexibiliteit. Met Item Reponse Theory (IRT) werd aangetoond dat de items niet verschillend functioneren voor mannen en vrouwen en enigszins verschillend functioneren voor drie leeftijdscategorieën. Ook werd met IRT aangetoond dat de AAQ-II een unidimensionele vragenlijst was, waarbij de lokale meetprecisie goed was. Daarnaast bleek de AAQ-II incrementele validiteit te hebben naast vijf mindfulnessfacetten voor het voorspellen van depressie, angst en positieve geestelijke gezondheid. Er werd dus geconcludeerd dat de AAQ-II een valide en betrouwbare vragenlijst is voor het meten van psychologische flexibiliteit. 
In het derde hoofdstuk werd besproken of experiëntiële vermijding de relatie tussen maladaptieve copingstijlen (palliatieve, vermijdende, en passieve coping) en psychopathologie en positieve geestelijke gezondheid medieert. In totaal vulden 93 volwassenen met lichte tot matige psychologische stress vragenlijsten in die copingstijlen, psychopathologie (depressie, angst en alcoholgebruik) en positieve geestelijke gezondheid (emotioneel, sociaal en psychologisch welbevinden) meten. De resultaten lieten zien dat experiëntiële vermijding de effecten van passieve coping op zowel toegenomen angst en depressie als op afgenomen emotionele en psychologisch welbevinden medieerde. Deze resultaten laten zien dat als iemand meer geneigd is om passieve coping in het teken van experiëntiële vermijding toe te passen in stressvolle situaties, hij of zij een hoger risico heeft op het ontwikkelen van psychopathologie en op het ervaren van een lagere positieve geestelijke gezondheid. Het hoofdstuk sloot af met de suggestie dat interventies die zijn gericht op mensen die een hoog niveau van experiëntiële vermijding hebben, zeer relevant zijn.

In het vierde en vijfde hoofdstuk werd de effectiviteit beschreven van de preventieve groepscursus "Voluit leven" gebaseerd op ACT. De interventie is gericht op het verhogen van acceptatie van negatieve gedachten en emoties en op het bevorderen van meer mindful en waardengericht gedrag. Volwassenen met lichte tot matige depressieklachten werden geworven door zeven geestelijke gezondheidszorginstellingen in Nederland. In totaal namen 93 volwassenen mee aan het onderzoek. Zij werden gerandomiseerd over de ACT interventie $(n=49)$ en de wachtlijstgroep $(n=44)$. De meeste deelnemers waren Nederlandse vrouwen met een gemiddelde leeftijd van 49 jaar. Alle deelnemers vulden vragenlijsten in voorafgaand aan de interventie, direct na de interventie (na 9 weken) en 3 maanden na afloop van de interventie.

In hoofdstuk vier bleek uit de resultaten dat de deelnemers die de interventie hadden gevolgd significant minder depressieklachten hadden in vergelijking tot de deelnemers die op de wachtlijst stonden (Cohen's $d=.60$ ). Deze vermindering in klachten bleef behouden bij de follow-up na drie maanden. Daarnaast bleek ook dat angst en vermoeidheid significant waren afgenomen en dat acceptatie was toegenomen na de interventie. Deze positieve effecten bleven behouden bij de follow-up na drie maanden. Verder bleek uit mediatie-analyses dat de verhoging van acceptatie tijdens de interventie de effecten op depressie bij de follow-up medieerde. De resultaten suggereren dat de preventieve interventie gebaseerd op ACT, gericht op de verhoging van acceptatie, effectief is in het verminderen van depressieklachten.

In hoofdstuk vijf werd onderzocht of de groepscursus "Voluit leven" positieve geestelijke gezondheid kan bevorderen door het versterken van de psychologische flexibiliteit. Uit de resultaten kwam naar voren dat deelnemers die de cursus hadden gevolgd een hoger emotioneel en psychologisch welbevinden ervaarden in vergelijking tot de deelnemers op 
de wachtlijst, zowel na de interventie als bij de follow-up na drie maanden. Mediatianalyses lieten zien dat de versterking van psychologische flexibiliteit tijdens de interventie de effecten op positieve geestelijke gezondheid medieerde. De resultaten impliceren dat de interventie "Voluit leven" effectief is in het bevorderen van de positieve geestelijke gezondheid door het versterken van de vaardigheden "acceptatie" en "waardevol gedrag".

In het zesde hoofdstuk werden de effecten van een op ACT gebaseerde preventieve zelfhulpinterventie "Voluit leven" met e-mailbegeleiding geëvalueerd. Deelnemers met milde tot matige depressieklachten of angstklachten werden geworven via advertenties in kranten en gerandomiseerd over de cursus met intensieve e-mailbegeleiding $(n=125)$, de cursus met procesbegeleiding via e-mail $(n=125)$ en een wachtlijstcontrolegroep $(n=126)$. Deelnemers vulden vragenlijsten in voorafgaand aan de interventie en negen weken na de interventie. De wekelijkse begeleiding via e-mail werd uitgevoerd door vijf psychologiestudenten onder leiding van een GZ-psycholoog. Alleen de deelnemers in de experimentele condities vulden ook de vragenlijsten in bij een follow-up na drie maanden. Uit de resultaten blijkt dat deelnemers die de zelfhulpcursus volgden significant minder depressie, angst, vermoeidheid, experiëntiële vermijding en meer positieve geestelijke gezondheid en mindfulness ervaarden in vergelijking tot de wachtlijstcontrolegroep (Cohen's $d$ effectgroottes tussen .51-1.00). Ook tijdens de follow-up na drie maanden bleven deze effecten behouden in de experimentele groepen. Het bleek dat er geen verschillen waren in de effecten tussen de twee soorten e-mailbegeleiding. Er werd geconcludeerd dat de zelfhulpcursus met minimale e-mailbegeleiding effectief is voor mensen met lichte tot matige depressieklachten.

In het zevende hoofdstuk werd de invloed van veranderingen in psychologische flexibiliteit op depressie en angst van de zelfhulpcursus "Voluit leven" onderzocht. De deelnemers in de experimentele condities $(n=250)$ vulden naast de meetmomenten die in hoofdstuk 6 zijn beschreven, vragenlijsten in tijdens de interventie (na drie en zes weken) die angst, depressie en psychologische flexibiliteit meten. Uit de resultaten blijkt dat de effecten van de ACT-interventie op angst en depressie werden gemediëerd door verbetering in psychologische flexibiliteit. Met multilevel-analyses werd aangetoond dat deze verbeteringen in psychologische flexibiliteit meteen vanaf de start van de interventie positieve effecten hadden op depressie en angst tijdens en na de interventie. Daarnaast bleek dat als de deelnemers een hoger niveau van psychologische flexibiliteit ontwikkelden gedurende en na de interventie, dit een sterker positief effect had op depressie en angst. Uit de cross-lagged regressie-analyses bleek dat voornamelijk de versterking van psychologische flexibiliteit aan het einde van de interventie belangrijk te zijn voor een verdere afname in angst. Deze studie bevestigt dat het belangrijk is om een interventie te richten op psychologische flexibiliteit voor het bereiken van een langetermijneffect op het verminderen van psychologisch leed. 
In het laatste hoofdstuk werden de resultaten van de verschillende studies besproken tegen de achtergrond van eerder uitgevoerde studies naar de effecten van ACT en preventie van depressie. In het algemeen blijkt dat de cursus "Voluit leven" (zowel als groepscursus als zelfhulpcursus) effectief is in het verlagen van meerdere psychische klachten (depressie, angst, vermoeidheid) en in het bevorderen van de positieve geestelijke gezondheid. Door het versterken van positieve vaardigheden (psychologische flexibiliteit en mindfulness), heeft de interventie een grote impact op de publieke gezondheid. Er werd beargumenteerd dat de interventie goed past binnen de nieuwe benadering in de geestelijke gezondheidszorg, namelijk dat geestelijke gezondheid meer is dan alleen de afwezigheid van geestelijke ziekte. De groepscursus is bij minstens 13 geestelijke gezondheidszorg instellingen geïmplementeerd. Uit cijfers over de deelnemersaantallen blijkt dat de cursus goed wordt bezocht. In dit hoofdstuk werden verschillende aanbevelingen gegeven voor verdere implementatie van de interventie en werden de sterke en zwakke punten van deze thesis besproken. Ten slotte werden implicaties voor toekomstig onderzoek bediscussieerd. 
$170 \quad$ Chapter 9 


\section{Dankwoord}

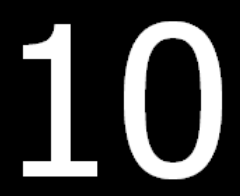




\section{Dankwoord}

Graag wil ik een aantal mensen bedanken die mij hebben geholpen om het proefschrift tot een mooi einde te brengen. Ten eerste mijn promotor Ernst Bohlmeijer. Wat ben ik blij dat je me na mijn afstuderen even de tijd hebt gegeven om na te denken over de mogelijkheid om te promoveren in Enschede. Het was een hele goede keuze! Ik heb ontzettend veel geleerd en jouw creatieve geest vind ik zeer bewonderenswaardig. Ondanks dat het af en toe hele worstelingen waren, ben ik blij dat je me altijd probeerde uit te dagen om zelf net weer een stapje verder te komen.

Ook Marcel Pieterse wil ik graag bedanken als mijn tweede dagelijkse begeleider. Ik vond het altijd erg prettig om even flink met jou te discussiëren! Door jouw scherpe blik heb ik geleerd dat je je altijd goed moet blijven afvragen waarom je bepaalde stappen hebt genomen, ook als je denkt dat je eigenlijk al wel het meeste weet.

En in dit rijtje hoort ook Karlein Schreurs thuis. Door jouw adviezen en af en toe even stevige feedback is het me gelukt om steeds verder te komen met mijn promotietraject. Ik vond ook onze reis en gezamenlijke presentatie in de VS een heel mooi avontuur, bedankt daarvoor!

Maar promoveren was niet gelukt wanneer ik niet zo'n leuke groep meiden om me heen had gehad. De meiden van de gang, namelijk: Sanne, Jojanneke, Saskia, Laurien, Stephy, Ingrid, Marloes en Roos. Wat ben ik blij dat ik jullie om me heen had, om even de frustraties te delen, om samen te werken, elkaar te helpen en niet te vergeten de vele leuke etentjes, sportuurtjes en gewoon geklets op de gang. Ik ben heel blij dat ik jullie stuk voor stuk heb ontmoet en ik vind jullie supermeiden!

Mijn allerliefste kamergenootjes en tevens paranimfen, Laurien en Stephy wil ik in het bijzonder bedanken. Ik vond het altijd een heel fijne sfeer bij ons op de kamer. Af en toe keihard werken, maar wel met een gezonde dosis afleiding!

Ook de andere collega's van het team Geestelijke Gezondheidsbevordering van de afgelopen jaren wil ik graag bedanken voor de fijne samenwerking en gezelligheid: Rilana, Hester, Martine Veehof, Lieke, Wendy, Linda, Peter, Anne Marie en Gerben. Daarbij wil ik ook alle collega's van de vakgroep hartelijk bedanken voor de prettige sfeer op de afdeling.

En in het bijzonder wil ik nog Stans bedanken voor de vele gezellige treinuren. Jouw motivatie voor alles werkt heel aanstekelijk en jouw opbeurende gesprekken zijn heel enthousiasmerend. Door jou is het reizen een stuk minder lang. 
Mijn lieve schoonouders, Annelies en Silvo, bedankt dat jullie altijd zo hebben meegeleefd tijdens mijn promotietraject en veel interesse hebben getoond.

Mam, bedankt dat je altijd de telefoon opneemt rond half 7 als ik weer de trein uit kom en nog naar huis moet lopen! Je bent een supersterke vrouw en ik bewonder echt hoe je probeert het beste uit het leven te halen. Dat is nu echt voluit leven! Ook broertje Joost, zusje Judith en schoonzusje Marieke wil ik bedanken voor alle ondersteuning en ik vind het fijn dat we alles met elkaar kunnen delen en het leuk samen hebben met elkaar! Pap, wat zou ik graag het boekje aan je willen overhandigen. Helaas heb je niet meer mee mogen maken dat ik toch ben gaan promoveren, iets wat jij allang tegen me had gezegd wat bij me zou passen. Ik weet gelukkig dat je enorm trots op me zou zijn. Jij bent bij het overhandigen van de doctorstitel degene die het meest aanwezig zal zijn.

Melle, bedankt dat je er altijd voor mij bent en mij helpt om in het moment te leven. Met jou samen kan ik zeker voluit leven! 
174 Chapter 10 